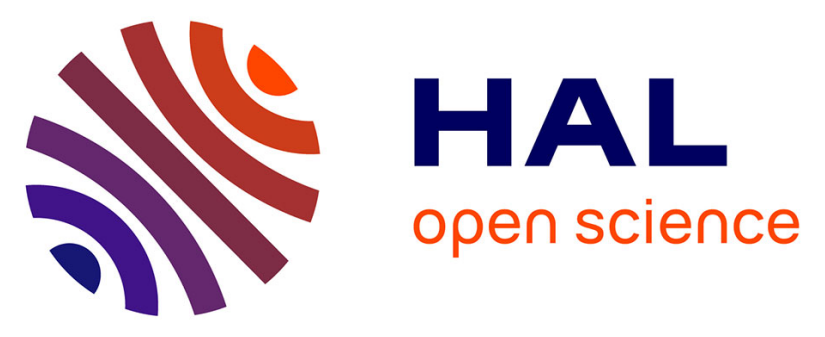

\title{
La France du Nord (Champagne-Ardenne, Île-de-France, Nord, Basse-Normandie, Haute-Normandie, Pas-de-Calais, Picardie)
}

Jean-Louis Brunaux, Claude Malagoli, Bernard Lambot, Gérard Bataille

\section{- To cite this version:}

Jean-Louis Brunaux, Claude Malagoli, Bernard Lambot, Gérard Bataille. La France du Nord (Champagne-Ardenne, Île-de-France, Nord, Basse-Normandie, Haute-Normandie, Pas-de-Calais, Picardie). Gallia - Archéologie de la France antique, 2003, Cultes et sanctuaires en France à l'âge du Fer, 60, pp.9-73. 10.3406/galia.2003.3143 . hal-01911706

\section{HAL Id: hal-01911706 \\ https://hal.science/hal-01911706}

Submitted on 8 Jan 2020

HAL is a multi-disciplinary open access archive for the deposit and dissemination of scientific research documents, whether they are published or not. The documents may come from teaching and research institutions in France or abroad, or from public or private research centers.
L'archive ouverte pluridisciplinaire HAL, est destinée au dépôt et à la diffusion de documents scientifiques de niveau recherche, publiés ou non, émanant des établissements d'enseignement et de recherche français ou étrangers, des laboratoires publics ou privés.

\section{(ㅇ)(1) $\$$}

Distributed under a Creative Commons Attribution - NonCommercial - NoDerivatives $\mid 4.0$ 


\title{
LA FRANCE DU NORD
}

\author{
(Champagne-Ardenne, Ille-de-France, Nord, \\ Basse-Normandie, Haute-Normandie, Pas-de-Calais, Picardie)
}

\author{
Jean-Louis BRUNAUX et Claude MALAGOLI \\ avec la participation de Gérard BATAILlE et Bernard LAMBOT
}

\begin{abstract}
Mots-clés. Enclos, porche (propylée), autel creux, couverture de l'autel, sacrifice animal, armes, trophée.
Résumé. C'est dans le Nord de la France qu'ont été mis en évidence pour la première fois d'authentiques sanctuaires attribuables aux Celtes de La Tène moyenne (III s. avant J.-C.), essentiellement grâce aux fouilles de Gournay-sur-Aronde (Oise). Les principales caractéristiques de ces lieux de culte s'y sont révélées de façon exemplaire : espace sacré de plan quadrangulaire, matérialisé par un fossé et une palissade, porche d'entrée monumental, absence de temple mais présence au centre de l'espace d'un autel creux souvent associé à un foyer et généralement couvert d'un bâtiment de protection. Sur ces lieux les vestiges culluels sont abondants : os animaux témoignant de la pratique régulière de sacrifices de bovidés, moutons et porcs, armes déposées en offrandes. Ces découvertes confirment largement les témoignages recueillis par les auteurs antiques et en permettent la relecture : ainsi les informations de Poseidonios sur la religion remonleraient pour la plus grande part à la fin du $I^{*}$ s. et au début du III s., et concerneraient les régions septentrionales de la Gaule. Désormais la recherche sur les lieux de culte en cette région s'oriente vers d'autres types d'installation, trophée, hérôon, lieu de justice...
\end{abstract}

Key-words. Enclosure, porch (propylaeum), hollow altar, altar shelter, animal sacrifice, weapons, trophaeum.

Abstract. It is in Northern France that excavations provided the first evidence for true Celtic sanctuaries of the Middle La Tene period ( $3^{\text {rl }}$ century $B C$ ), especially at Gournay-sur-Aronde (Oise). The main features of these cult places strongly appear here: a quadrangular sacred area within a ditch and a timber palisade, a monumental entranceway, the presence at the centre of the space, not of a shrine but of a hollow altar, often connected to a hearth and generally covered by a shelter. Cult remains are numerous: animal bones testifying regular sacrifices of cattle, sheep, pig, weapon votive deposits. These discoveries largely confirm the testimonies collected from classical authors, of which a reassessment can be done: so the facts recorded by Posidonius about religion could belong for the most part, to the end of the fourth century or early third century, and refer to the Northern part of Gaul. From now on, investigations on cult sites in this region are moving towards other types of arrangements, trophaeum, hérôon, place of justice...

Schlagwörter. Einfriedung, Tor (Propylon), eingetiefter Altar, Altarüberdachung, Tieropfer, Waffen, Tropaion.

Zusammenfassung. In Nordfrankreich gelang, hauptsächlich durch die Ausgrabungen in Gournay-sur-Aronde (Oise), erstmalig der Nachweis von regelrechten Heiligtümern der keltischen Bevölkerung der Mittellatènezeit (3. Jahrh. v. Chr.). Exemplarisch sind dort die wichtigsten Grundzüge dieser Kultstätten abzulesen: ein heiliger Bezirk von rechteckigem Grundriß, ausgeführt als Graben und Palisade, ein monumentales Eingangstor und - anstelle eines Tempels - im Zentrum des Areals ein eingetiefter Altar, letzterer oft in Verbindung mil einer Feuerstelle und meist durch ein Gebäude geschützt. An diesen Plätzen gibt es Überreste von Kulthandlungen in Fülle: Tierknochen, die von der regelhaft geübten Opferung von Rindern, Schafen und Schweinen zeugen, sowie Waffen, die hier als Weihegaben niedergelegt wurden. Diese Entdeckungen bestätigen vorzüglich das Zeugnis der antiken Autoren und erlauben eine Überprüfung der Texte. Danach dürften die Nachrichten des Poseidonios über die Religion zum Großteil bis ans Ende des 4. bzw. den Beginn des 3. Jahrh. v. Chr. zurückreichen und könnten die nördlichen Gegenden Galliens betreffen. Zukünftig wird sich die Erforschung der Kultstätten in dieser Region verslärkt einer Interpretation der Anlagen als Tropaion, Heroon oder Gerichtsstätte widmen.

Ïhersetzt. vom Stefan WIRTH 


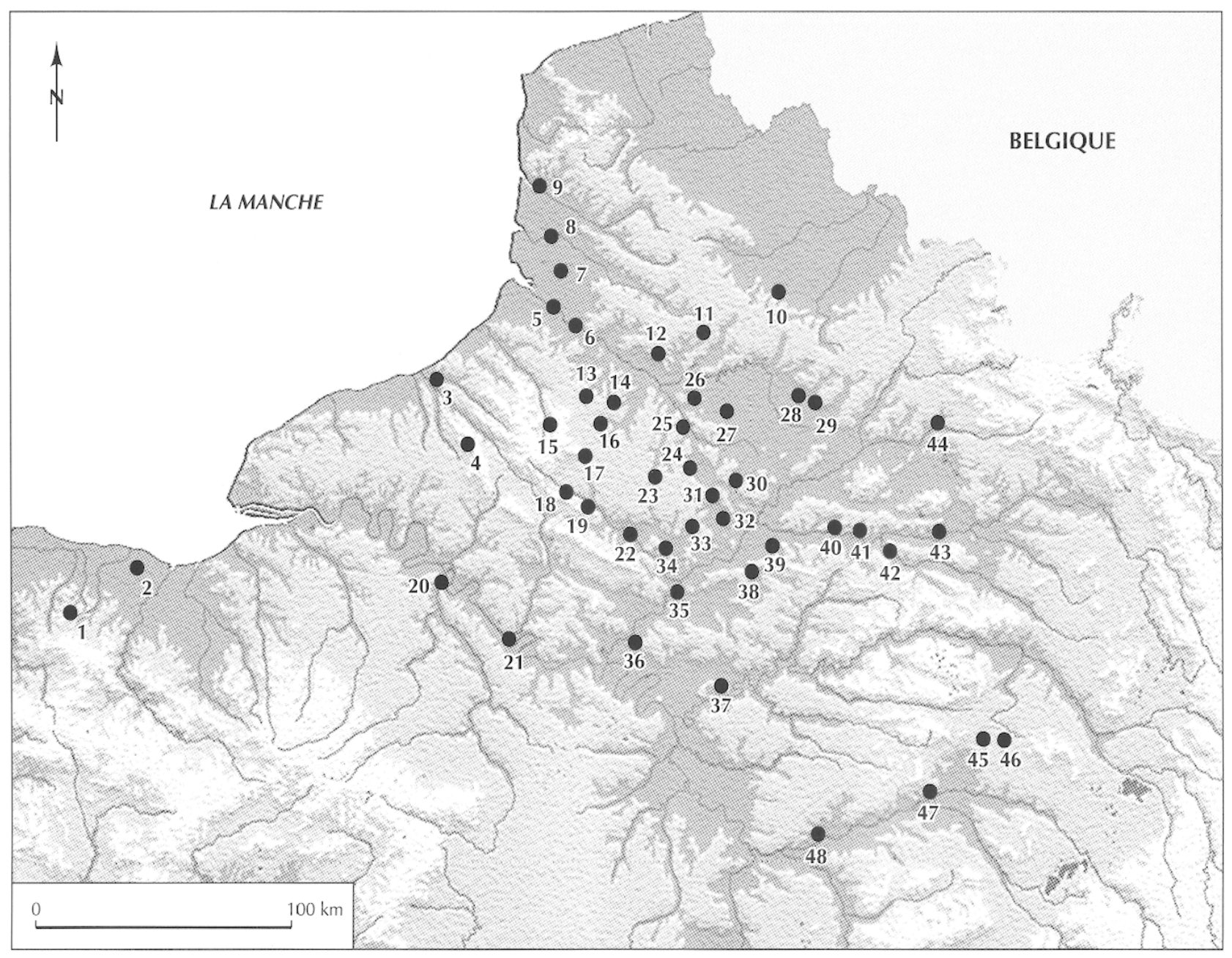

Fig. 2 - Carte de répartition des principaux sites du Nord de la France mentionnés dans le texte, voir tableau I (fond de carte P. Arcelin ; DAO G. Devilder, CNRS).

C'est dans cette région, et plus précisément en Picardie, que furent mis en évidence dans les années 1970-1980 les premiers sanctuaires gaulois, bien antérieurs à la conquête romaine. Ces découvertes spectaculaires ont alors généré une recherche dynamique qui, 25 ans plus tard, produit toujours des résultats étonnants. On a craint un moment que ces travaux emblématiques de la recherche protohistorique française aboutissent à une sclérose de la typologie des lieux de culte et des pratiques rituelles : assez rapidement, après avoir produit son effet heuristique, le modèle de Gournay-sur-Aronde est devenu encombrant. On voyait son double un peu partout, alors que souvent les indices pour une telle identification étaient ténus. C'est certainement la multiplication des fouilles d'habitat et une étude approfondie de leurs sites les plus remarquables qui ont permis de sortir de cette impasse. Il est apparu que ces lieux, que l'on avait trop longtemps considérés comme seulement profanes, avaient $\mathrm{pu}$ connaître eux aussi des manifestations cultuelles plus ou moins fortes, se traduisant par des installations parfois monumentales. Une typologie beaucoup plus large des lieux de culte commençait à s'esquisser. Il était prévisible que tôt ou tard celle-ci soit étendue au domaine funéraire.

Cependant, dans le même temps, les recherches sur les pratiques funéraires paraissaient étonnamment figées, victimes encore des schémas étriqués hérités du XIX ${ }^{\mathrm{c}} \mathrm{s}$. : la sépulture comme unique destination du cadavre, et l'inhumation et l'incinération comme seuls modes de traitements. Mais, là encore, c'est une multitude de travaux engagés dès les années 1970 et des découvertes moins aisément classables qui remirent progressivement en cause les interprétations habituelles : le funéraire déborde largement dans le domaine de l'habitat, comme en témoignent tous les squelettes rencontrés dans les silos ou dans de simples fosses ou fossés détritiques. La découverte récente à Ribemont-surAncre d'une forme de traitement du cadavre, inconnue 


\begin{tabular}{|c|c|c|c|c|c|}
\hline $\mathrm{N}^{0}$ & Commune & Lieu-dit & Département & $N^{\circ}$ notice & Pagination \\
\hline 1 & Baron-sur-Odon & Le Mesnil & Calvados & - & - \\
\hline 2 & Thaon & Les Quatre Acres & Calvados & - & - \\
\hline 3 & $\mathrm{Eu}$ & Bois-l'Ahbé & Seine-Maritime & - & - \\
\hline 4 & Fesques & Le Mont du Val aux Moines & Seine-Maritime & 8 & $56-59$ \\
\hline 5 & Grand-Laviers & Le Mont Henry & Somme & - & - \\
\hline 6 & Cocquerel & Le Beau Bucquet & Somme & - & - \\
\hline 7 & Bernay-en-Ponthieu & Tirancourt & Somme & - & - \\
\hline 8 & Dompierre-sur-Authie & La Plaine au-dessus du Bois & Somme & 6 & 55 \\
\hline 9 & La Calotterie & La Fontaine aux Linottes & Pas-de-Calais & - & - \\
\hline 10 & Mœuvres & Le canal du Nord & Nord & 11 & $60-61$ \\
\hline 11 & Ribemont-sur-Ancre & Le Champ Crezette & Somme & 14 & 64-68 \\
\hline 12 & Allonville & Le Coquingard & Somme & - & - \\
\hline 13 & Vendeuil-Caply & Les Châtelets & Oise & 17 & 71 \\
\hline 14 & Tartigny & Le Moulin de Tartigny & Oise & - & - \\
\hline 15 & Morvillers-Saint-Saturnin & Digeon & Somme & 13 & $62-64$ \\
\hline 16 & Mory-Montcrux & Sous la Vigne d'en Haut & Oise & - & - \\
\hline 17 & Saint-Maur & Les Catelets & Oise & 16 & $69-71$ \\
\hline 18 & Beauvais & Les Aulnes du Canada & Oise & 3 & 53 \\
\hline 19 & Allonne & Les Quarante Mines & Oise & - & - \\
\hline 20 & Tournedos-sur-Seine & Le Beau Soleil & Eure & - & - \\
\hline 21 & Bennecourt & La Butte du Moulin à Vent & Yvelines & 4 & $53-54$ \\
\hline 22 & Bailleul-sur-Thérain & Le Mont-César & Oise & 2 & 52 \\
\hline 23 & Saint-Just-en-Chaussée & Le Rossignol & Oise & 15 & $68-69$ \\
\hline 24 & Montiers & Les Noirs Cailloux & Oise & - & - \\
\hline 25 & Villers-lès-Roye & Les Longs Champs & Somme & - & - \\
\hline 26 & Marcelcave & Le Chemin d'Ignaucourt & Somme & - & - \\
\hline 27 & Chilly & Le Bois du Carme & Somme & 5 & $54-55$ \\
\hline 28 & Vermand & Le Champ des Lavoirs & Aisne & - & - \\
\hline 29 & Vermand & Marteville & Aisne & - & - \\
\hline 30 & Antheuil-Portes & Le Fond de Saint-Maur & Oise & - & - \\
\hline 31 & Gournay-sur-Aronde & Le Parc & Oise & 9 & $59-60$ \\
\hline 32 & Montmartin & La Fosse Muette & Oise & 12 & $61-63$ \\
\hline 33 & Estrées-Saint-Denis & Le Moulin des Hayes & Oise & 7 & 56 \\
\hline 34 & Breuil-le-Sec & Le Bois de Breuil-le-Sec & Oise & - & - \\
\hline 35 & Saint-Maximin & Le Pont de Saint-Leu & Oise & - & - \\
\hline 36 & Roissy-en-France & Le Château & Val-d'Oise & - & - \\
\hline 37 & Meaux & La Bauve & Seine-et-Marne & 10 & 60 \\
\hline 38 & Orrouy & Champlieu & Oise & - & - \\
\hline 39 & Pierrefonds & Le Mont-Berny & Oise & - & - \\
\hline 40 & Bucy-le-Long & Le Fond du Petit Marais & Aisne & - & - \\
\hline 41 & Villeneuve-Saint-Germain & Les Grandes Grèves & Aisne & - & - \\
\hline 42 & Braine & La Grange des Moines & Aisne & - & - \\
\hline 43 & Cuiry-lès-Chaudardes & & Aisne & - & - \\
\hline 44 & Acy-Romance & La Warde & Ardennes & 1 & $47-52$ \\
\hline 45 & Normée & La Tempête & Marne & - & - \\
\hline 46 & Fère-Champenoise & Le Faubourg de Conantre & Marne & - & - \\
\hline 47 & La Villeneuve-au-Châtelot & Les Grèves & Aube & 18 & $71-73$ \\
\hline 48 & Balloy & Le Bois de Roselle & Seine-et-Marne & - & - \\
\hline
\end{tabular}

Tabl. I - Tableau des sites mentionnés sur la carte figure 2. jusqu'à présent par les vestiges archéologiques mais bien attestée par les sources littéraires ou iconographiques, amène désormais à douter de l'autonomie d'une sphère funéraire qui se distinguerait de celle de l'habitat et de celle du cultuel. Les aménagements architecturaux et les pratiques rituelles que l'on croyait ressortir à chacun de ces "domaines » paraissent indissociablement liés. Cela ne signifie nullement qu'il faille en faire une analyse indifférenciée en simples termes de rites non caractérisés et de lieux de culte, mais qu'il faudra pousser beaucoup plus loin l'analyse des vestiges matériels en s'aidant du contexte immédiat où le rite et l'aménagement qu'il avait suscité prenaient leur sens, en se référant au contexte cultuel plus large, celui de la cité ou de ses composantes.

Comme toute synthèse, celle-ci paraîtra prématurée, surtout en regard de ce qui vient d'être dit. Mais c'est le propre de toute synthèse d'être déjà dépassée, alors qu'elle vient d'être formulée. Dans cette région, l'état remarquable de la documentation la dispense de toute justification : tradition de travaux archéologiques qui remonte à la fin du $\mathrm{XVI}^{\mathrm{e}}$ s. (le prince de Condé à Vendeuil-Caply), intenses prospections aériennes de R. Agache notamment, nombreux 
grands travaux au cours des trente dernières années qui ont occasionné beaucoup de fouilles d'urgence mais surtout depuis une intense recherche basée sur la fouille programmée de sites significatifs (fig. 2 et tabl. I).

\section{LE TERRITOIRE À LA FIN DE L'ÂGE DU BRONZE ET LES PREMIÈRES MANIFESTATIONS CULTUELLES AU DÉBUT DE L'ÂGE DU FER}

\section{PAYSAGE, PEUPLEMENT ET AGRICULTURE}

À l'époque protohistorique, le paysage peut jouer un rôle dans la topographie mythologique et dans le choix de l'emplacement des lieux de culte. Il en joue un, en tout cas, dans le peuplement et parallèlement dans l'utilisation des sols pour l'agriculture et l'élevage. Il convient donc d'examiner en tout premier lieu cette donnée fondamentale.

La première remarque que l'on doit faire est qu'il s'agit d'une région étonnamment homogène par son paysage, c'est-à-dire son relief et son couvert végétal. Il s'agit, pour l'essentiel, d'un pays de plaines et de plateaux où les montagnes sont totalement absentes. Les principales dénivelées sont dues aux marges du Massif armoricain en BasseNormandie, à des buttes-témoins du Tertiaire et à l'encaissement de quelques vallées dans les plateaux. Hormis donc la Basse-Normandie qui se rattache au massif primaire de Bretagne, le reste de la région présente une belle unité géologique: ce sont des bas plateaux calcaires couverts de limons et d'argiles à silex.

La déforestation y a donc été intense dès le Néolithique. Et au second âge du Fer, au moins pour le Nord - Pasde-Calais et la Picardie qui ont été bien étudiés, le paysage était aussi découvert qu'il l'est maintenant. L'anthropisation du paysage semble cependant avoir été lente. Et il est probable que le convert forestier ait été peu à peu remplacé par des friches, des pâturages plus ou moins bien entretenus. Les plateaux limoneux, tout autant que les argiles à silex, se prêtaient mal à l'agriculture. Il s'agit de terres qui n'étaient pas naturellement fertiles, qu'il fallait amender surtout par un apport de craie (marnage) et qui étaient difficiles à labourer: elles nécessitaient de puissants attelages.

La deuxième particularité de la région tient à sa proximité avec la mer. Elle constitue, en fait, l'arrièrepays côtier, une sorte de croissant de $200 \mathrm{~km}$ de profondeur autour de la Manche. Les conséquences naturelles en sont climatiques : l'influence atlantique y est très forte. Mais ce qui nous intéressera surtout c'est l'influence cultu- relle atlantique qui caractérise l'âge du Bronze en cette région et qui persiste au premier âge du Fer. Cette proximité maritime se traduit surtout par les relations commerciales côtières et trans-Manche. Ces contacts, qu'ils soient côtiers ou maritimes, n'affectent pas seulement la frange maritime mais les vallées principales et les voies terrestres qui relient la région aux grands centres culturels, la Bourgogne et le Sud-Est de la France par la vallée de la Seine, la Champagne et la vallée du Rhin par les vallées de la Somme et de l'Aisne.

Le peuplement, dans l'état actuel de la documentation, trahit les contraintes agricoles et reflète l'intérêt suscité par les vallées comme voies de communication. Au premier âge du Fer et à La Tène ancienne, les plateaux ne sont quasiment pas habités. Seules les vallées et les côtes maritimes sont plus ou moins densément occupées. Parmi elles, celles qui ont servi d'axes de communications majeurs présentent les habitats les plus nombreux, souvent associés à des lieux funéraires. Ce sont les vallées de la Seine, de l'Aisne et de l'Oise. Elles présentent un double intérêt, celui qui vient d'être évoqué, servir de voies de communication et de commerce, et celui d'offrir dans les larges plaines alluviales des terres légères, faciles à mettre en culture.

L'occupation générale du territoire n'intervient qu'à la fin de La Tène ancienne et au cours de La Tène moyenne. Cet agrandissement des terroirs va de pair avec une mise en culture généralisée qui touche désormais aussi bien les plateaux limoneux que des terres peu fertiles qui, plus tard, au Moyen Âge seront regagnées par la forêt. Ce phénomène apparaît clairement à travers la multiplication des établissements agricoles, dans la plaine de France au IV $\mathrm{IV}^{\mathrm{e}}$., dans la plaine de Caen un peu plus tard, sur le plateau picard à la fin du $\mathrm{III}^{\mathrm{e}} \mathrm{s}$. et au début du $\mathrm{II}^{\mathrm{c}} \mathrm{s}$.

Cette extension remarquable suppose de nouvelles pratiques culturales, fondées sur de véritables innovations agronomiques et technologiques: le marnage et de nouvelles façons de labourer. Cette authentique révolution agricole qui préfigure la prospérité de la campagne à l'époque gallo-romaine (Agache, Bréart, 1975) accompagne, en réalité, un nouvel afflux de population, les Belges, dont l'arrivée dans le Nord de la Gaule est située à cette époque (le souvenir en est transmis entre autres par César). La nouvelle population, certainement limitée en nombre, et dont l'arrivée a pu s'étaler sur plus d'un siècle, a probablement généré un essor démographique qui est aussi la condition sine qua non d'une telle extension des terres agricoles. Elle atteint son apogée dans les premières décennies du ${ }^{\mathrm{cr}} \mathrm{s}$. C'est l'image que nous en donne César dans son récit de la conquête et qui est maintenant bien confirmée par les travaux archéologiques. 


\section{LES MONUMENTS FUNÉRAIRES ANCIENS}

Au premier âge du Fer, les habitats demeurent peu nombreux et le territoire paraît surtout marqué par des nuées de cercles funéraires qui occupent les versants des vallées et les rebords des plateaux (Agache, Bréart, 1975). Beaucoup sont datables de l'âge du Bronze mais, d'une manière générale, il est difficile de les dater sans les fouiller. On n'arrive pas, en effet, à en constituer une typologie qui aurait une valeur chronologique. De fait, leur variété est immense. Les structures ont un diamètre qui peut varier de quelques mètres à plusieurs dizaines de mètres. Le fossé qui les marque au sol peut être simple, mais aussi double, voire triple. Les fouilles révèlent une matérialisation au sol plus complexe encore. Dans un certain nombre de cas, le fossé peut être doublé à l'intérieur mais aussi à l'extérieur d'une série de poteaux, pas toujours décelables sur les photographies aériennes.

Ces cercles sont souvent interprétés comme des tumulus. La généralisation de cette interprétation est sans doute fautive. En effet, la question de leur élévation se pose. Si la présence d'un tertre original est bien souvent déduite de la lecture des anomalies de remplissage du fossé périphérique ou de la présence d'un toponyme évoquant le tumulus (aux Tombelles par exemple), elle n'est certainement pas systématique et l'on peut se demander si le tertre était vraiment conséquent. Ainsi à La Calotterie (Desfossés et al., 2000), le tertre du cercle 38 est suggéré par une répartition différentielle des sépultures mérovingiennes qui sont venues s'installer sur lui mais la présence, à cheval sur le fossé, d'un petit enclos laténien montre que ce tertre devait être circonscrit à la zone centrale et d'une faible hauteur (fig. 3).

La présence de trous de poteaux, parfois d'un important diamètre, suggère la présence d'un véritable monument construit, de type henge. Un seul exemplaire est connu dans le Nord de la France, à Antheuil-Portes (Blanchet, 1989) ; il s'agit d'un enclos circulaire palissadé avec une entrée au nord, entouré d'une couronne de poteaux d'un diamètre de $50 \mathrm{~cm}$ environ. Au centre de l'espace enclos se trouvait un petit bâtiment de $3 \mathrm{~m}$ de côté et reposant sur quatre poteaux (fig. 4). De telles structures, connues en GrandeBretagne, en Belgique et en Bourgogne (Baray et al., 1994, p. 110), sont datées généralement du Bronze final mais on les rencontre encore au premier âge du Fer au HünsrückEiffel. L'unique exemplaire picard montre, en tout cas, qu'il ne s'agit pas d'un simple tumulus mais bien d'une installation cultuelle, peut-être en contexte funéraire, puisqu'elle se trouve à l'intérieur d'un groupe de six ou sept cercles.

La monumentalité de telles installations aurait pu générer postérieurement un lieu cultuel el funéraire du type de Gurgy en Bourgogne. Aucun complexe semblable
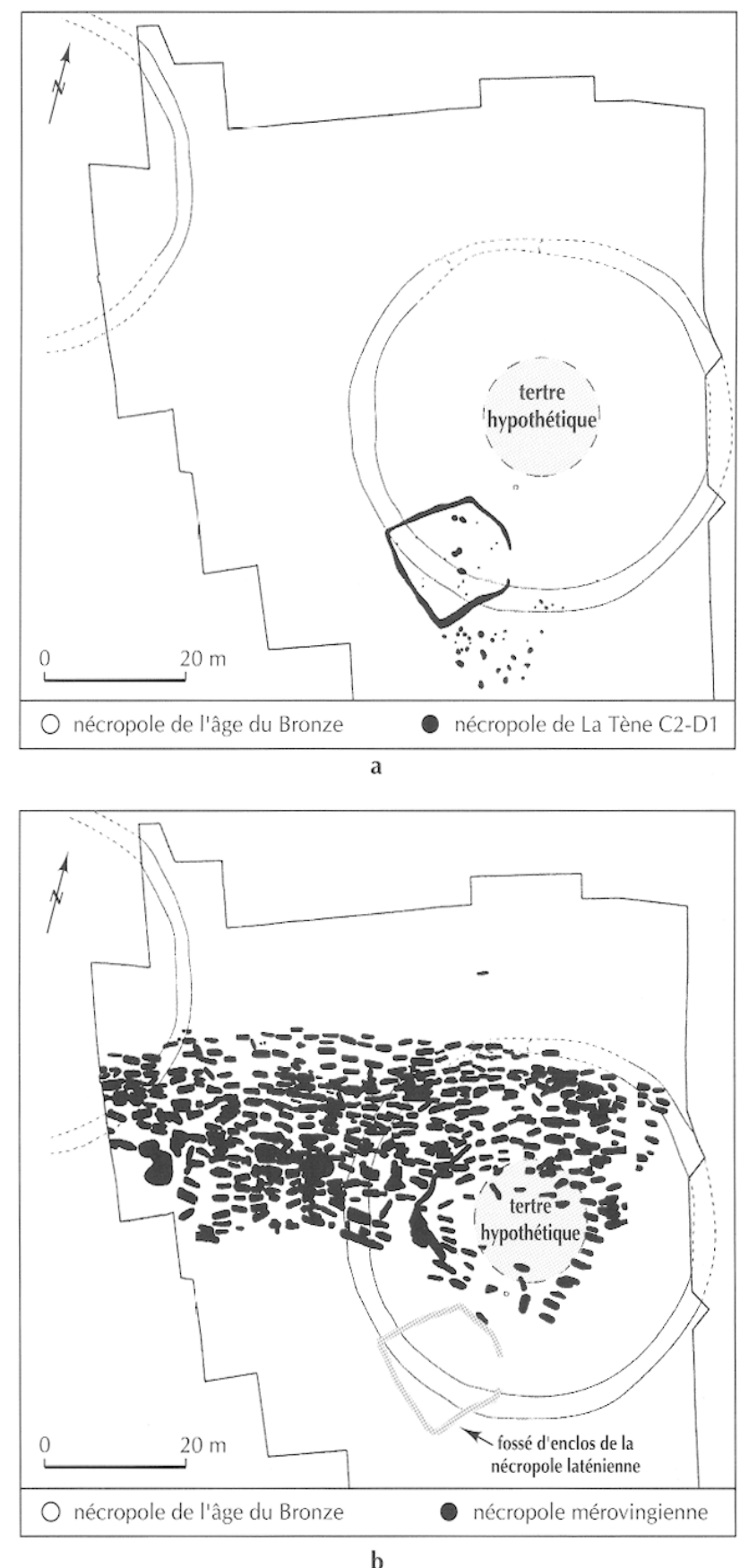

Fig. 3 - La Calotterie (Pas-de-Calais), La Fontaine aux Linottes. Enclos de l'âge du Bronze dont la présence du tertre est trahie par l'implantation postérieure d'un enclos laténien et de sépultures mérovingiennes (d'après Desfossés et al., 2000).

n'a été rencontré dans la région concernée. En revanche, on constate la présence d'associations d'un enclos circulaire avec un enclos quadrangulaire qui pourrait avoir une telle origine. Ces enclos n'ont malheureusement pas fait l'objct de fouille. Quant à l'enclos quadrangulaire de $25 \mathrm{~m}$ de côté 


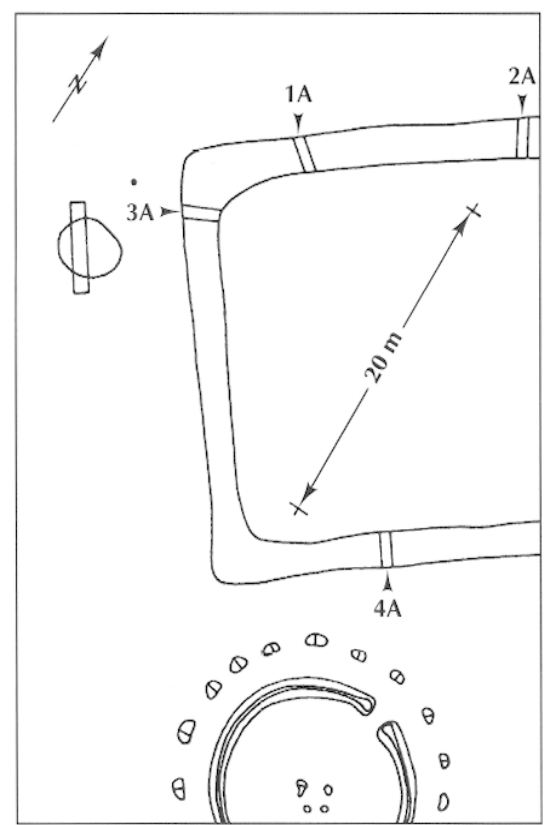

Fig. 4 - Antheuil-Portes (Oise), La Fond de Saint-Maur. Plan des enclos. Fouille J.-L. Brunaux (d'après Blanchet, 1989).

qui se trouve à proximité du monument d'Antheuil-Portes, il n'a livré aucun matériel datable.

En tout état de cause, l'absence, au premier âge du Fer, de toute installation cultuellc ct/ou funćrairc remarquable ne peut être expliquée par un état déficient de la recherche. Les tumulus et les enclos fossoyés sont demeurés visibles au moins jusqu'au second âge du Fer. Le fait qu'ils n'aient pas été réutilisés au premier âge du Fer ne peut s'expliquer que par deux raisons probablement complémentaires, une population peu nombreuse et disséminée et une cohésion sociale faible et limitée aux groupes familiaux, ne permettant pas l'installation et le fonctionnement de grandes structures cultuelles.

Ainsi à l'aube du second âge du Fer, cette région ne présentait aucune tradition cultuelle visible soit dans le mobilier archéologique, soit dans les aménagements architecturaux.

\section{UN PREMIER ÂGE DU FER PEU OU PAS MARQUÉ PAR LA GULTURE DU HALLSTATT}

Cette pauvreté de l'univers cultuel n'est, en réalité, que le reflet du désert culturel du premier âge du Fer. Ce dernier dans cette région n'est à bien des égards, comme le remarquait il y a 25 ans $R$. Agache, que le prolongement de relui de l'âge du Bronze (Agache, 1978, p. 105). Certes il faut tempérer ce constat qui n'est plus tout aussi juste dès que l'on aborde les marges orientale et méridionale du territoire. Si des influences se font ressentir en Champagne et jusque dans l'Aisne et probablement tout le long de la vallée de la Seine, ainsi que dans la jonction entre ces deux axes que constitue la basse vallée de l'Oise, celles-ci restent très limitées et ne se traduisent pas dans la réalité cultuelle. La raison en est simple : même dans ces régions limitrophes il n'existe pas de centre princier qui aurait pu générer des installations cultuelles conséquentes.

La seule influence de la culture hallstattienne notable est parfaitement indirecte, c'est celle que l'on peut percevoir dans la riche culture de La Tène ancienne en Champagne et dans la vallée de l'Aisne, qui est probablement un avatar, une retombée sous forme d'éclatement dans le monde aristocratique du luxe princier. Les tombes à char souvent pourvoyeuses d'un riche mobilier en sont l'expression la plus évidente.

\section{UN MONUMENT EXCEPTIONNEL, SAINT-MAXIMIN DANS L'OISE}

Une découverte fait cependant exception. Il s'agit d'un grand bâtiment de plan quadrangulaire, d'une quinzaine de mètres de longueur sur 7 à $8 \mathrm{~m}$ de largeur. Construit sur des poteaux porteurs dont le diamètre des trous avoisinait $1 \mathrm{~m}$ de diamètre, il s'ouvrait à l'ouest grâce à une façade reposant sur quatre poteaux isolés. À l'intérieur du bâtiment se trouvait une fosse circulaire d'un diamètre de plus de $2 \mathrm{~m}$, comblée de gros blocs de pierres. Incomplètement fouillée lors d'une opération préventive, cette structure insigne n'a pas pu être directement datée. On doit malheureusement noter aussi que, bien qu'ayant fait l'objet d'une opération " de sauvetage ", elle n'a donné lieu à aucun rapport de fouille ni à aucune mention dans les Bilans scientifiques du Service régional de l'archéologie. Son environnement permet cependant de lui attribuer une fonction cultuelle et de la situer dans le temps. Elle se trouve, en effet, au milieu d'un " champ d'urnes " de la fin de l'âge du Bronze ou du premier âge du Fer. Le bâtiment ne recoupe ou n'est réoccupé par aucune fosse funéraire. On peut donc présumer qu'il en est contemporain et qu'il avait probablement une fonction cultuelle, en rapport direct avec les rites funéraires qui se sont déroulés autour de lui.

\section{LES DEUX VISAGES DE LA TÈNE ANCIENNE}

La situation terne qui a été décrite pour le premier âge $\mathrm{du}$ Fer se prolonge jusqu'au $\mathrm{V}^{\mathrm{c}} \mathrm{s}$., en plein début du second âge du Fer. Mais le désert que l'on a constaté paraît se 
réduire en un mouvement centrifuge, cependant nettement plus fort du côté oriental que du côté occidental.

La culture qu'on appelait " marnienne " au début du $\mathrm{XX}^{\mathrm{c}}$ s. se propage assez rapidement le long de la vallée de l'Aisne jusqu'à sa confluence avec l'Oise à partir de laquelle elle semble lancer deux branches, l'une importante vers la Seine, l'autre moins forte vers l'amont de la rivière Oise. Au sud, au nord et sur la côte de la Manche, les foyers de La Tène ancienne paraissent plus sporadiques.

Mais c'est surtout la nature des vestiges qui permet de distinguer deux ensembles géographiques parfaitement opposés. Le premier correspond à la presque totalité du territoire, marqué par des trouvailles isolées et une densité légèrement supérieure sur les marges. Ce sont exclusivement des vestiges d'habitat ou d'artisanat dont les témoins archéologiques sont toujours modestes: une ou quelques fosses, parfois un four de potier, rarement des unités d'habitations clairement identifiables. Rencontrés sur de vastes décapages nécessités par des fouilles d'urgence, ces vestiges ne montrent pas d'extension spatiale, comme c'est le cas pour les vestiges de La Tène C ou D. Il faut donc en conclure que l'on a affaire à l'habitat de groupes humains restreints et dont le niveau de vie était particulièrement faible. L'absence de toute nécropole sur ces lieux pourrait accréditer cette hypothèse : les communautés qui ont laissé ces maigres témoins n'étaient ni assez nombreuses ni assez structurées pour concevoir des monuments pour leurs morts illustres, qui servent par la suite d'ancrage à de véritables nécropoles.

Le second ensemble géographique est, au contraire, bien circonscrit dans l'espace. Il correspond à la vallée de l'Aisne qui n'est, en fait, qu'un appendice occidental du groupe champenois. Ici on a affaire à une succession dense de sites d'habitat et de nécropoles. Mais les vestiges les plus spectaculaires sont funéraires, à travers la présence d'un certain nombre de tombes à char que l'on ne rencontre nulle part ailleurs que dans cette vallée (au moins pour le $\mathrm{V}^{\mathrm{e}} \mathrm{s}$.) et celle, parfois associée à ces tombes à char, de véritables monuments, enclos et bâtiments. Ces derniers seront examinés infra (p. 27 sq.). La chronologie de ces nécropoles est tout à fait instructive. Les plus anciennes tombes à inhumation datent du début du $\mathrm{V}^{\mathrm{e}} \mathrm{s}$. et les premières installations architecturales conséquentes n'apparaissent que plus tard, à la fin de ce même siècle et au début du IVe. Or nous savons qu'il existe des nécropoles plus anciennes en Champagne. Cela suggère que la vallée de l'Aisne représente une extension territoriale d'un foyer qui était situé à l'est, dans l'actuel département de la Marne, et qui lui-même avait subi antérieurement l'influence des foyers de culture hallstattienne établis encore plus à l'cst ct au sud-est.
Très curieusement, ce mouvement d'est en ouest ne parvient pas à franchir la vallée de l'Oise mais s'infléchit vers le sud-ouest en suivant le cours de cette vallée. Cette résistance n'est compréhensible que si l'on imagine une population nouvellement installée dans le pays bellovaque et qui possède une forte individualité culturelle se traduisant notamment dans ses moeurs funéraires. Vers la fin du $I V^{\mathrm{e}} \mathrm{s}$. dans cette région (le bassin du Thérain), l'incinération paraît déjà fortement ancrée. À l'opposé, on trouve dans la basse vallée de l'Oise et dans la plaine de France des nécropoles à inhumations parmi lesquelles figurent des tombes à char qui subsistent jusqu'au milieu du III $^{\mathrm{e}} \mathrm{s}$. (Ginoux, Marti, 1999, p. 23).

\section{LES PREMIÈRES GRANDES INSTALLATIONS CULTUELLES}

\section{LE RÔLE DE LA GUERRE, UNE POPULATION RENOUVELÉE}

Les grands sanctuaires dont il va être question maintenant marquent indéniablement une nouvelle conception du culte nécessitant de grandes installations collectives, fruit d'une véritable réflexion architecturale. Ces créations soudaines, non annoncées par des réalisations antérieures de plus petites dimensions et qui seraient autant d'essais, ont dès les premières découvertes suscité des interrogations qui sont toujours à l'ordre du jour. Une hypothèse avait été proposée pour le sanctuaire de Gournay-sur-Aronde qui était le plus représentatif de cette nouveauté cultuelle (Brunaux, Méniel, Poplin, 1985 et infra notice 9, p. 59-60) : la création du sanctuaire serait la conséquence directe d'un afflux de population au début du III $^{\text {e }}$ s. dont les historiens antiques se sont fait l'écho, l'invasion des Belges. Cette interprétation, dans les années 1980, n'a guère pu être étayée directement par la découverte de séries de matériels spécifiques (si ce n'est celles d'armes en plus ou moins grand nombre) ou par la reconnaissance du synchronisme de la création de tous les nouveaux sanctuaires. Cependant, de façon indirecte, tous les travaux réalisés ces trente dernières années confirment pleinement l'innovation que représentent ces lieux de culte qui, nulle part dans tout le Nord de la Gaule, ne sont précédés par ce qui pourrait être considéré comme leurs antécédents. De fait, comme nous venons de l'évoquer, les sanctuaires apparaissent soudainement dans ce que l'on pourrait qualifier de désert cultuel. Ce qui, dans les années 1970, pouvait être perçu comme une illusion due à la déficience des recherches, après trente ans de recherches intensives, apparaît comme une réalité indéniable et problématique. 
Les fouilles du site de Ribemont-sur-Ancre et l'interprétation qui en a été proposée en 1999 (Brunaux dir., 1999) apportent des éléments qui renouvellent totalement la problématique (voir infra notice 14, p. 64-68 et fig. 38). Considéré trop hâtivement comme un sanctuaire, plus vaste que celui de Gournay et légèrement plus tardif (fin de La Tène $\mathrm{Cl}$ ), il se révèle un monument militaire édifié à $\mathrm{La}$ Tène $\mathrm{B} 2 \mathrm{~b}$, à la suite d'un épisode guerrier de grande ampleur. Dès lors, la comparaison avec Gournay, évoquée dès 1983 (Cadoux, 1984) et fondée sur la similarité des dépôts d'armes et d'ossements humains, doit désormais être envisagée sous un nouvel angle, celui de la chronologie. En effet, les objets les plus anciens de Gournay (bracelet décoré dans le style plastique et fourreaux d'épées à bouterolle ajourée ou massive) sont datables du début de La Tène B2 mais on sait que leur enfouissement a été plus tardif. Le nombre important des pièces appartenant à la seconde moitié de La Tène B2 laisse supposer une création du sanctuaire dans cet horizon bien défini par R. Gebhard (1989), soit entre 280 et 260 , c'est-à-dire quelques années avant Ribemont. On est alors fondé à se demander si les mêmes faits n'ont pas produit les mêmes effets, ou tout au moins des résultats assez similaires. L'apport considérable d'armes de cette époque à Gournay ne s'explique que par une origine guerrière : prise de butin des plus belles panoplies et offrandes dans le temple. Un raisonnement un peu similaire peut être formulé pour le sanctuaire de Saint-Maur qui montre également quelques pièces remontant à la même période, fin de La Tène B2 (voir infra notice 16, p. 69-71 et fig. 41).

Ces précisions chronologiques permettent de mieux comprendre la nature et le processus du nouveau peuplement. À l'évidence, il s'est fait sur un mode guerrier, souvent de façon violente à travers des batailles dont témoignent au moins deux sites, celui de Ribemont et celui de Mœurres (Salomon, 1913 et infra notice 11, p. 60-61 et fig. 35). Cependant le mouvement de population, interprété depuis César ( $B . G .$, II, 4,1$)$ comme "l'arrivée des Belges », ne s'est pas produit sur une courte période mais s'est étalé dans le tcmps, au moins sur un siècle, entre La Tène B2 et La Tène C2. Cette durée s'explique par la multiplicité des groupes ethniques qui se sont mis en branle et que seule l'appellation générique de "Belges " permet de regrouper en un même ensemble. Il ne s'agit donc nullement d'une invasion, comme on l'a cru longtemps, mais plutôt d'une multitude de colonies belges qui se sont insérées dans le maillage très lâche du peuplement indigène, un peu à la façon de l'occupation celtique de la Cisalpine, telle que la décrit Polybe (Histoires, II, 17).

À l'évidence, - et le Bellum Gallicum ne cesse deux siècles plus tard de le répéter - ces groupes ethniques ont imposé leur autorité grâce à une force guerrière qu'ils n'ont jamais cessé d'entretenir. Ainsi ont-ils pu dominer la population " gauloise ", comme la nomme César, qui était probablement plus nombreuse qu'eux. Ce pouvoir fort, qui s'est affirmé par la violence de la guerre, a ensuite été entretenu par des symboles puissants, tels que les trophées, les sanctuaires guerriers et un culte public à forte connotation militaire. On a remarqué depuis longtemps que dans le Belgium, territoire de conquête des Belges entre la fin du $\mathrm{IV}^{\mathrm{c}}$ s. et le début du II ${ }^{\mathrm{e}}$ s., les oppida, les fortifications sont absentes, comme si la réputation guerrière certainement soigneusement entretenue suffisait à la défense du territoire (Brunaux, 1996).

\section{LES PRINCIPAUX LIEUX DE CULTE DE LA TÈNE MOYENNE}

La mise en évidence des structures et du fonctionnement du sanctuaire de Gournay à la fin des années 1970 a longtemps fait croire que les grands ensembles cultuels de La Tène moyenne dans le Nord de la Gaule avaient été conçus d'après un modèle identique et avaient fonctionné de façon plus ou moins similaire (fig. 5). Aujourd'hui, cela ne paraît plus tout à fait vrai. Il y a cependant quelques constantes, nous en retiendrons cinq :

- il s'agit chaquc fois de lieux communautaires, par opposition aux structures familiales qui caractérisaient les périodes précédentes;

- tous ces lieux sont fermés et marqués au sol par une clôture, plus ou moins symbolique ;

- ils livrent chaque fois du mobilier militaire, en proportion plus ou moins grande ;

- ils sont généralement isolés, c'est-à-dire plus ou moins éloignés des zones d'habitation contemporaines ;

- ils laissent des vestiges matériels qui trahissent une longévité de l'occupation, souvent sur plusieurs siècles.

Face à ces constantes les différences peuvent être marquées. Elles tiennent tout d'abord à la taille de l'enclos. Le plus petit, à Bennecourt, mesure une quinzaine de mètres de côté (Bourgeois dir., 1999 et infra notice 4, p. 53-54 et fig. 31). Le plus grand, celui de Fesques, a une longueur maximale de $500 \mathrm{~m}$ (Mantel el al., 1997 et infra notice 8, p. 56-59). Mais, le plus souvent, ils mesurent entre 30 et $50 \mathrm{~m}$ de côté.

Le plan n'est pas non plus constant, même si les formes géométriques sont les plus courantes. La forme rectangulaire est la mieux représentée: Ribemont (notice 14, p. 64-68), Gournay (notice 9, p. 59-60), Saint-Maur (notice 16, p. 69-71 et Brunaux, Lambot, 1991), Bennecourt (notice 4, p. 53-54), Beauvais (notice 3, p. 53), Estrées- 


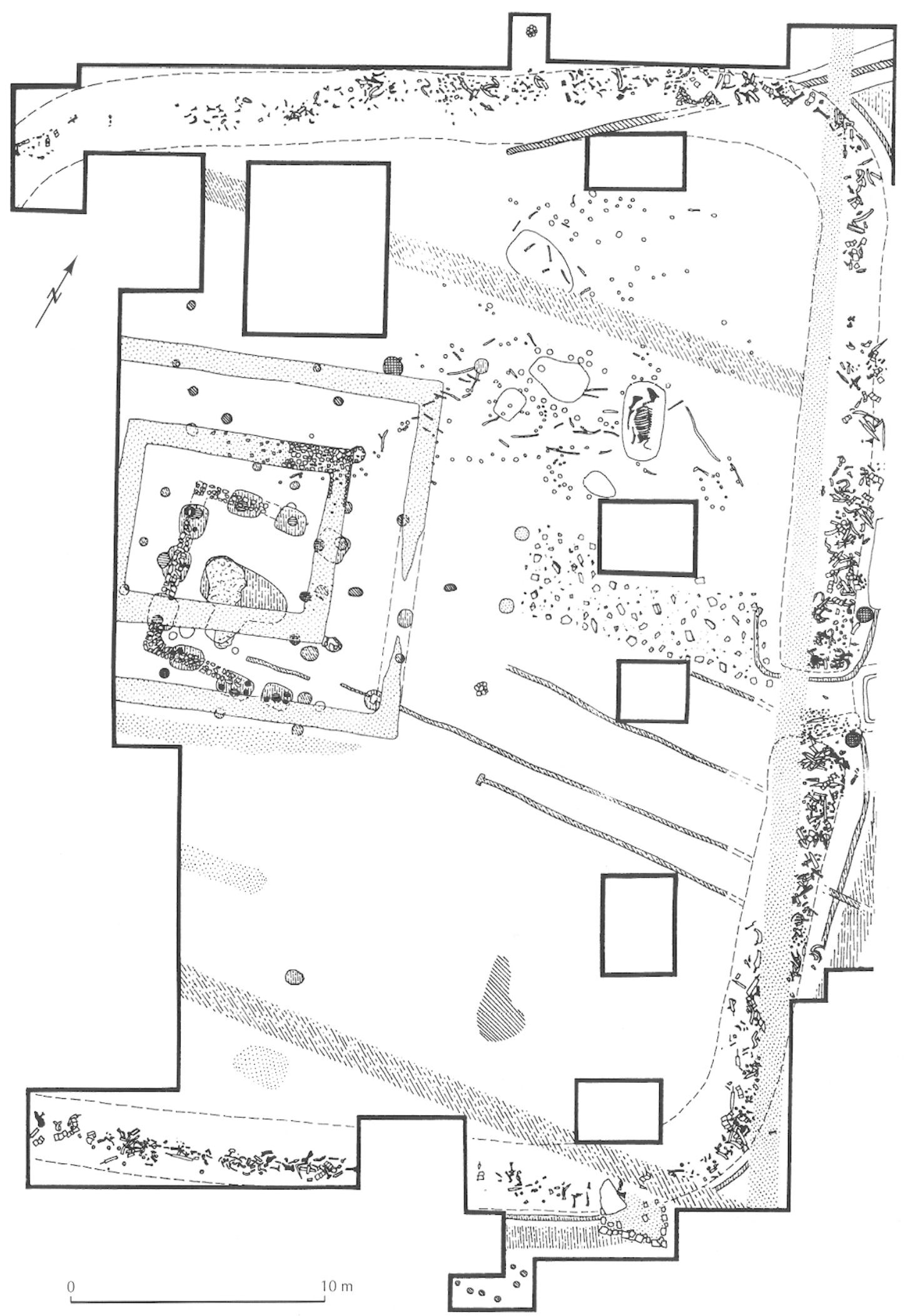

Fig. 5 - Gournay-sur-Aronde (Oise), Le Parc. Plan du sanctuaire (d'après Brunaux, Méniel, Poplin, 1985). 
Saint-Denis (notice 7, p. 56), Morvillers-Saint-Saturnin (Delplace, 1991 et infra notice 13, p. 62-64) et Saint-Just-enChaussée (notice 15, p. 68-69). Le plan curviligne n'est connu qu'à un seul exemplaire, à Ribemont (Brunaux, 2002). Le plan piriforme de Fesques s'explique par la topographie naturelle. Mais ce qui est le plus étonnant c'est l'opposition entre des plans montrant la régularité la plus parfaite dans le tracé rectiligne des fossés et des angles - c'est le cas des deux enclos de Ribemont (notice 14, p. 64-68) et, de façon un peu moins spectaculaire, de celui de Gournay - et ceux au contour " mou », tels Saint-Maur et Fesques.

La différence la plus grande tient à la présence ou à l'absence d'un aménagement cultuel au centre de l'enclos. Celui-ci prend la forme d'une ou plusieurs fosses, utilisées comme autel. On les connaît bien à Gournay, à SaintMaur et à Vendeuil-Caply (notice 17, p. 71). Elles sont identifiables, bien que remaniées à Morvillers-SaintSaturnin (notice 13, p. 62-64), à Bennecourt et à Chilly (notice 5, p. 54-55). En revanche, l'enclos quadrangulaire de Ribemont n'en présente pas. Dans l'enclos curviligne de Ribemont la fosse-autel est totalement décentrée. À Fesques, il n'est pas sûr que l'état le plus ancien ait possédé un tel aménagement qui n'est connu que dans la phase récente.

Ces disparités qui apparaissent aujourd'hui avec une assez grande évidence obligent à réviser les premiers cssais de synthèse sur ces lieux de culte. Ainsi ce n'est plus la seule fosse-autel qui permet d'identifier un grand sanctuaire, dans le sens d'un grand lieu de culte autonome. De telles structures ont, en effet, été rencontrées sur les habitats (Montmartin par exemple, voir infra notice 12, p. 61-63) mais aussi en contexte funéraire (enclos curviligne de Ribemont). L'absence de ce type d'autel ne doit pas être interprétée systématiquement comme une absence de culte sacrificiel, au moins à grande échelle, à l'intérieur de l'enclos. La fouille de l'enclos quadrangulaire de Ribemont a montré que celui-ci a servi de trophée militaire où les dépouilles des morts, cadavres humains et armes, avaient été utilisécs comme offrandes. Cette activité cultuelle, répandue dans cette région, au moins sous la forme d'offrandes d'armes (Gournay, Saint-Maur, Morvillers), ne s'est pas accompagnée à Ribemont de sacrifices animaux. À Fesques, la fouille a révélé un autre type de fonctionnement: dans une première phase l'enclos semble avoir accueilli d'immenses banquets qui réunissaient des centaines, voire des milliers de participants.

Ces progrès dans l'analyse des sites ont été rendus possibles par des fouilles extensives, voire exhaustives. Les installations et le fonctionnement du sanctuaire de Gournay ont été compris à la faveur de la fouille totale de l'enclos qui a permis de distinguer les différentes phases chronologiques et, dans celles-ci, des ensembles fonctionnels. À Ribemont, c'est la fouille également complète des enclos qui a révélé leur nature votive pour le premier et funéraire pour le second, en autorisant chaque fois l'attribution des séries de matériel à des phases chronologiques distinctes. À Fesques, une fouille de grande envergure a révélé un enclos hors norme par la taille. À Morvillers, de grands décapages ont mis en évidence la présence d'un enclos fossoyé qui n'était pas directement décelable à l'examen des seules structures gallo-romaines. À l'inverse, lorsque les fouilles ont été limitées dans leur extension spatiale, la nature du lieu cultuel n'a pas pu être parfaitement établie. Ainsi à Vendeuil-Caply où l'installation cultuelle est tout à fait similaire à celles de Gournay et de Saint-Maur, on n'est pas sûr de la présence d'un enclos dont l'existence peut cependant être présumée grâce à la photographie aérienne. À Meaux, ni l'enclos ni une éventuelle fosse-autel n'ont pu être reconnus et l'on peut se demander si le matériel (probablement votif) découvert n'a pas fait l'objet d'un déplacement (Magnan, 2000 et infra notice 10, p. 60). De tels déplacements, voire des fermetures ne sont pas rares. Ils ont pu être prouvés sur les sites de Gournay et de Ribemont (enclos quadrangulaire). On peut les postuler pour des sites dont la nature cultuelle spécifique reste énigmatique, tels que Dompierre-sur-Authie (Piton, Dilly, 1990 et infra notice 6, p. 55) ou Baron-sur-Odon (Bertin, 1977). La nonreconnaissance des éléments architecturaux laténiens ne permet pas de la découvrir. Il paraît donc évident que les fouilles futures sur de tels lieux ne devront jamais se limiter à des sondages ou à des fouilles partielles qui ne permettraient de connaître ni la structure englobante (enclos) ni un éventuel aménagement cultuel central. En tout état de cause, seule la localisation du centre fonctionnel du culte peut aider à la recherche des limites du site et ainsi à connaître son extension, voire à reconnaître un déplacement ou une fermeture dont on peut postuler les traces sur tous les grands lieux de culte.

Ainsi, après 25 ans d'intenses travaux sur le terrain, les grands lieux cultuels se répartissent en plusieurs types dont on n'a certainement pas épuisé la diversité. Le mieux connu est celui qui sera décrit ci-après, c'est le sanctuaire au sens propre du terme, enclos sacré uniquement réservé à un culte public régulier. Les principaux représentants sont Gournay, Saint-Maur, Morvillers-Saint-Saturnin, probablement Vendeuil-Caply, Bailleul-sur-Thérain (Renet, 1879 et infra notice 2, p. 52), Baron-sur-Odon, Dompierre-surAuthie. Un autre type de lieu cultuel, attesté par la littérature antique et soupçonné d'après une découverte archéologique il y a près d'un siècle, est le trophée guerricr, représenté par deux lieux, Ribemont et Mœuvres. Un 
troisième type, plus difficile à définir, n'est connu que par un seul lieu, celui de Fesques. Il s'agit probablement d'un aménagement mixte, non seulement cultuel mais aussi politique et communautaire. Dans ce cas, la présence autour de l'enceinte de cadavres présentés initialement en position verticale pourrait se rapporter à une pratique judiciaire (Brunaux, 2000a). Là encore ce type de lieu est attesté dans la littérature antique et plus précisément dans l'œuvre de César (tribunal des Helvètes devant juger Orgétorix). Le dernier type n'est également connu que par un seul exemplaire, l'enclos polygonal de Ribemont, il s'agirait d'une sorte d'hérôon. Bien représenté dans le Sud-Est de la Gaule et peut-être dans l'est (enclos de Vix), ces sortes de mémoriaux ont dû prendre des formes très diverses qui restent encore à dćcouvrir.

\section{L'AMÉNAGEMENT ARCHITECTURAL DES SANCTUAIRES}

Le III ${ }^{c}$ s. avant J.-C. est marqué par cette grande innovation religieuse, la mise en cuvre de lieux de culte autonomes. Ce sont des installations qui ne sont conçues que pour l'exercice du culte et dont la justification topographique ne tient qu'à la seule fonction religieuse. Elles ne sont pas des annexes d'habitat ou de lieux funéraires. Nous avons pris l'habitude d'appeler ces lieux "sanctuaires ", en réservant cette dénomination exclusivement aux installations qui présentent les caractéristiques qui viennent d'être mentionnées (voir infra notice 9, p. 59-60).

Le sanctuaire se présente avant tout, dans sa réalité matérielle, comme un lieu coupé du monde. Il est le terrain de la divinité, autant sa propriété que sa représentation. Les Celtes protohistoriques sont, en effet, réputés ne pas pratiquer la représentation matérielle de leurs dieux sous forme anthropomorphe et nous ne connaissons aucun exemple de statuaire divine chez eux avant les premiers effets de la romanisation. La réalité physique de la divinité devait donc se manifester sous une autre forme, qui devait néanmoins permettre le contact entre humains et dieux. Le terrain sacré le permettait.

Plus précisément, il semble que ce soit ce terrain et son développement végétal, et plus spécifiquement arboré, autrement dit le "bois sacré " qu'on a laissé se développer à sa surface, que les Celtes aient voulu honorer. Comme les Germains, ils révéraient les arbres et les végétaux avec ferveur. Cependant la conception du bois sacré ne leur était pas propre. Ces bois sacrés étaient répandus en Grèce archaique, chez les peuples italiques, les Romains et on en voit encore de nombreux exemplaires actuellement en Afrique (Cazanove dir., 1993). Il ne faut pas se tromper sur la signification de cette appellation. Le «bois sacré " n'est bien souvent qu'un bosquet, voire une sorte de jardin botanique qui peut prendre une forme très artificielle comme à Gabii dans le Latium (Coarelli, 1993). C'est la plupart du temps une parcelle de terrain sauvage où on laisse se développer naturellement la végétation, sans couper les arbres, si ce n'est dans des rituels exceptionnels et très respectueux de l'espèce végétale.

Dans le Nord de la Gaule deux aménagements boisés, des terrains sacrés, ont à présent été reconnus. À Gournay dans la partie septentrionale de l'aire intérieure du sanctuaire a été mis en évidence un petit enclos attenant aux structures cultuelles. Dans celui-ci des cuvettes produites par le pourrissement des chablis, des empreintes laissées dans le sol ancien par des branches témoignent sans ambiguité de la présence d'arbres qu'on a laissés sans soin. Dans l'enclos quadrangulaire de Ribemont c'est toute la zone centrale, une surface de $500 \mathrm{~m}^{2}$, qui montre un sol végétal parfaitement conservé, sans trace d'anthropisation où les traces de chablis, les pollens d'arbres et d'arbustes abondent. De tels vestiges sont évidemment difficiles à mettre en évidence lors de fouilles, surtout si elles sont faites en urgence, il ne faut donc pas s'étonner que le nombre de ces «bois sacrés » identifiés soit encore limité.

Du sanctuaire ce qui est le plus marquant pour l'archéologue c'est la coupure avec le reste du paysage, un monde profane abandonné aux humains, à leurs cultures et à leurs animaux domestiques. Cette découpe du sol est avant tout symbolique mais elle s'exprime souvent dans une matérialisation très forte. Le fossé, élément fondamental de ces aménagements, est souvent relativement profond, entre $1,50 \mathrm{~m}$ et $2 \mathrm{~m}$, large de 2 à $3 \mathrm{~m}$ et, dans quelques cas, montre un tracé régulier quasi parfait (Gournay, Ribemont, SaintMaur). Le fossé est toujours ouvert et se double dans la plupart des cas d'une palissade. Des fouilles plus systématiques et plus attentives aux structures légères devraient montrer que la présence de cette palissade était aussi consubstantielle au sanctuaire que l'est celle du fossé. En effet, si le fossé marque physiquement la propriété divine (c'est l'origine du mot grec temenos désignant l'enceinte sacrée) en découpant le sol, la palissade ou mur de bois a un autre rôle, celui d'enfermer l'activité cultuelle dans une enceinte qui la rende invisible au monde extérieur.

La taille et la forme de l'espace sacré répondent à des normes, même si les données disponibles paraissent un peu disparates. Il est remarquable, en effet, que l'on ait toujours affaire à des espaces de taille moyenne ou petite. Ils n'excèdent jamais $2500 \mathrm{~m}^{2}$. C'est la taille de l'enclos quadrangulaire de Ribemont. L'enclos le plus petit est celui de Bennecourt, dix fois plus petit, avec $225 \mathrm{~m}^{2}$ (voir infra notice 4, p. 53-54). La moyenne semble se situer aux 


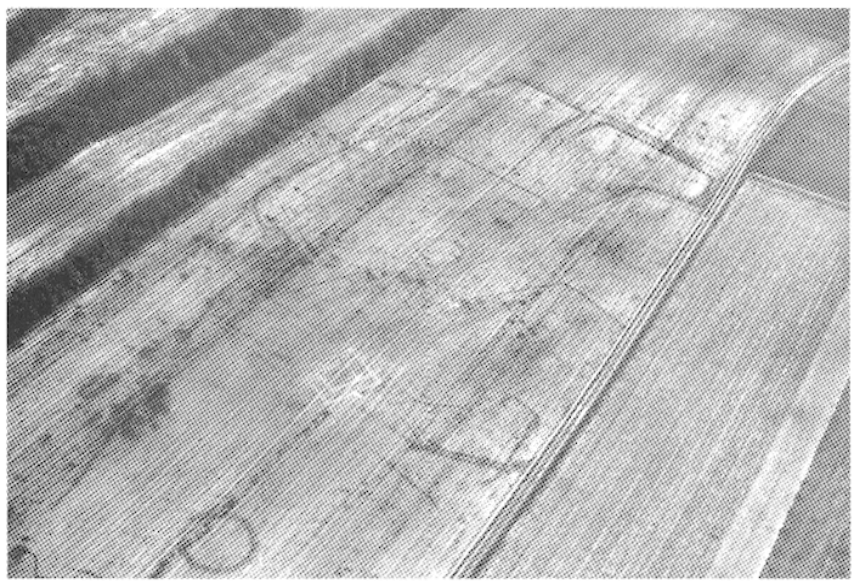

Fig. 6 - Cocquerel (Somme), Le Beau Bucquet. Fanum implanté à l'emplacement d'un ensemble d'enclos lalénien, situé à proximité d'un enclos circulaire (photo R. Agache, ministère de la Culture).

environs de $35 \mathrm{~m}$ de côté. La forme est plus normalisée. Elle est très généralement quadrangulaire et souvent montre un plan à la rigueur géométrique (Gournay, Ribemont, Morvillers, Bennecourt, Fesques). L'enclos de VendeuilCaply, qui n'est connu que par la photographie aérienne, a une forme exceptionnelle relativement circulaire. Ses dimensions, supérieures à $100 \mathrm{~m}$ de diamètre, le sont également.

Ainsi le sanctuaire apparaît comme un espace relativement circonscrit, conçu pour des groupes humains limités en nombre. Quelques dizaines de personnes tout au plus pouvaient s'y réunir en même temps. Les espaces de plus grande taille, tel celui de Fesques ou encore celui de Montmartin (Brunaux, Méniel, 1997), paraissent n'avoir pas connu la seule destination religieuse et ce sont les fonctions qui lui étaient associées (politique, édilitaire, juridique) qui justifiaient une ouverture publique plus large.

L'enclos sacré obéit donc à des règles de dimensions, de forme mais aussi d'implantation. Le choix du site répond certainement à des impératifs qui malheureusement demeurent presque toujours inaccessibles à la recherche archéologique. Même si ce choix devait être assez souvent arbitraire, les créateurs du lieu l'ont paré de raisons étiologiques: manifestation surnaturelle, présence d'un signe interprété comme d'origine divine, etc. On a remarqué que plusieurs sanctuaires celtiques et fana qui pourraient avoir une origine protohistorique se trouvent à proximité immédiate d'un ou plusieurs tumulus de la fin de l'âge du Bronze. C'est le cas à Ribemont, ainsi qu'à Cocquerel (fig. 6) (Agache, 1978). Il n'est pas improbable que dans certains cas la population localc ait imaginé que tel ou tel tumulus ait abrité les restes d'un héros fondateur du lieu, comme cela est souvent arrivé en Grèce. Mais à Ribemont, comme à Gournay, ce sont des raisons conjoncturelles qui expliquent le choix du lieu. À Ribemont c'est une importante bataille qui a occasionné l'installation de deux monuments guerriers, l'un de type trophée, le second de type hérôon. À Gournay c'est la présence d'une petite installation cultuelle de la fin du IV $\mathrm{V}^{\mathrm{c}} \mathrm{s}$. avant J.-C. qui paraît avoir suscité la création du grand sanctuaire.

Le plan quadrangulaire présentait le grand avantage de permettre son orientation. De fait, l'entrée ouvre toujours à l'est, contrairement aux enclos funéraires qui s'ouvrent très généralement vers l'ouest ou vers le nord. Cette orientation ne correspond pas systématiquement à l'est réel. On constate une variation entre l'est-nord-est (Gournay, Bennecourt) et l'est-sud-est (Ribemont), d'environ $80^{\circ}$. Cet alignement sur le soleil levant traduit certainement des dates d'inauguration différentes dans l'année. À Gournay, l'axe du sanctuaire correspond approximativement à celle du soleil au solstice d'été, la différence entre les deux étant probablement attribuable à la déclinaison magnétique.

L'enclos une fois inauguré, certaincment lors de sa délimitation fossoyée, fait l'objet d'un véritable aménagement architectural. L'élément le plus important en est la palissade de bois ou le mur en torchis, situé le long du bord intérieur du fossé, toujours dans l'espace central, lorsqu'il existe deux fossés parallèles, comme à Saint-Maur et à Morvillers. C'est ce mur de clòture qui matérialisait réellement l'enceinte sacrée. Les traces de ces murs ont été découvertes à Gournay, Saint-Maur, Fesques et Chilly. Dans tous ces cas, le mur paraît continu et ne laisse qu'un passage étroit $(2$ à $3 \mathrm{~m}$ de largeur) au niveau de l'entrée. Cette disposition correspond à l'installation d'une véritable porte qui parfois prend les allures d'un porche monumental (Gournay, Saint-Maur, Ribemont peut-être). Le plus important est celui de Gournay, de $5 \mathrm{~m}$ de largeur pour $8 \mathrm{~m}$ de profondeur, reposant sur huit poteaux. Ce porche devait être muni d'un étage et ressembler assez aux portes couvertes des oppida. Sur ces parois et surtout à l'étage était stocké l'essentiel des armes qui furent rejetées ensuite dans le fossé, de chaque côté de l'entrée.

Incontestablement l'entrée constituait le point fort de ces enceintes. Elle était non seulement scrupuleusement fermée de vantaux mais aussi décorée. La meilleure documentation nous est donnée par le sanctuaire de Gournay. Là, non seulement les offrandes d'armes y étaient accrochées avec un certain esthétisme dont au moins un faisceau de fourreaux et d'épées témoigne, mais encore on y avait suspendu de nombreux crânes humains ainsi que des crânes de bovidés. Ce décorum était destiné à sensibiliser la conscience de ceux qui pénétraient dans le territuire de la divinité. Pour cela des rites étaient aussi nécessaires dont 
l'aménagement architectural et les restes matériels rendent également compte à leur manière. Dans trois sanctuaires du pays bellovaque (Gournay, Saint-Maur et Morvillers), l'entrée nécessitait le passage d'un fossé continu ou d'une fosse à l'aide d'une passerelle. À une époque plus tardive, à La Tène D2, le passage s'accompagnait d'une offrande obligatoire, dépôt de monnaies par exemple à Saint-Maur. Un porche aussi monumental que celui de Gournay, avec sa décoration particulière de crânes humains, permet d'expliquer pourquoi Strabon (Géographie, c 198) utilise le terme tout à fait spécifique de " propylée ", littéralement l' "entrée monumentale du sanctuaire ». Ce lieu " où [dit-il] les Gaulois accrochaient les crânes de leurs ennemis, est bien un sanctuaire et non la porte de leur maison, comme des traductions fautives l'ont jadis proposé ».

L'architecture de ces sanctuaires est plus ou moins élaborée. Elle l'est certainement en fonction d'une hiérarchie, selon qu'ils s'adressaient à une communauté plus ou moins vaste (tribu toute entière, pagus, ou unité territoriale plus petite). Elle l'est aussi en fonction de la tradition religieuse propre à chaque peuple. Ainsi les aménagements les plus complexes comprenant deux fossés parallèles, une ou deux palissades et un porche monumental sont pour l'instant circonscrits au pays des Bellovaques.

\section{LES INSTALLATIONS CULTUELLES}

L'espace sacré, une fois que la terre élue avait été découpée et qu'une enceinte murale la séparait plus matériellement du reste de la nature, se suffisait à lui-même. Les rites pouvaient se dérouler à même le sol dans le «bois sacré " ou à sa bordure. C'est ainsi probablement que les premiers voyageurs ou les informateurs anciens de Poseidonios perçurent ces sanctuaires dans le courant du III $^{e}$ s. avant J.-C. L'archéologie le confirme : le sanctuaire dans lequel on trouve un bric-à-brac invraisemblable d'objets, de restes sacrificiels, correspond bien à ces enceintes dans lesquelles, nous dit Diodore (Bibliothèque historique, V, 27) : "d'après Poseidonios, on avait jeté d'incroyables richesses ». Les lieux de culte gaulois méritent pleinement l'appellation de temene que leur donnent les auteurs grecs. Ils ne différaient guère de bien de leurs homologues en Grèce archaïque ou dans le Latium, qui étaient de simples enceintes entourant un bosquet sans temple.

La caractéristique des sanctuaires du Nord de la Gaule et probablement du monde celtique protohistorique est l'absence de temple. Le dieu qui n'avait pas forme humaine n'avait pas besoin d'une pseudo-maison - un naos ou une cella - pour abriter son image. Il était présent sous la terre sacrée et se manifestait dans les frondaisons de son "bois sacré ". Pour communiquer avec lui l'homme n'avait pas besoin d'installation complexe ou dispendieuse, tels que temple, autel monumental, statue cultuelle. Les offrandes pouvaient être déposées directement sur le sol ou accrochées aux arbres. Nous avons vu que le mur de clôture et le porche d'entrée pouvaient également jouer ce rôle de support. Le sacrifice ne nécessitait qu'un simple foyer, parfois une fosse.

On ne doit donc pas s'étonner que des enceintes sacrées, révélées par leur plan et le matériel qu'elles ont livré, ne montrent aucun aménagement cultuel particulier ou tout au moins discernable par l'archéologue. Dans la plupart des cas, les aménagements réalisés sur le sol ou a fortiori audessus de celui-ci ont disparu sans laisser de trace, en même temps que les sols anciens. Cependant, bien des sites livrent les parties excavées de ceux-ci, des fosses.

L'exemple le mieux documenté est donné par le sanctuaire de Gournay qui, une fois encore, s'est révélé être un modèle trompeur. Il s'agit d'un ensemble complexe de dix fosses situées précisément au centre de l'enclos. Neuf fosses carrées aux angles très arrondis, de 1,20 m de côté environ et de plus de $1 \mathrm{~m}$ de profondeur, entourent une fosse ovalaire de 3,50 m de côté, $2 \mathrm{~m}$ de largeur et $2 \mathrm{~m}$ de profondeur (fig. 7a). Sur le long côté sud se trouve un appendice de $1,50 \mathrm{~m}$ de longueur qui a pu servir d'accès au fond de la fosse. Le fonctionnement de la grande fosse est bien connu grâce à l'analyse ostéologique des restes animaux découverts sur le site et de quelques pièces anatomiques trouvées au fond de la fosse. Ainsi il a pu être établi que la fosse avait servi de pourrissoir aux bovidés qu'on sacrifiait régulièrement dans l'enceinte. Les dépouilles étaient déposées entières dans la fosse et elles y demeuraient le temps que les chairs se décomposent.

On a pu croire que les fosses découvertes au centre des autres sanctuaires (Saint-Maur, Morvillers, Vendeuil-Caply, Bennecourt, etc.) avaient connu la même fonction, celle d'un autel creux utilisé comme pourrissoir. Cette interprétation était quasiment imposée par le fait que ces structures avaient été recreusées tardivement et ne pouvaient livrer la moindre documentation susceptible d'éclairer leur utilisation (fig. 7b). La découverte de deux nouveaux autels creux oblige à reconsidérer le mode de leur fonctionnement. À Montmartin (place publique et cultuelle) et à Ribemont (enclos curviligne), une fosse cylindrique de très grande dimension $(2,50 \mathrm{~m}$ à $3,50 \mathrm{~m}$ de diamètre pour $2 \mathrm{~m}$ de profondeur) est associée physiquement à un foyer installé sur son bord et dont les cendres ont été déversées dans le remplissage final de la fosse. C'est la structure de Ribemont et le matériel qui y a été découvert qui permettent de comprendre comment foyer et fosse ont été utilisés. 


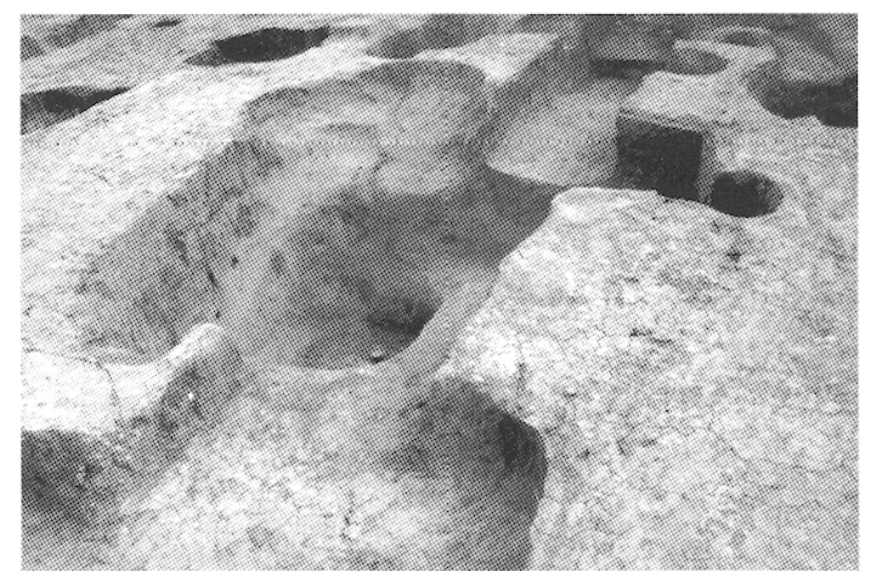

a

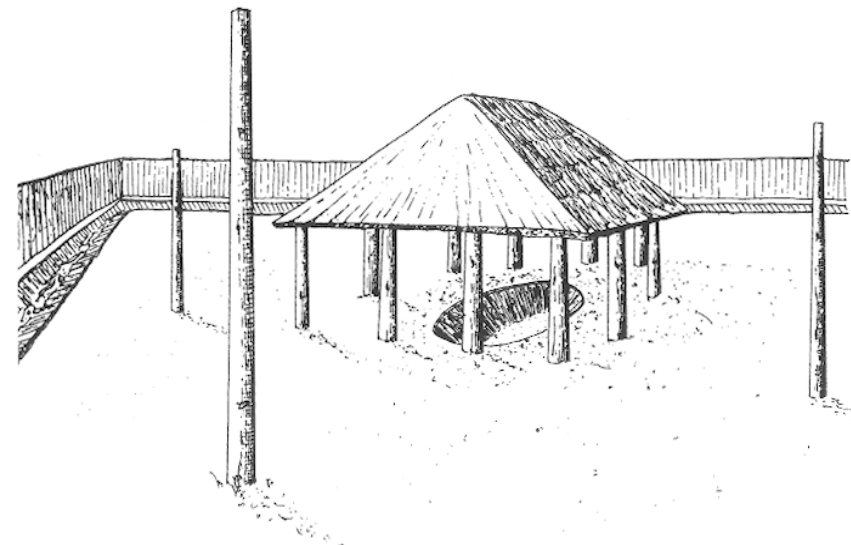

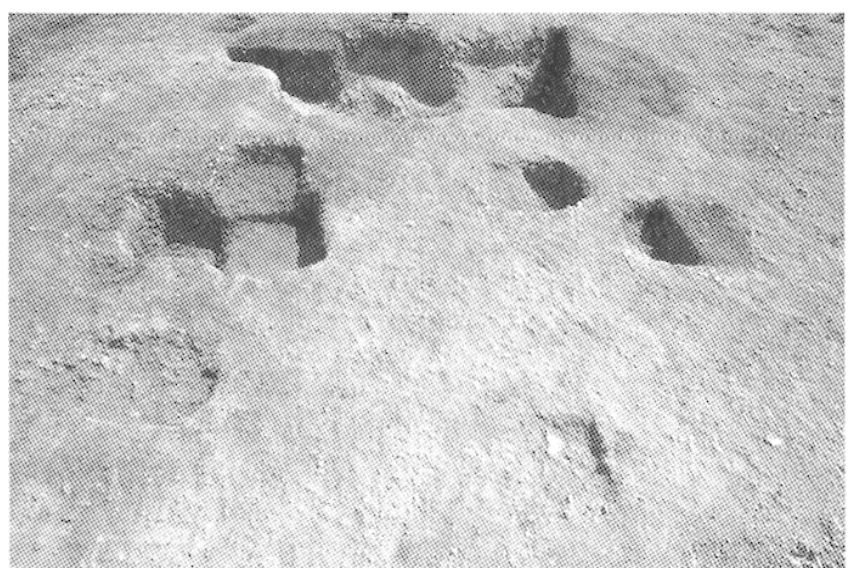

b

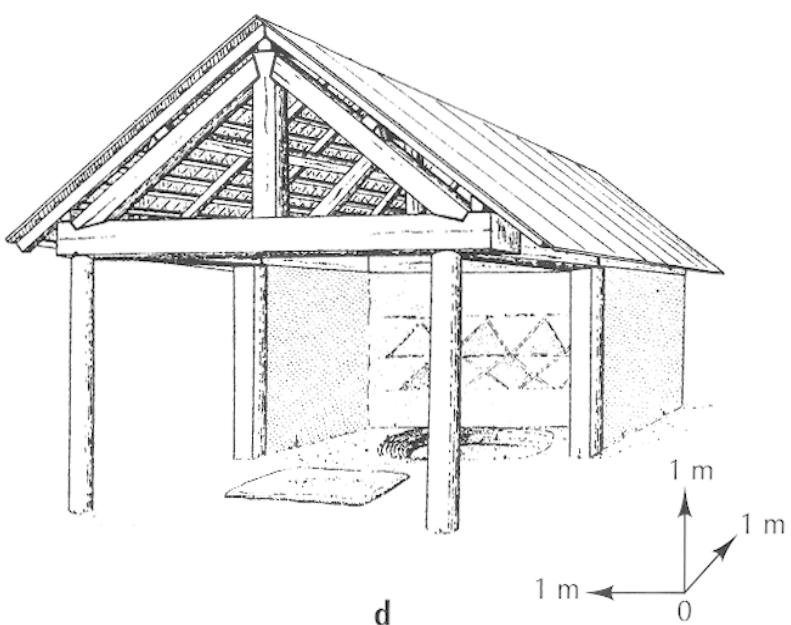

Fig. 7 - a, fosse centrale (autel creux) du sanctuaire de Gournay-sur-Aronde (Oise) (photo J.-L. Brunaux, CNRS); b, l'aménagemenl cultuel de Montmartin (Oise) : autel creux et trous de poteaux du bâtiment de couverture (photo J.-L. Brunaux, CNRS); c, reconstitution du premier autel couvert de Gournay-sur-Aronde (d'après Brunaux, Méniel, Poplin, 1985); d, reconstitution de l'autel couvert de Montmartin (Oise) (d'après Brunaux, Méniel, 1997).

La fosse n'avait qu'un usage symbolique (elle représentait la divinité ou un moyen de communication avec elle) et ne recevait que le sang des victimes et des libations. Quant au foyer, il servait à cuire les parts de viande et certainement la fressure destinées aux dieux.

C'est probablement cette utilisation qu'ont connue les fosses périphériques de Gournay. Dans le fond de plusieurs d'entre elles fut observée une importante couche de limon très oxydé. Ce phénomène important d'oxydo-réduction n'a pu être provoqué que par un apport massif de matières organiques et une carence en oxygène. Or nous savons que ces fosses étaient la plupart du temps soigneusement fermées. La fosse centrale de Bennecourt montre également une tellc couche. Or, là aussi, les fouilleurs avaient conclu que la fosse était habituellement fermée. Les fosses périphériques ne sont pas une particularité du sanc- tuaire de Gournay. On les retrouve disposées sur un plan parfaitement similaire à Saint-Maur et à Vendeuil-Caply.

Le sanctuaire de Gournay, parce qu'il est jusqu'à présent le plus précoce et parce que les aménagements de La Tène moyenne sont bien conservés, nous apprend qu'à date haute, au milieu du $\mathrm{III}^{\mathrm{e}} \mathrm{s}$. avant J.-C., l'installation cultuelle se limitait à ces fosses creusées dans le sol et simplement protégées par des couvercles en bois. C'est probablement l'agrandissement de la fosse centrale qui a obligé les utilisateurs à imaginer une protection plus efficace qui permettait en les abritant de pratiquer le culte par tous les temps. Une toiture était installée au-dessus de la grande fosse (fig. 7c). Les poteaux qui la soutenaient étaient ancrés dans les fosses périphériques qui, pour cette raison, ont été rebouchées. Les fosses de Saint-Maur ont connu la même utilisation secondaire. À Vendeuil-Caply on ne peut en avoir la 
certitude. À Gournay, où l'érosion est relativement faible, on n'a pas observé, entre les trous porteurs de la toiture, de tranchée de palissade ou de trous pouvant correspondre à des piquets ou aux supports des murs. Nous en concluons donc que, dans son premier état, cette construction était ouverte sur tous les côtés et n'avait pour fonction que de protéger l'autel des intempéries.

Un véritable bâtiment partiellement fermé n'apparaît à Gournay que dans le courant du II ${ }^{e}$ s. avant J.-C. Le plan en est alors sensiblement modifié, il adopte une forme quadrangulaire, mieux adaptée à la réalisation de murs et d'une toiture à deux pans. Le bâtiment est partiellement ouvert, notamment sa façade qui repose sur quatre poteaux. Les trois autres parois, fond et côtés, sont complètement fermées. On retrouve le même aménagement à Montmartin (fig. 7d) et à Bennecourt. La disposition est toujours la même: le bâtiment est construit autour de la fosse, en ménageant autour d'elle un espace de circulation, la façade se situe juste devant l'emplacement d'un éventuel foyer. La construction permettait donc une utilisation confortable de la structure sacrificielle en laissant, d'une part, une éventuelle assistance contempler les rites qui se déroulaient à l'intérieur et, d'autre part, en laissant facilement échapper les fumées se dégageant du foyer.

Un tel bâtiment ne peut être considéré comme un temple authentique, même si par son apparence extérieure (plan quadrangulaire, toit à double pente, façade en colonnade) il s'en rapprochait de manière indéniable. Il n'abritait toujours pas l'image du dieu et surtout, à la différence des temples du monde classique, l'autel se trouvait à l'intérieur du bâtiment et non à l'extérieur, devant lui.

\section{LES ACTIVITÉS CULTUELLES DANS LE SANCTUAIRE}

Les lieux de culte fouillés dans cette région n'ont pas tenu les promesses qu'annonçait le sanctuaire de Gournay. En fait, peu de choses nouvelles ont été apprises depuis et pour ce qui est des principales pratiques rituelles c'est encore à ce site qu'il faut se référer pour obtenir une documentation un peu consistante. On demeure étonné de l'absence de diversité de ces dernières. À Gournay où elles sont le mieux connues, on peut distinguer trois ensembles, le sacrifice animal, l'offrande d'armes et le traitement du corps humain. Mais dans bien des cas, seul le sacrifice animal se révèle avec une plus ou moins grande évidence.

\section{LE SACRIFICE ANIMAL}

Si l'on examine l'ensemble des données, on pourrait en conclure que les sanctuaires ont été édifiés presque exclusi- vement pour y accomplir des sacrifices animaux. La plupart des sites n'offrent pourtant qu'un reflet assez. terne de cette activité. Les os qui en témoigncnt sont surtout dćcouverts en situation résiduelle et donnent une très mauvaise image de la régularité des sacrifices et de la quantité des victimes. Ils ne nous révèlent que l'identité des espèces. Dans tous les cas, il s'agit d'animaux domestiques. Les espèces les plus souvent mises à mort sont le porc, le mouton et, dans une moindre mesure, le chien. Le bœuf apparaît comme une victime exceptionnelle. Quant au cheval, il n'est pas prouvé qu'il fût sacrifié, encore moins qu'il le fût régulièrement.

Le sanctuaire de Gournay montre que ces sacrifices se répartissaient en deux grandes catégories qui pouvaient coexister sur le même lieu de culte, le sacrifice de type chthonien et le sacrifice de commensalité. C'est le premier qui nous est actuellement le mieux connu grâce à des restes bien conservés. Ce sont les bovidés qui sont les victimes privilégiées de ce type de sacrifice, mais on ne peut en exclure les chevaux. Le terme de chthonien se comprend ici par comparaison avec cette forme de culte en Grèce, un sacrifice qui s'adresse à des divinités infernales par l'intermédiaire d'un autel creux auprès duquel on abat des mammifères, généralement de couleur sombre, dont toute la chair est laissée à la divinité. À Gournay, ce sacrifice prend une forme tout à fait originale, qui n'est cependant pas inconnue dans le monde classique mais qui y semble assez rare : les victimes, après avoir été mises à mort, sont jetées dans la fosse qui leur sert de pourrissoir. Cette période de pourrissement suivie de la récupération des restes n'est pas sans rappeler, en effet, l'une des formes de sacrifice exécuté aux Thesmophories. Même s'il est le mieux connu, grâce aux vestiges exceptionnels de Gournay, ce sacrifice ne devait pas être le plus courant. Deux découvertes récentes, à Montmartin et à Ribemont dans l'enclos curviligne, indiquent que le culte chthonien chez les Gaulois du Nord de la Gaule pouvait prendre effectivement une forme étonnamment proche de celle qui est le plus rëpandue en Grèce et en Italie. Dans les deux cas l'association d'une grande fosse cylindrique et d'un foyer attenant suppose que la chair des animaux était brûlée (fig. 8). Les os ne portent aucune trace de combustion, ce qui prouve que la chair avait été entièrement prélevée. La stratigraphie des fosses et l'état de surface de leur fond nous renseignent également sur leur utilisation, elles n'ont pas reçu de dépouilles entières et n'ont pas été curées à de multiples reprises. On doit donc croire qu'elles n'étaient que le moyen de communication symbolique avec la divinité souterraine. Leurs homologues du monde classique ne recevaient que le sang des victimes ou certaines libations. C'est l'utilisation qu'a connue la grande fosse de l'enclos circulaire de Ribemont. 


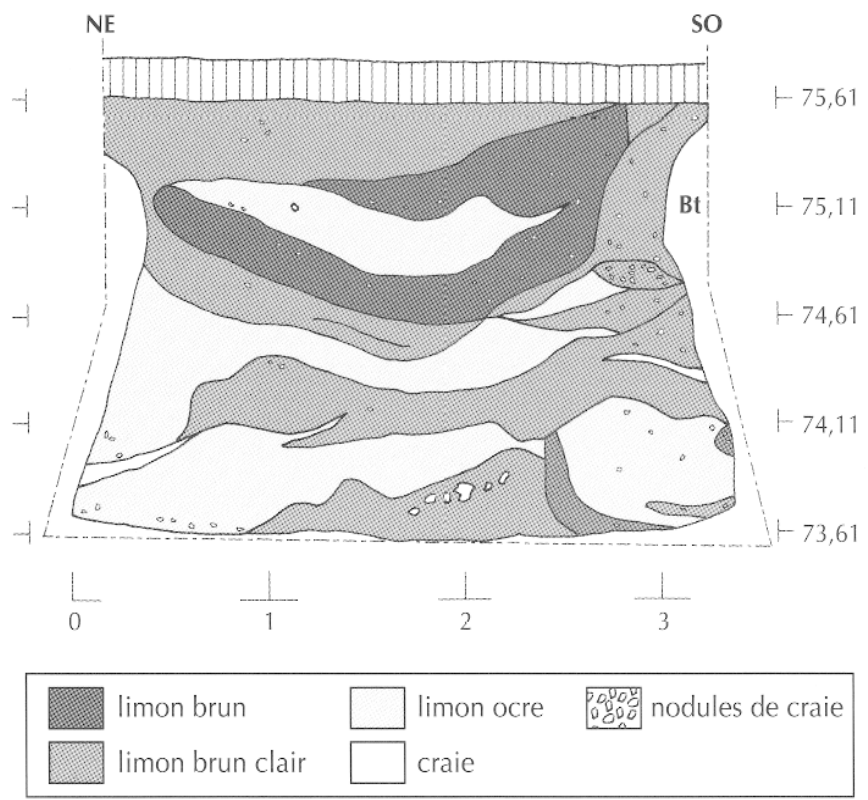

a

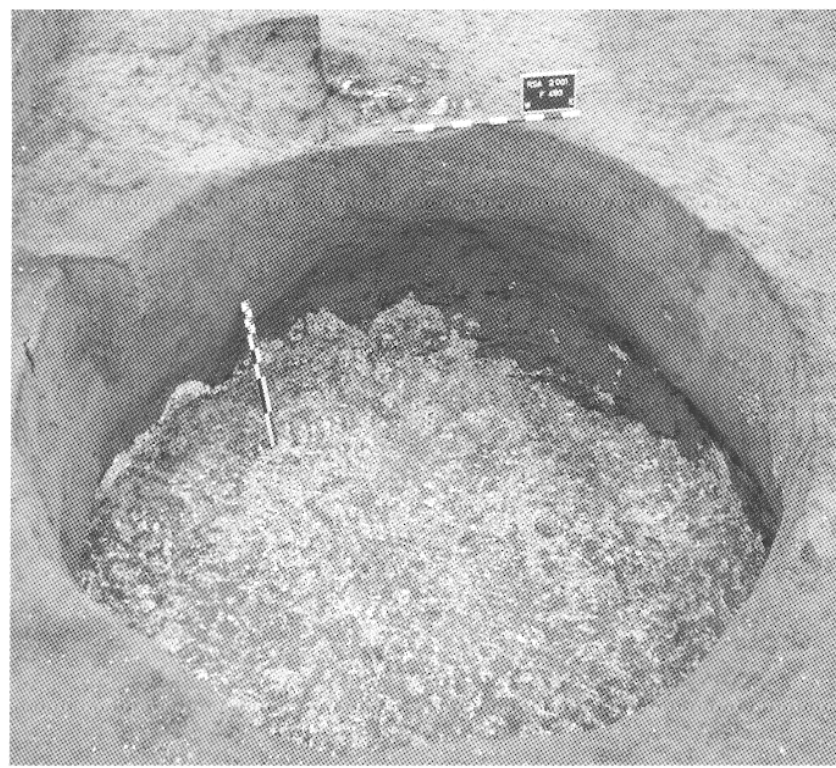

b

Fig. 8 - Ribemont-sur-Ancre (Somme), Le Champ Crezette : a, coupe de la fosse (autel creux) de l'enclos polygonal; $b$, installation cultuelle de l'enclos polygonal (dessin C. Malagoli, Centre archéologique de Ribemont ; photo J.-L. Brunaux, CNRS).

Le second type de sacrifice, dit « de commensalité ", était le plus courant. On en retrouve les vestiges, en plus ou moins grande quantité, sur tous les sites cultuels. Il ne touche, semble-t-il, que les mammifères : bovidés, porcs, ovins et chiens. Les trois dernières espèces sont de loin les plus représentées. Le sacrifice consiste à tuer l'animal pour que sa consommation soit partagée entre les dieux et les hommes qui les honorent. Il est probable que ce partage était relativement simple: les hommes consommaient la viande et les dieux la fressure. Il n'est pas sûr que toute la viande d'une victime ait été consommée dans le cadre du sanctuaire ; en effet tous les os du squelette ne sont généralement pas présents sur celui-ci. On peut donc imaginer qu'une partie de la bête quittait le lieu pour être redistribuée à la population qui ne pénétrait pas dans l'enceinte sacrée. Les meilleurs morceaux, si l'on en croit les restes animaux trouvés à Gournay, faisaient l'objet d'un banquet dans l'enceinte même du sanctuaire, tandis que les dieux devaient se repaître des fumées montant du foyer où grillait la fressure. Ces repas, probablement réservés à l'élite guerrière et religieuse, ne se départaient pas d'un certain luxe alimentaire. À Gournay, on mangeait préférentiellement de l'agneau et du porcelet.

La mise à mort des animaux est documentée à Gournay, seul site à avoir livré des crânes entiers de bovidés portant des traces de coups mortels. Trois types de coups ont été relevés, le coup de hache sur la nuque, le coup de merlin à travers l'os frontal, le coup de lance également dans le front de la victime. Un certain nombre de crânes ne portent aucune trace, ce qui laisse supposer que les bêtes furent égorgées. Un même type de sacrifice (chthonien avec pourrissement en fosse) pouvait donc se dérouler de différentes manières. Les raisons de cette variété ne nous sont évidemment pas connues (différentes fêtes religieuses, forme de mise à mort déterminée par la divination ?).

\section{LES OFFRANDES D'ARMES}

Un certain nombre de sites cultuels livrent des armes en plus ou moins grand nombre: Ribemont, Gournay, SaintMaur, Estrées-Saint-Denis (Woimant, 1991), Meaux, Dompierre-sur-Authie, Bailleul-sur-Thérain, Marteville à Vermand (Agache, 1978), Morvillers, Bennecourt, etc. Ces dernières couvrent une période qui va de La Tène B2 jusqu'à La Tène D2. Les découvertes de Gournay, confirmées par celles de Ribemont et de Saint-Maur, révèlent que ces armes étaient accrochées aux parois du sanctuaire et principalement au porche d'entrée. Il s'agissait d'une véritable exposition et le fait même de les fixer sur des montants verticaux suffisait à en faire d'authentiques offrandes, avec le même sens qu'ont les anathemata en Grèce (Rudhardt, 1992).

La fouille du sanctuaire de Gournay et l'étude des armes qui en proviennent ont bien montré que le rite consistait en une suite de gestes qui ne se limitaient pas à leur seul accrochage. Celles-ci avaient une vertu, une efficacité qui se dégageait dans la durée, quelques décennies, pendant 

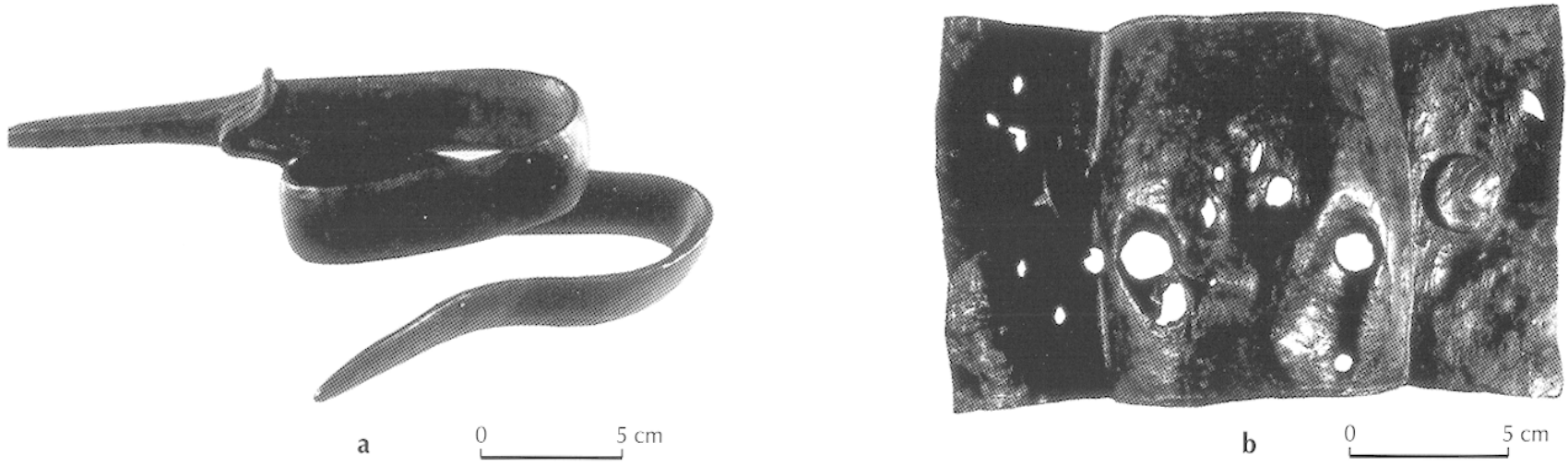

Fig. 9 - Gournay-sur-Aronde (Oise), Le Parc. Épée (a) el umbo de bouclier (b) provenant du sanctuaire (photos J.-L. Brunaux, CNRS).

lesquelles l'énergie des offrandes était active. Quand, à force de pourrissement des parties ligneuses ou organiques, à force de corrosion des parties métalliques, ce qui restait des armes glissait au sol, leur valeur sacrée cessait tout à coup. On mutilait le fer corrodé jusqu'à le rendre impropre à tout nouvel usage et on jetait les tôles cassées et pliées dans le fossé de clôture en un véritable rite de désacralisation (fig. 9). Les Romains et les Crecs, du temps où ils confectionnaient encore des trophées avec des armes réelles, n'agissaient pas autrement, si l'on en croit Plutarque (Questions romaines, XXXVII, $273 \mathrm{E}$ ) qui cherchait à trouver la cause de ce soudain désintérêt pour des objets sacrés. Les raisons qu'il donne (notamment volonté de ne pas prolonger trop longtemps ce qui est une humiliation pour les ennemis) ne sont guère convaincantes. Il est sûr, en tout cas, que ces armes prestigieuses prises à des ennemis valeureux étaient investies d'un pouvoir quasi magique dont l'efficacité devait être d'autant plus forte qu'elle n'était pas éternelle.

Une mauvaise compréhension des découvertes de Gournay a conduit plusieurs archéologues à parler de "sacrifice des armes". L'expression est particulièrement impropre, parce qu'elle rend très mal compte de la réalité physique du mobilier archéologique. Les armes sont, en effet, volontairement mutilées après un très long processus de dégradation, au terme duquel elles avaient beaucoup perdu de leur aspect initial. Il ne s'agissait plus que de morceaux de fer, de tôles très rouillées. Briser, tordre ce qui restait de ces armes, après qu'elles avaient déjà été utilisées religieusement, ne peut donc s'assimiler à un sacrifice, au sens propre du mot qui veut que l'on se sépare volontairement d'un être animé ou d'un objet qui a encore toute sa valeur. De plus, nous savons que ces gestes destructifs précédaient immédiatement la relégation de ces restes dans ce qui s'assimile bien à une sorte de poubelle. Il est donc plus tentant de voir là un rite de désacralisation qui clôt la période active de l'offrande ou plus précisément de l'anathema. À notre connaissance, il n'a été montré sur aucun site que des armes ou même, plus généralement, d'autres types d'objets aient été volontairement détruits au moment de leur introduction dans l'enceinte sacrée.

On voit bien, par ces armes offertes aux dieux, que dans bien des cas le sanctuaire présente une double fonction, celle du lieu où l'on pratique le culte régulièrement et celle d'un trophée perpétuel que l'on continue en quelque sorte à alimenter. Il n'est dès lors pas anodin que l'un des plus anciens sites cultuels, celui de Ribemont, se présente avant tout comme un trophée. On peut se demander, à l'analyse d'un sanctuaire tel que celui de Gournay, légèrement antérieur à Ribemont, si le sanctuaire ne fut pas initialement un lieu de trophée où le culte sacrificiel l'a emporté progressivement sur les offrandes d'armes.

\section{LE TRATTEMENT DES CORPS HUMAINS}

C'est dans ce cadre conceptuel qu'il faut interpréter des découvertes énigmatiques, celles de restes humains souvent en petit nombre. La question ne se pose évidemment pas pour Ribemont où leur présence en quantités impressionnantes a fait l'objet d'une interprétation qui écarte le site de la série des sanctuaires authentiques. Les lieux qui posent un problème sont, entre autres, ceux de Gournay, EstréesSaint-Denis, Saint-Maur et Dompierre-sur-Authie. Dans la plupart des cas, les os sont retrouvés en situation résiduelle, après de nombreuses manipulations qui ont effacé une grande partie de leur message et qui ôtent toute possibilité de situer chronologiquement leur arrivée dans le lieu de culte. Seuls les os de Gournay sont significatifs pour poser efficacement le problème (voir infra notice 9 , p. 59-60). 


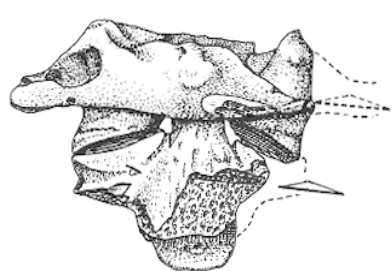

a

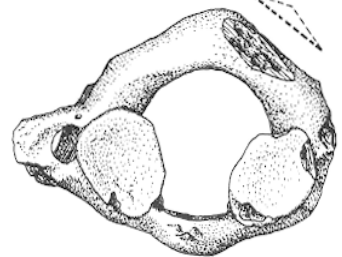

b

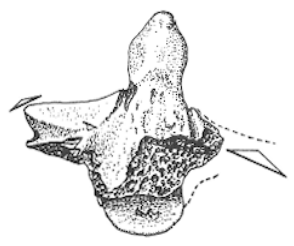

Fig. 10 - Gournay-sur-Aronde (Oise), Le Parc. Vertèbres cervicales humaines provenant du sanctuaire et montrant des traces de décollation (d'après Brunaux, Méniel, Poplin, 1985).

Ici, en effet, on a affaire à une petite collection d'une soixantaine de pièces qui, malgré leur nombre limité, sont évocatrices. Elles permettent la détermination d'une douzaine d'individus parmi lesquels la moitié seraient des femmes. Les os ne portent aucune trace flagrante de mise à mort mais témoignent sûrement d'un dépeçage assez systématique. Une douzaine de pièces concernant le crâne ou la colonne vertébrale attenante indiquent aussi la pratique répétée de la décollation (fig. 10), celle également répétée de l'agrandissement du foramen magnum, enfin la fixation des crânes ainsi préparés sur le porche d'entrée, au pied duquel ces pièces ont été découvertes.

Comme le concluait François Poplin (Brunaux, Méniel, Poplin, 1985, p. 162 sqq.) à l'issue de leur étude, il est difficile de tirer des conclusions qui se voudraient définitives. Cependant, depuis, nous avons acquis une meilleure connaissance de ces problèmes grâce à la fouille et à l'étude des os de Ribemont. Celles-ci nous permettent de reconsidérer les découvertes de Gournay sous un nouveau jour. Ces os ne nous plongent pas dans une alternative forcée, entre hypothèse guerrière et hypothèse sacrificielle. La présence d'os féminins exclut que la première soit la seule explication, cependant le traitement du crâne nous ramène vers la pratique du trophée. Ainsi est-il probable qu'on ait affaire à plusieurs rites qui n'ont pas concerné tous les individus. La présence de femmes soulève cependant les plus grandes interrogations. On ne peut imaginer qu'elles aient subi un traitement guerrier ni que leur dépouille ait fait l'objet d'un traitement funéraire, tel que celui réservé aux héros de Ribemont. Dans leur cas, l'hypothèse sacrificielle, si elle n'est pas certaine, reste pourtant la plus probable.

\section{LE TRAITEMENT DES MORTS}

\section{LES TRAITEMENTS DIVERS REFLÉTANT DES STATUTS SOCLAUX INÉGAUX ET DES DESTINÉES DIVERSES}

Nous ne voulons pas aborder ici ce qu'il est convenu d'appeler le traitement funéraire, c'est-à-dire le mode de sépulture habituel. Nous considérons, à tort peut-être, provisoirement tout au moins, qu'il s'agit là de pratiques familiales, voire individuelles, ponctuelles, qui ne donnent généralement pas lieu à une activité cultuelle régulière. Ce ne sont que les exceptions dans le traitement du corps, des aménagements particuliers de la sépulture, des gestes répétés autour de celle-ci qui seront évoqués. Le nombre des faits exposés montre que, dans le Nord de la Gaule, il conviendra certainement à l'avenir de ne plus garder la distinction certainement artificielle entre funéraire et cultuel, car visiblement il n'y a pas de norme qui ferait de la sépulture un domaine propre, exempt de préoccupations religieuses.

Depuis le tout début du XX $\mathrm{X}^{\mathrm{s}}$ s., les archéologues mais aussi les historiens ont pris l'habitude de parler de sépulture chaque fois qu'un squelette était découvert. Ces dernières ont été systématiquement classées en inhumations ou en incinérations, comme s'il n'existait pas d'autre destinée pour un cadavre. Il s'agit moins d'un nouvel exemple d'ethnocentrisme que d'une contamination ou d'une projection des conceptions grecques et latines sur le monde celtique. En Gaule du Nord, l'individu n'a pas une vocation, qui lui serait consubstantielle, à devenir l'objet d'une sépulture. Les données numériques le prouvent: on constate un déficit très marqué entre les sépultures et l'habitat. Lorsqu'on dispose de données chiffrées en matière de démographie - celles approximatives mais précieuses que donne César pour La Tène D1 - le déficit des tombes apparaît encore plus manifeste.

Lcs dćcouvcrtcs archéologiques font apparaître un autre phénomène. La sépulture authentique (inhumation jusqu'au III ${ }^{\mathrm{e}}$ s. avant J.-C., puis incinération) ne constitue pas la règle absolue du traitement du cadavre. Loin s'en faut. Le squelette apparaît souvent dans un contexte de " poubelle " ou d'abandon, dans les habitats notamment. Mais il apparaît surtout, sans qu'on y ait pris garde avant les découvertes de Ribemont, sous une forme morcelée : des os provenant de cadavres qui ont subi des traitements étranges étalés en plusieurs étapes qui ont fini par faire presque disparaître le squelette.

La mise au jour de squelettes dans des contextes qui ne témoignent pas, pour le moins, du respect dû à l'individu, fût-il mort, a évidemment attiré l'attention des archéo- 
logues sur le statut social de ces individus. Il est patent dans ce cas que l'homme de son vivant n'était pas intégré à une structure sociale qui assurait à son cadavre une sépulture décente (Brunaux, 1998). Probablement n'était-il pas un citoyen à part entière. Mais le problème est certainement plus complexe, comme en témoignent les découvertes récentes de Ribemont qui seront évoquées plus bas. Sur ce site, des centaines d'individus du plus haut niveau social non seulement n'ont pas connu de sépulture mais leur cadavre a subi un traitement qui est l'inverse même de la sépulture, une exposition perpétuelle. Il est clair que ce sont d'autres préoccupations qui entrent en jeu. L'individu connaît un sort eschatologique directement dépendant des circonstances de sa mort. On ne se trouve plus dans le schéma gréco-romain, formalisć par Cicéron dans le De legibus par exemple, mais dans un autre univers mental, plus proche de celui des populations altaiques.

\section{NÉCROPOLES ET ENCLOS}

Ce particularisme du traitement funéraire au sens large chez les Celtes du Nord de la Gaule apparaît de façon quasi caricaturale dans la localisation des sépultures. Les archéologues parlent de nécropole. Dans la plupart des cas cet usage est impropre ; le mot suppose une vaste concentration de sépultures sous une forme organisée. Cette occurrence ne se présente qu'à La Tène ancienne en Champagne. Là se rencontrent de rares ensembles qui peuvent compter quelques centaines de tombes sur une superficie de quelques dizaines d'ares. Aucun de ces ensembles funéraires ne montre une organisation générale, on suppose seulement des regroupements familiaux de quelques unités. On n'observe pas de partition de l'espace, pas même d'allée qui pourrait le structurer.

Ces caractères qui permettent tout au plus de parler de cimetières ne concernent que La Tène ancienne ( $\mathrm{V}^{\mathrm{e}} \mathrm{s}$. avant J.-C. essentiellement). Pour les époques postérieures, La Tène $\mathrm{C}$ et La Tène $\mathrm{D}$, on ne peut guère parler que d'espace funéraire. La relation entre lieu d'habitat et lieu de sépulture n'est pas clairement établie, dans la mesure où elle ne semble pas obéir à des règles générales. La situation des lieux de sépultures semble assez aléatoire et répond certainement à des critères qu'il nous est difficile aujourd'hui d'appréhender : terrains incultes ou délaissés, zones de marge entre des terroirs, croyances peut-être d'ordre mythologique liées à certains lieux, etc.

D'une façon générale, de La Tène ancienne à la fin de La Tène finale, si l'on considère l'ensemble de la rëgion étudiée (de la Basse-Normandie à la Champagne), on voit des situations très contrastées. Ainsi à La Tène ancienne, les cimetières sont nombreux et relativement peuplés à l'Est, ils sont quasi absents à l'Ouest. À La Tène moyenne, cette image s'inverse : les sépultures se raréfient à l'Est et deviennent nombreuses à l'Ouest. Enfin à La Tène finale, on retrouve des cimetières très structurés en ChampagneArdenne, tandis qu'à l'Ouest on ne voit que de petits groupes de sépultures souvent accolés à des fermes (fig. 11). Ces différences reflètent des traditions culturelles fortes qui perdurent plusieurs siècles.

Les enclos montrent une même hétérogénéité. On distingue trois types qui ont à peu près une répartition géographique propre.

Le plus remarquable par le nombre d'exemplaires et la standardisation des formes cst cclui de l'cst. Il concernc la Champagne, les Ardennes et, dans une moindre mesure, le Sénonais. Il se développe au cours de La Tène C2, quand les sépultures réapparaissent dans cette région, et perdure jusqu'à la conquête. Il est caractérisé par de petits enclos quadrangulaires, souvent carrés et souvent accolés, comprenant des groupes de quelques sépultures. Il paraît assez évident qu'on a là affaire à de petits ensembles familiaux, peut-être eux-mêmes regroupés par ensemble familial ou tribal plus grand.

Un deuxième type correspond à la même période chronologique mais sur une région voisine, la Picardie. La forme et la nature des enclos sont cette fois variables. Ils sont souvent accolés aux enclos domestiques (fermes notamment). Parfois, ils semblent reprendre un cloisonnement de l'espace préexistant : Villers-lès-Roye (Buchez et $a l ., 1998$ ) et Grand-Laviers (fig. 12) (Baray, 1998), en tout cas pas spécialement adapté à un lieu de sépulture.

Le troisième type est le moins caractéristique, car il n'est représenté que par quelques exemplaires, hors normes, tant dans la forme que dans la situation chronologique. Le meilleur exemple est celui de Tournedossur-Seine (Carré, 1993) qui présente un enclos de forme carré de $45 \mathrm{~m}$ de côté, fermé par une puissante palissade, possédant une entrée ouverte au sud et montrant des similitudes avec les structures de Ribemont, de même qu'une datation assez proche, puisque l'on se trouve ici à la fin $\mathrm{du} \mathrm{IV}^{\mathrm{e}} \mathbf{s}$.

Ces enclos paraissent bien ne pas avoir connu la même fonction. Ceux du premier type témoignent d'une volonté de «monumentaliser " le lieu, il leur arrive d'ailleurs souvent de souligner et d'entourer une construction imposante en bois sur laquelle on reviendra (fig. 13). Les enclos du deuxième type n'ont pour autre mission que de séparer l'espace funéraire d'un espace domestique trop proche. Il s'agissait alors autant d'éloigner les morts ou leurs âmes volatiles que de les protéger de l'éventuel 


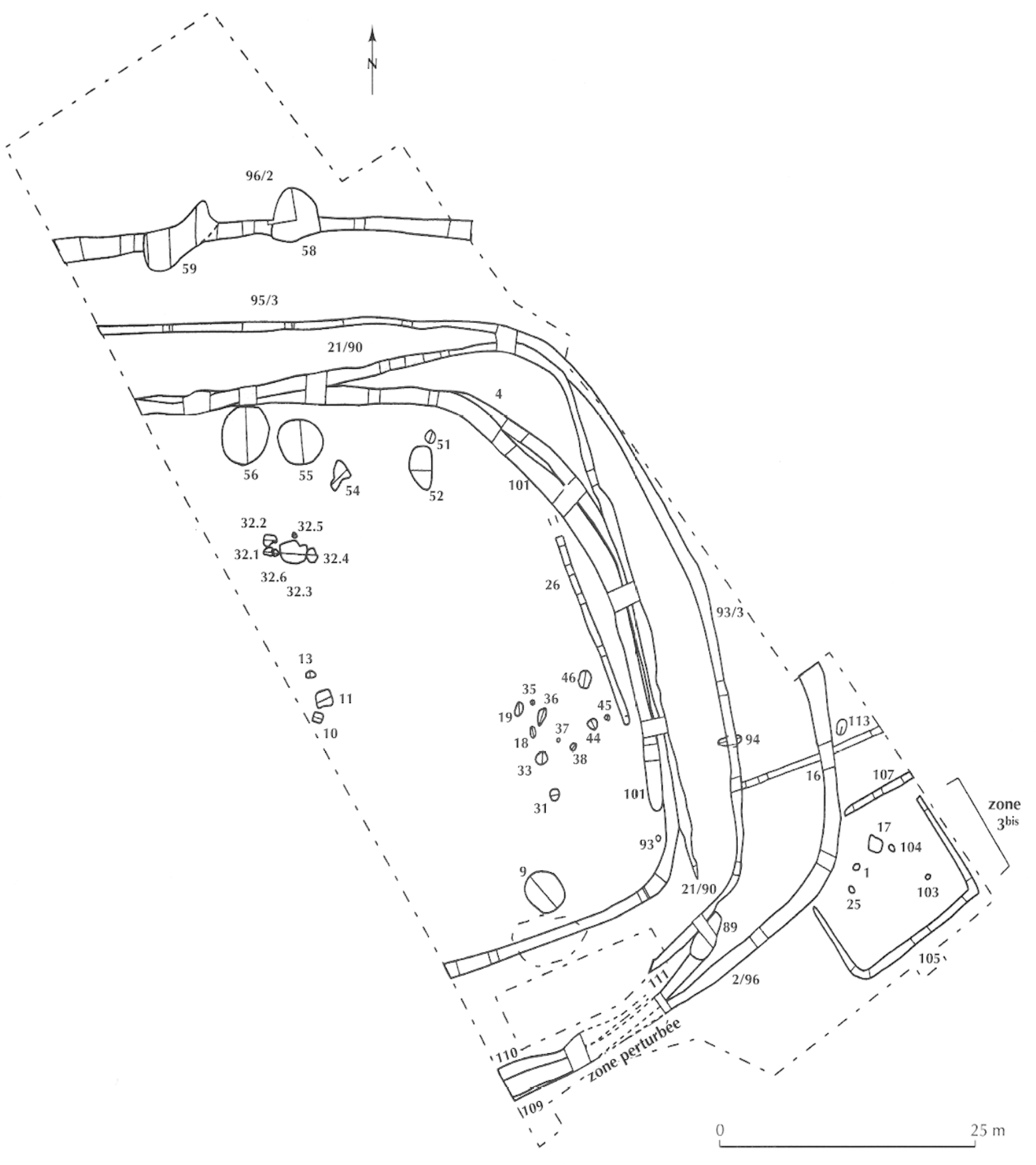

Fig. 11 - Bernay-en-Ponthieu (Somme).

Petit enclos funéraire accolé à un établissement agricole (d'après Baray, 1998).

vagabondage des animaux de la ferme. Le troisième type ressort plutôt de l'activité cultuelle. On peut imaginer qu'un lieu de culte provisoire ait précédé l'installation des sépultures, soit de façon fonctionnelle et nécessaire, soit par pur hasard ou par occasion. C'est peut-être le cas à Tournedos.

\section{TEMPLES FUNÉRAIRES, MAUSOLÉE OU HÉRÔON?}

Le souci de monumentalité des lieux de sépultures est surtout perceptible dans la partie orientale de la région (Ardennes, Champagne, Sénonais, vallée de l'Aisne). Il concerne les deux époques où les sépultures sont abon- 


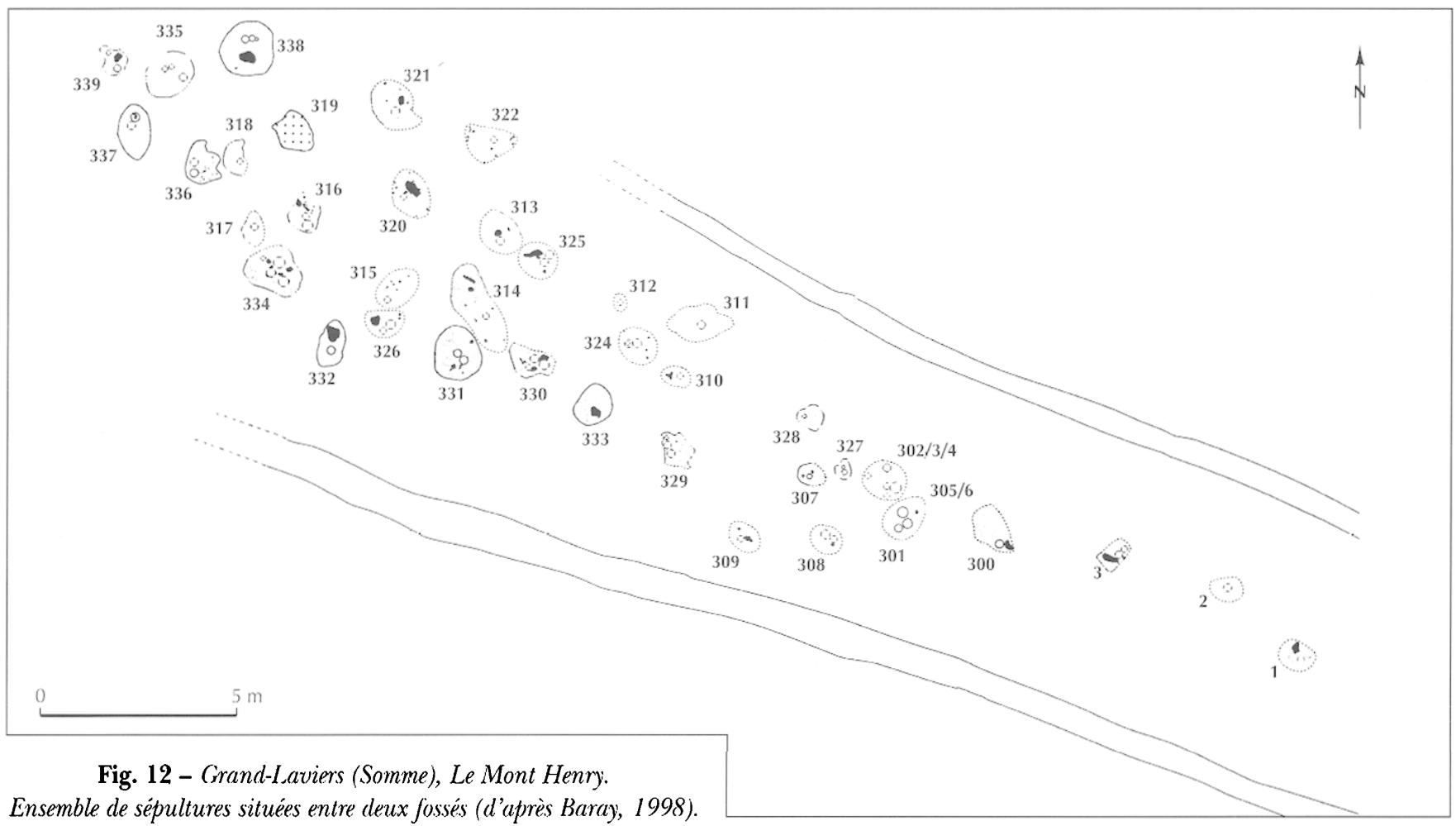

dantes, à La Tène ancienne et à La Tène finale. Les fouilleurs du XIX s. ont été les premiers à s'intéresser à l'environnement de la sépulture, mais c'est surtout dans la première moitié du $\mathrm{XX}^{c} \mathrm{~s}$. que lcurs successeurs ont mis en évidence des enclos, des trous de poteaux dessinant parfois des bâtiments, des fosses et des foyers. Les théories n'ont pas manqué pour expliquer ces aménagements souvent énigmatiques. On a parlé pour les fosses sans sépulture de cénotaphes, de fosses sacrificielles, voire de tombes de héros. Pour les bâtiments, il a été question de «maisons du mort ", de chapelles, d'hérôa.

On aimerait que les fouilles réalisées au cours des dernières décennies jettent quelque lumière nouvelle sur tous ces problèmes. Force est de constater que ce n'est guère le cas, pour des raisons assez diverses. Parce qu'il n'a pas été rencontré d'ensembles aussi cxccptionnels que ceux découverts lors des fouilles anciennes. Parce que, quand ce fut le cas, les structures étaient souvent mal conservées. Enfin, parce que les fouilleurs de sépultures n'analysèrent le plus souvent leur découverte qu'avec la seule grille d'interprétation du funéraire, sans se soucier des comparaisons qu'ils auraient pu trouver dans le milieu proprement cultuel.

Faute de véritable stratigraphie, il est aujourd'hui, à partir de la sculc documentation, impossible de distinguer des fossés ouverts de tranchées de fondation de palissade, de distinguer un trou de poteau d'une fosse cultuelle. Faute

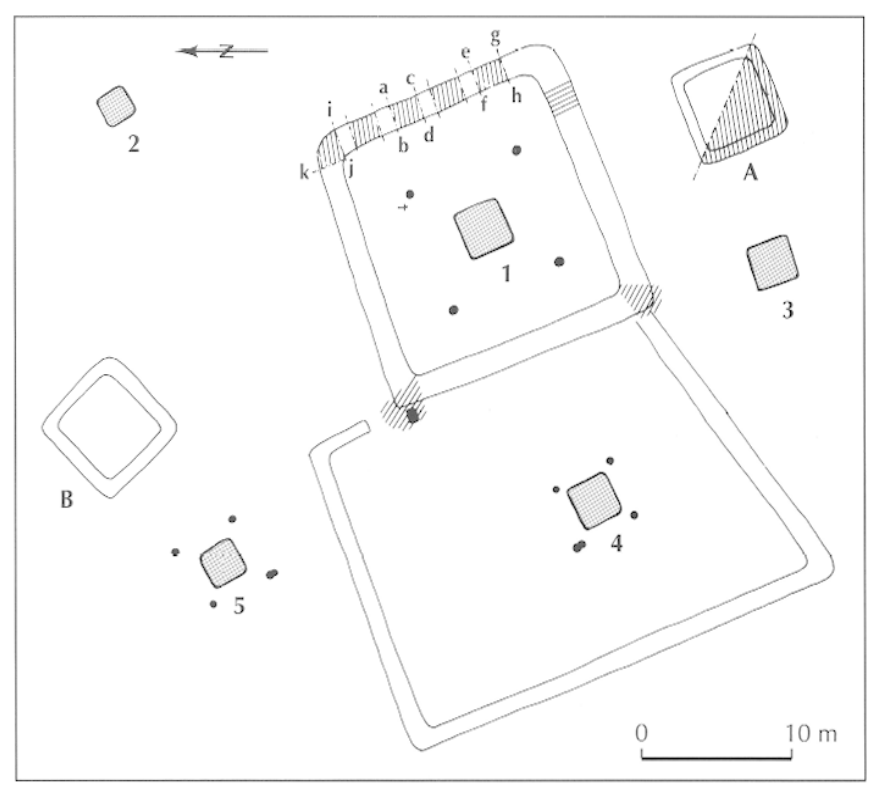

Fig. 13 - Tartigny (Oise), Le Moulin Plan des sépultures (d'après Massy et al., 1986).

d'avoir bien étudié le matériel souvent pauvre et sans attrait de ces structures annexes, il est difficile de savoir si on a affaire à un matériel cultuel ou simplement détritique et, surtout, s'il est synchrone des sépultures proches. Ainsi, 


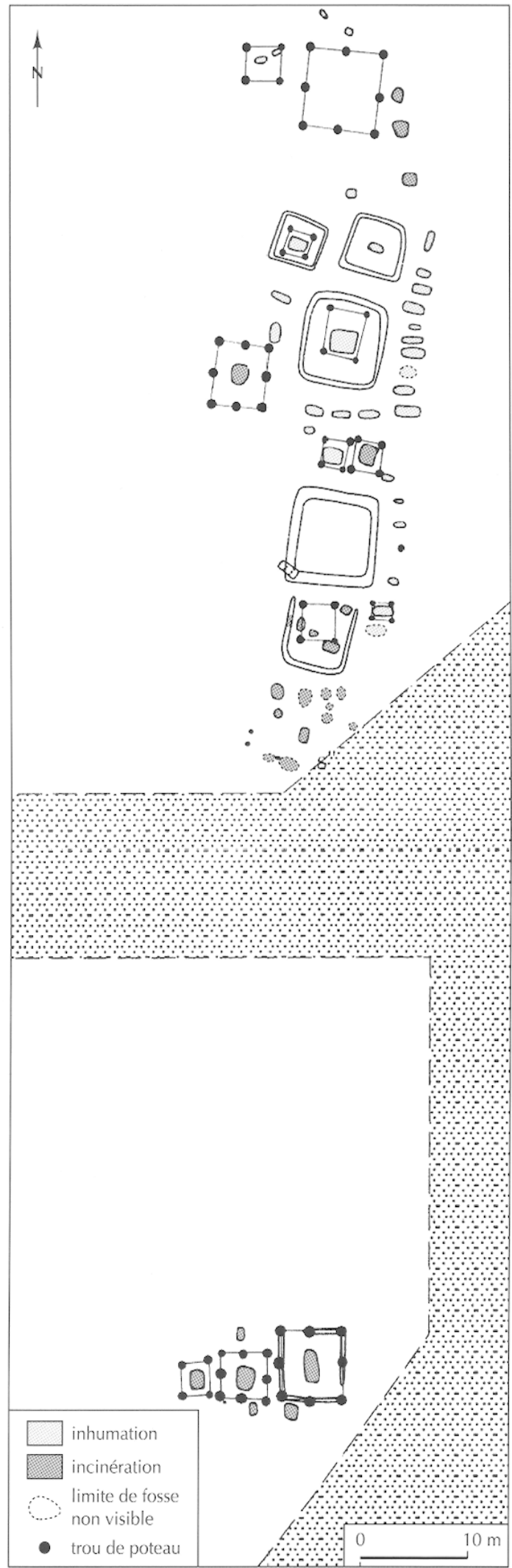

Fig. 14-Bucy-le-Long (Aisne).

Plan de la nécropole (d'après Pommepuy et al., 1998).

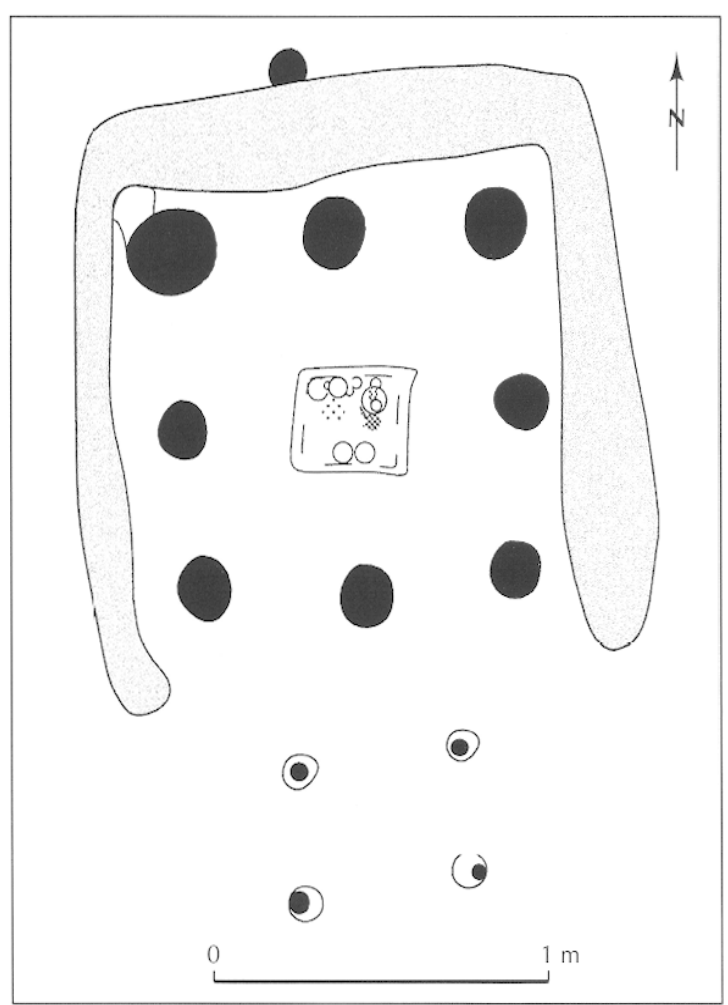

Fig. 15 - Cuiry-lès-Chaudardes (Aisne).

Plan de la tombe (d'après Pommepuy et al., 1998).

dans bien des cas, la sépulture qui occupe l'espace central d'une construction n'est peut-être pas contemporaine de cette construction : elle a pu être postérieure comme elle a pu aussi la précéder. On peut aussi, dans de nombreux cas, douter de la réalité de la sépulture, appelée ainsi sur la simple foi d'ossements brisés ou incinérés qui n'étaient pas forcément humains.

Les fouilles récentes menées avec des méthodes plus fiables, notamment dans la vallée de l'Aisne, autorisent au moins quelques certitudes (fig. 14). À partir du début de La Tène moyenne, apparaissent des monuments entourant des sépultures individuelles, qu'elles soient à inhumation ou à incinération. Les traces laissées au sol par ces constructions sont souvent conséquentes : trous de poteaux de fort diamètre, parfois reliés entre eux par des tranchées d'implantation de sablière ou de palissade. Toujours de plan quadrangulaire, ces édifices ont des dimensions qui varient entre $3 \mathrm{~m}$ et $14 \mathrm{~m}$. Les fouilleurs ont cherché à restituer l'allure de ces bâtiments. Il semble que l'on ait affaire à deux types de monument. Les petits édifices bâtis sur quatre ou huit poteaux appartiennent incontestablement à un bâtiment couvert édifié au-dessus de la sépulture (fig. 15). Les grands ensembles pouvant compter jusqu'à vingt-deux trous de poteaux sur des côtés d'une quinzaine de mètres 


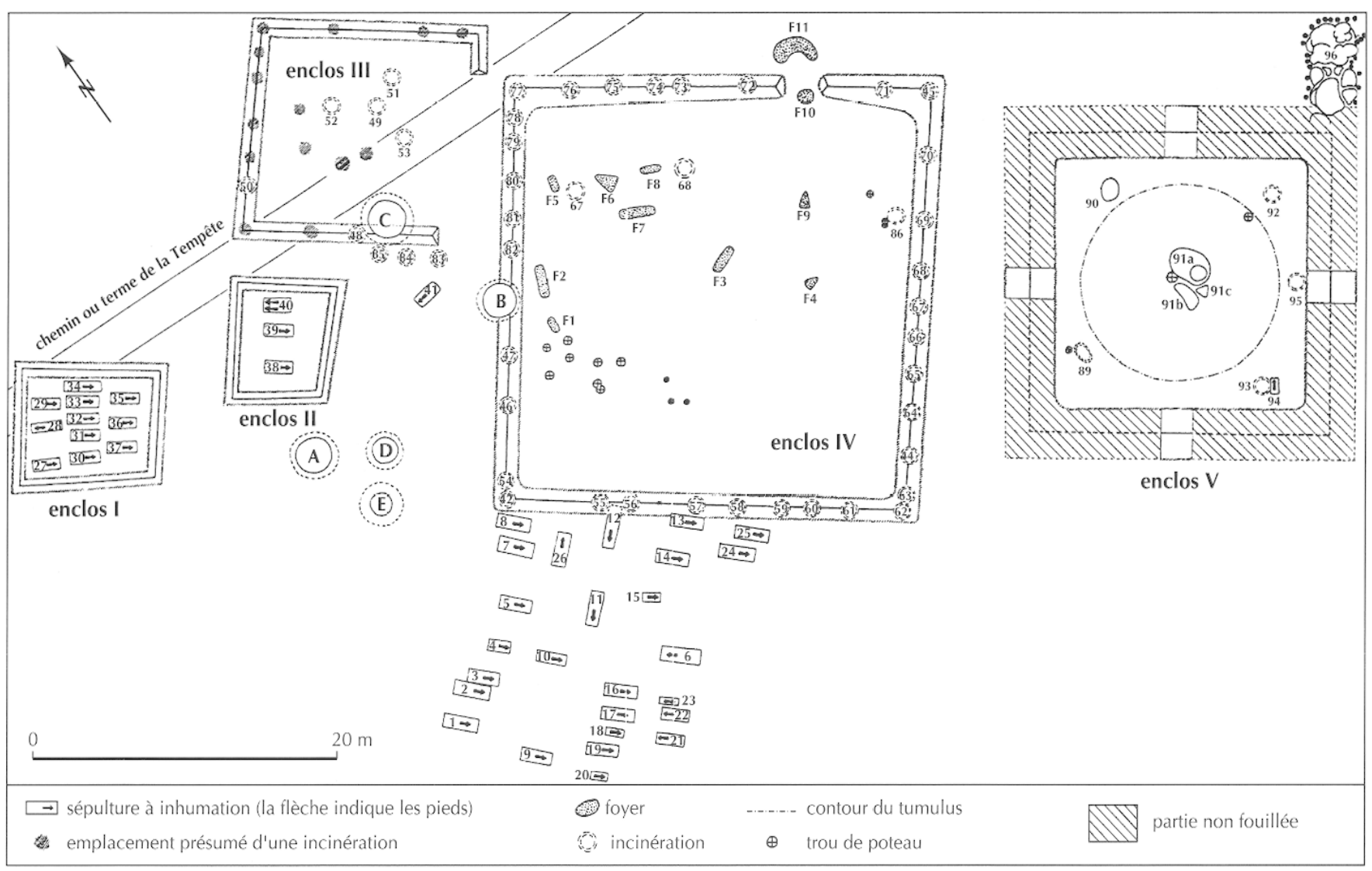

Fig. 16 - Normée (Marne), La Tempête. Plan des enclos (d'après Brisson, Hatt, 1969).

forment plutôt des clôtures monumentales, sous forme de colonnades.

Quelle était leur fonction? La disparition des sols anciens dans tous les cas ne permet pas vraiment d'y répondre, car on n'a plus trace de l'activité qui a pu s'y dérouler. Lorsque effectivement une sépulture en marque le centre, on peut s'accorder à y reconnaître une sorte de mausolée qui a pu accueillir une activité rituelle régulière, sous forme d'offrandes, voire de sacrifice. Cette appellation, même si l'élévation des bâtiments est encore source d'interrogation, paraît préférable à celle de " maison du mort » ou de « chapelle funéraire".

En revanche, pour la période précédente et essentiellement en Champagne, l'existence d'aménagements proprement cultuels sur le lieu funéraire est probable. Un certain nombre d'enclos dépourvus de sépultures ou qui en ont accueilli tardivement ont pu connaître une utilisation proprement cultuelle. Deux exemples sont particulièrement intéressants. Le premier à Normée (fig. 16) : un tel enclos, quadrangulaire, d'une vingtaine de mètres de côté, n'abritait en son centre qu'une grande fosse ovalaire qui fait songer aux autels des sanctuaires de Picardie (Brisson, Hatt,
1969). La fouille ancienne ne permet malheureusement pas de savoir quel type d'activité rituelle elle a pu abriter. Le second à Fère-Champenoise (Brisson et al., 1970) montre un enclos quadrangulaire d'une dizaine de mètres de côté pourvu d'une entrée à l'est et seulement occupé, en son centre, par une grande fosse circulaire présentant des traces de foyer. Dans ces deux cas, une chronologie fine nous serait du plus grand secours. Elle permettrait peut-être de savoir si l'installation cultuelle a précédé la nécropole, peut-être en attirant autour d'elle des sépultures, ou si elle l'a accompagnée, dans un fonctionnement conjoint.

\section{SÉPULTURE OU AUTEL ?}

Au début de La Tène moyenne, cette ambivalence d'un espace qu'on ne sait qualifier de funéraire ou de cultuel se retrouve à l'échelle la plus petite, celle de la sépulture. Le phénomène ne semble concerner que le centre de cette région, autrement dit le pays des Bellovaques et ses marges. Ou peut-être est-ce là qu'il est le plus perceptible. On a affaire à deux types de structures, différents par leur forme 


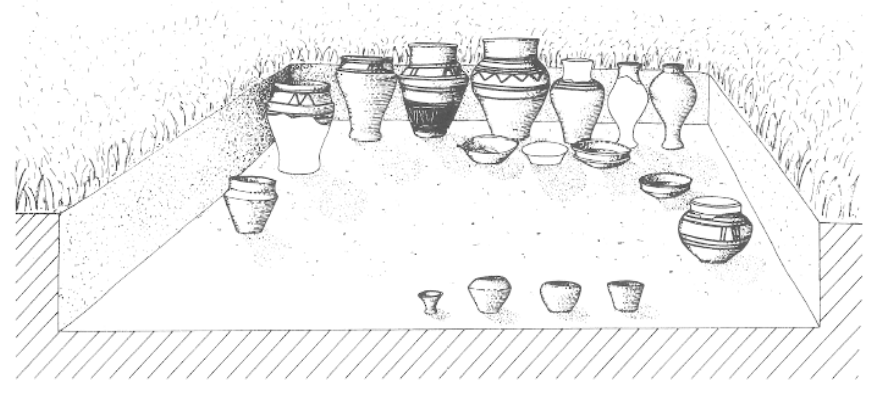

Fig. 17 - Gournay-sur-Aronde (Oise), Le Parc La fosse dite " aux vases " située près du sanctuaire (d'après Brunaux, Méniel, Poplin, 1985).

et leur environnement, mais assez similaires par leur contenu, simples fosses non signalées à la surface du sol ou sépultures dans des enclos.

La forme la plus surprenante est révélée par des ensembles funéraires précoces (La Tène Cl) situés sur le territoire des Bellovaques : Allonne, Breuil-le-Sec (Degenne, Duval, 1983), Mory-Montcrux (Blanchet, 1983), Gournay et Saint-Maur (Blanchet, Duval, 1975), etc. Les sépultures forment des ensembles sans ordre ni regroupement. Certaines peuvent se trouver séparées de plus d'une dizaine de mètres, si bien qu'il est souvent difficile de connaître l'emprise exacte de l'espace funéraire. Mais ce sont les sćpulturcs surtout qui surprennent, informes, souvent très vastes et sans parois identifiables. Il s'agit dans tous les cas d'incinérations. Chaque fois que l'observation a pu en être faite, ce sont des incinérations d'os secs, autrement dit ce sont des sépultures secondaires. Une étude anthropologique réalisée sur les os des sépultures d'Allonne montre que cinq sépultures contenaient les restes de plusieurs individus (Paris, 1998). L'une d'elles a même livré des os appartenant à cinq individus différents. De façon générale, le dépôt des os incinérés n'occupe dans la fosse qu'une faible superficie et une place qui n'est pas particulièrement privilégiée. Comme le plus souvent, seule une faible partie des os incinérés de chaque individu a été déposée dans la fosse, on peut considérer que l'inhumation de ces restes est avant tout un geste symbolique.

Que ces pratiques funéraires doivent plus à une nécessité de représentation qu'à une volonté matérialiste d'inhumer les restes du mort, cela apparaît aussi dans le choix et la disposition du matériel d'accompagnement. Ce sont pour l'essentiel des vases hauts, souvent à piédouche, de type situliforme qui ne paraissent pas avoir connu de réel usage fonctionnel. Dans bien des cas, on assiste à une mise en scène des objets soigneusement disposés le long des parois, quelquefois par ordre de grandeur. À l'évidence le nombre important de ces pièces et leur qualité esthétique témoi- gnent du statut de l'individu mort ou de celui de son groupe familial. Ce statut n'est plus seulement exprimé par de simples attributs (armes notamment ou outils) ni par des signes de richesse. Il semble que, dans certains cas, la fosse où les restes incinérés et tout ce matériel venaient d'être déposés soit restée quelque temps ouverte. L'absence presque systématique de tout examen sédimentologique ne permet pas de mesurer la possible généralisation de cette interprétation.

Le caractère énigmatique de ces fosses apparaît bien dans celle découverte à l'extérieur du sanctuaire de Gournay (Brunaux, Méniel, Poplin, 1985, p. 53 sqq.) dans laquelle on hésite à reconnaître une sépulture (fig. 17). Il s'agit d'une fosse carrée de $2,50 \mathrm{~m}$ de côté environ, ses parois étant très difficiles à mettre en évidence. Au moins dix-sept vases s'y trouvaient rangés par ordre croissant, d'est en ouest, autour d'un espace central vide, d'environ $1,50 \mathrm{~m}$ de diamètre. Une perturbation postérieure de cette zone ne permet pas de savoir s'il s'y trouvait un dépôt osseux. On peut cependant en douter car pas la moindre esquille osseuse n'a été rencontrée, alors que les céramiques ont été dispersées dans toute la fosse. Il est sûr en tout cas que la fosse est restée suffisamment ouverte pour que les céramiques se soient naturellement détériorées et qu'elles s'écroulent au sol avant qu'un remblaiement naturel se produise. Si cette fosse, datable de la fin du IV s., ne fut pas unc sćpulture mais plutôt un petit aménagement cultuel, il est probable que ce sont de telles structures qui ont servi de modèles aux fosses à incinćration que l'on voit dans cette même région aux $\mathrm{III}^{e}$ et $\mathrm{II}^{\mathrm{e}} \mathrm{s}$. avant J.-C.

En effet, les fosses désormais célèbres de Tartigny (fig. 18), quelques décennies plus tard, en conservent encore les caractères essentiels (Massy el al., 1986) : plan quadrangulaire de $1,75 \mathrm{~m}$ à $3,10 \mathrm{~m}$ de côté, dépôt de nombreux vases hauts (9 exemplaires sur plus de 20), espace vide réservé au centre. Là aussi les fosses sont restées un certain temps ouvertes, ce que permettait la couverture de la fosse à l'aide d'un bâtiment ou d'une simple toiture reposant sur quatre poteaux. Mais surtout, c'est la présence dans quatre fosses d'une plaque d'argile cuite au centre de celles-ci, plaque assimilable à un petit autel, qui ramène ces structures à une fonction quasiment cultuelle. Son accès et la circulation autour de ce petit autel expliquent dès lors la fonction de l'espace vide, conséquent en surface. Des fosses similaires, avec un mobilier aussi riche et contemporain, ont été découvertes à Allonville (Ferdière et al., 1973).

Ces faits, malheureusement encore isolés, suggèrent en tout cas l'existence de pratiques rituelles qui ne sont pas seulement funéraires, dès la fin de La Tène ancienne. Leur apparition et leur diffusion sont probablement redevables au nouveau peuplement belge, qui se manifeste justement 


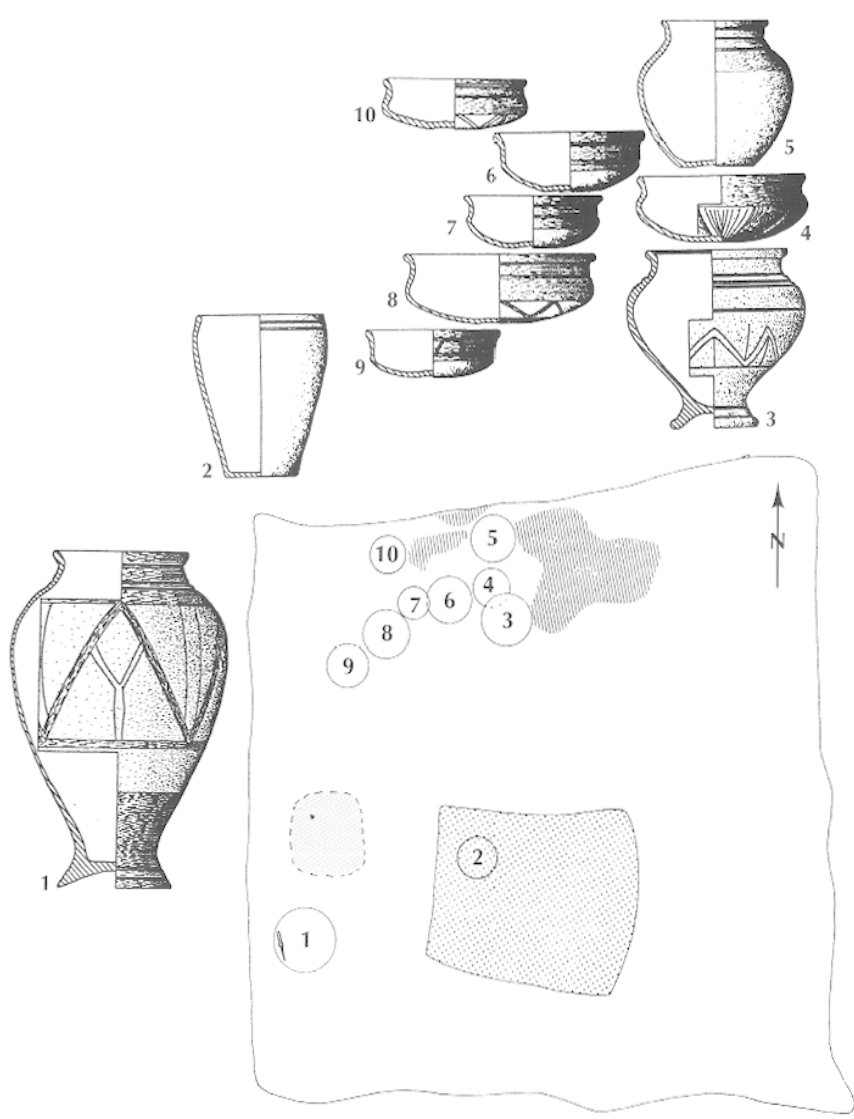

Fig. 18 - Tartigny (Oise), Le Moulin.

Plan d'une sépulture (d'après Massy et al., 1986).

avec la meilleure évidence dans la partie centrale de cette région. Ces pratiques ne se limitent pas à la seule offrande culinaire ou au simple banquet funéraire. Il paraît difficile d'admettre que des quartiers d'animaux aient pu jouer le rôle de viatiques pour des morts représentés par quelques os incinérés. D'autre part, si la pratique du banquet ne fait pas de doute, son déroulement à l'intérieur d'un enclos puissamment matérialisé le rapproche plutôt des banquets sacrificiels à l'intérieur des enceintes sacrées.

Ce modèle de fonctionnement funéraire semble avoir persisté, mais en se transformant, jusqu'à la fin de La Tène C2. Cependant, les données sont encore trop rares et surtout non publiées pour que l'on puisse, avec une certaine précision, en mesurer les modes de diffusion et de transformation.

\section{BANQUETS FUNÉRAIRES, OFFRANDES}

Encore une fois, il n'est pas question d'examiner ici les rites proprement funéraires, c'est-à-dire considérés sous leur angle individuel ou familial. Nous n'évoquerons ici que les faits qui évoquent des pratiques plus collectives ou des rites qui s'assimilent peu ou prou à ceux de l'aire spécifiquement cultuelle et qui peuvent nous aider à mieux l'appréhender. Dans ce cadre, deux pratiques méritent d'être examinées parce qu'elles sont des parties constitutives du culte régulier, ce sont l'offrande et le banquet.

Dans les rapports et publications archéologiques, l'emploi du terme offrande est souvent irraisonné et pour le moins confus. Il concerne aussi bien des éléments des vêtements du mort, de son équipement (guerrier, artisanal par exemple) que des ossements animaux et de la céramique. Ces mêmes restes sont tout aussi indifféremment qualifiés de "viatiques ». Or, ce qui peut se concevoir sous cette forme dans une sépulture où le mort est inhumé et conserve quelque chose de son intégrité physique pose autrement problème quand il s'agit d'incinération où le mort n'est même pas représenté par la totalité de ses cendres. Quoi qu'il en soit des croyances celtiques en une réincarnation, on ne peut considérer de la même manière comme offrande potentielle la fibule faisant partie intégrante d'un vêtement, un os animal et une céramique dont on ignore a priori l'usage qui en a été fait.

De fait, si l'on examine dans les sépultures de La Tène moyenne et finale les deux catégories de restes les plus courants, les os animaux et les céramiques, ces problèmes gagnent quelque peu en clarification. Pour les premiers, deux cas sont particulièrement éclairants, il s'agit des sépultures d'Allonville et de Tartigny, assez similaires par leur taille et les dépôts qui s'y trouvent. Dans les deux cas, des rachis de porc ont été mis au jour dans la fosse auprès des vases. Les vertèbres présentent les traces d'une découpe bouchère qui a consisté dans le prélèvement des filets de viande. Ces os ne peuvent donc être considérés ni comme une offrande animale ni comme un viatique, mais plutôt comme les reliefs d'un repas qui s'est tenu à proximité de la fosse, à l'intérieur des enclos qui ont été décrits plus haut. Ces deux cas ne sont pas exceptionnels. Ils supposent que la fosse était encore ouverte au moment du repas et que les os y ont été déposés, non pas comme dans une poubelle, mais plutôt à titre de souvenir ou de symbole de ce repas où le mort a pu recevoir une part, au même titre que les dieux dans un sacrifice de commensalité. Dans ce cas, il vaut donc mieux parler de "part du mort ". On peut dès lors se demander si les céramiques n'ont pas connu un rôle assez similaire, fonctionnel donc, qui avait sa place dans ce type de repas. Les écuelles, les gobelets étaient utilisables par des convives, tandis que les situles pouvaient servir aux libations.

On le voit, le banquet funéraire occupe dans l'enchaînement de ces rites une place centrale, qui s'explique bien par la place éminente qu'occupe le banquet dans la vie sociale des Celtes. Il s'agit très certainement de signifier à travers lui 
la place qu'occupait le mort dans sa communauté. La taille de cette dernière, qu'elle soit limitée à ses proches, à la famille élargie, voire à sa tribu, traduisait quant à elle l'aura que portait le mort sur celle-ci. Il s'agissait, comme on l'a vu, d'un rite de commensalité dans lequel le défunt avait une part plus ou moins active, ou plus ou moins symbolique. L'aménagement des lieux était, en grande partie, conditionné par cette pratique : enclos, taille de l'espace enclos, forme et dimension de la fosse, présence ou non d'une toiture sur celle-ci. Mais ce qui paraît le plus remarquable c'est la similarité entre ces aménagements qu'on peut qualifier par commodité de "funéraires " et ceux du culte. On retrouve chaque fois les mêmes composantes essentielles: un espace enclos d'un fossé ouvert, une fosse ouverte près du bûcher, un banquet dont les restes sont rejetés à la fois dans la fosse et dans le fossé de l'enclos. Certes les dimensions de ces aménagements et parfois la forme (circulaire pour l'autel et rectangulaire pour la fosse funéraire) diffèrent. Néanmoins, les conceptions similaires qu'elles révèlent ne peuvent être fortuites dans un univers mental et visuel qui demeurait étonnamment peu varié. Elles témoignent d'un ensemble de croyances qui a généré des pratiques communes ou assez similaires qu'on désigne, de façon pratique, sous le terme de chthoniennes. Elles s'adressent à ce monde d'en bas où demeurent des divinités qui gouvernent, entre autres, la génération terrestre, en s'abreuvant des morts, comme elles le font des victimes sacrificielles. L'évocation par César ( $B . G$., VI, 18, 1) d'un dieu assimilé à Dis Pater, considéré comme le père de tous les hommes, l'équivalent de Pluton, est tout à fait représentatif de telles croyances.

\section{LES GUERRIERS MORTS AU COMBAT, LES HÉROS}

La proximité des pratiques funéraires et des pratiques cultuelles n'est nulle part aussi manifeste que dans le traitement des dépouilles des guerriers morts au combat. On se trouve dans une région où pendant tout le second âge du Fer, le phénomène guerrier est, de tous les aspects de la société, probablement le plus spectaculaire. De la fin du Ve $\mathbf{s}$. au début du III $^{\mathrm{c}}$ s., les sépultures à inhumation, qu'elles soient à char ou qu'elles soient celles de guerriers, témoignent d'une valorisation incontestable de la fonction du guerrier et de sa place dans la société. À La Tène moyenne, ce sont les grands sanctuaires qui matérialisent une idéologie guerrière qui ne semble jamais avoir été autant diffusée. Enfin à La Tène finale, ce sont ces mêmes guerriers qui contrôlent la vie de la communauté et qui gardent, malgré l'émergence d'un fonctionnement purement politique, une place prééminente dans la hiérarchie sociale,

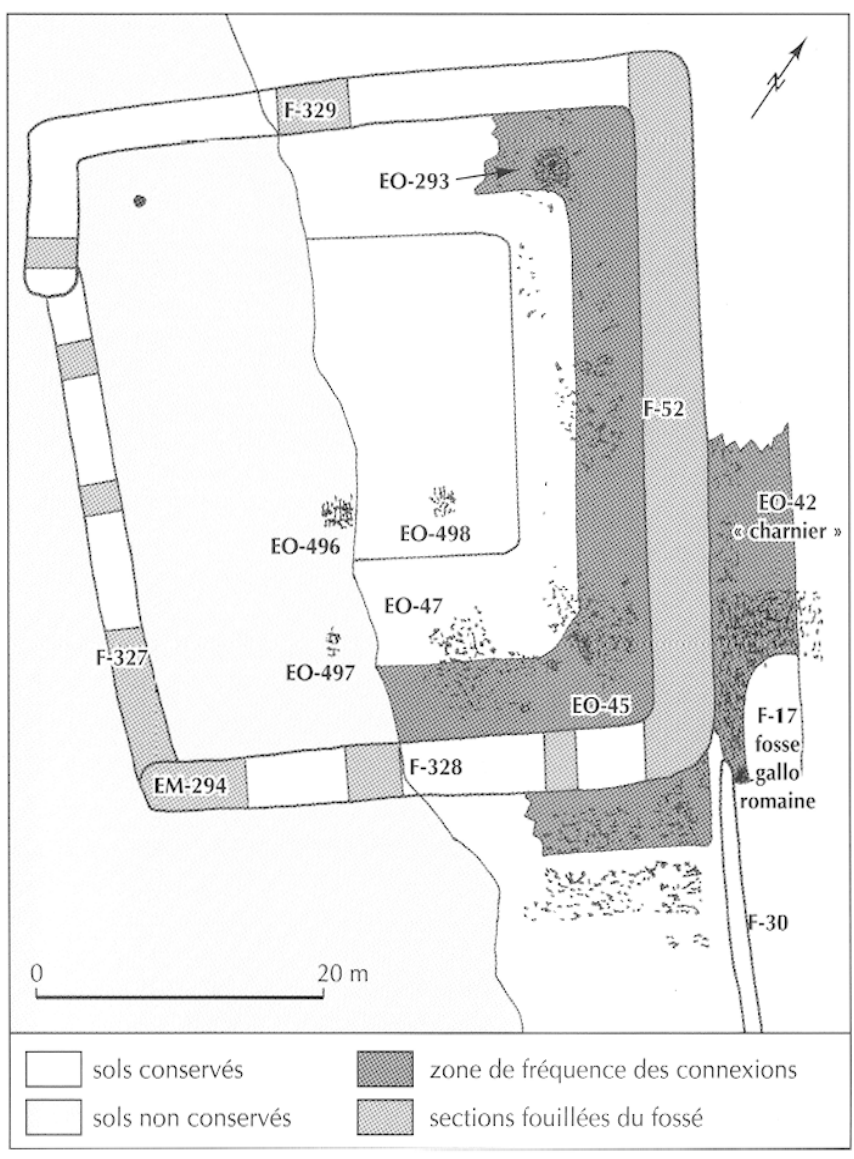

Fig. 19 - Ribemont-sur-Ancre (Somme), Le Champ Crezette. Plan de l'enclos quadrangulaire du trophée (C. Malagoli, Centre archéologique de Ribemont).

comme en témoigne clairement César à propos des peuples belges ( $B$. G., II, 4). Or les guerriers, bien présents dans les nécropoles de La Tène ancienne où ils représentent entre 10 et $20 \%$ des inhumés (Demoule, 1999, p. 196), disparaissent ensuite totalement du paysage funéraire, pour ne reparaître qu'à la fin de La Tène D1 dans quelques sépultures à incinération ne livrant généralement qu'une épée.

Cette absence de sépulture contraste évidemment, au plus haut point, avec les traitements de dépouilles guerrières que révèlent les monuments de Ribemont-sur-Ancre (voir infra notice 14 , p. 6468), par le nombre des dépouilles humaines mais aussi par la quantité et la qualité des armes qui les accompagnent. Il s'agit en fait de deux ensembles de restes situés à l'intérieur et à la périphérie de deux monuments distincts, érigés après une bataille qui s'est déroulée sur les lieux mêmes et qui a opposé une armée celtique d'origine armoricaine à une autre armée, belge, aux environs de 260 avant J.-C. Le premier est un enclos quadrangulairc qui cst intcrprćtć commc un trophćc. Lc sccond est un enclos circulaire, il s'agirait d'une sorte d'hérôon. 
Le trophée dans son aspect extérieur présente l'allure d'un lieu de culte (fig. 19) (Brunaux dir., 1999). C'est un terrain sacré, matérialisé par un fossé ouvert et surtout par la présence d'une végétation arborée qui témoigne de la présence divine. Il fallait, en effet, que cette divinité soit fixée au sol, dans une terre qui lui fût propre, pour que l'on puisse lui offrir tout le butin qui devait lui revenir. Cependant, à la différence des sanctuaires, ce terrain sacré n'a connu aucun sacrifice animal ni aucune activité cultuelle perpétuée pendant une longue période. Les seuls rites furent ponctuels et consistèrent à offrir à la divinité les dépouilles ramassées sur le champ de bataille, comme des libations déversées dans des autels creux. Cependant ces rites n'étaient pas immédiatement réalisables. Pour les accomplir il fallait transformer les cadavres des vaincus en une matière fluide, susceptible de descendre dans le soussol. À l'extérieur de l'enclos sacré, des bâtiments furent construits pour accueillir ces dépouilles et leur permettre de se transformer naturellement, c'est-à-dire perdre leur chair. Une fois ce stade atteint, les restes très décharnés étaient apportés dans l'enceinte (fig. 20). Les os étaient concassés, puis passés au feu pour les réduire encore et peut-être les purifier. Ce sont ces cendres qui étaient déversées dans des autels, disposés autour de la zone centrale, demeurée boisée. Une fois ces opérations achevées, le bois sacré avec ces étranges constructions ne connut plus d'activité humaine et demeura en l'état pendant plus de deux siècles, comme s'il avait été frappé d'un tabou.

Le deuxième monument de Ribemont n'est séparé du trophée que d'une quarantaine de mètres (Brunaux, 2002). Élevé également immédiatement après la bataille, il se présente sous une forme totalement différente, voire opposée. Il s'agit d'une cour entièrement fermée et de plan circulaire. Une petite entrée (simple porte) se trouve face à l'est, en direction du champ dc bataille. L'espace intérieur a été méticuleusement aménagé: le sol, sur toute son épaisseur arable, a été décapé et remplacé par un empierrement de rognons de silex et d'éclats de grès. Les murs de la palissade avaient été peints d'au moins trois couleurs (fig. 21). C'est sur l'aire empierrée que furent exposées les dépouilles de plusieurs dizaines de guerriers munis de leurs armes. Ces dernières sont parfaitement synchrones de celles trouvées dans le trophée, mais révèlent une typologie différente, pour les lances et les boucliers notamment. On doit penser qu'il s'agit des armes des morts du camp vainqueur. Les cadavres sont restés exposés pendant plusieurs mois, voire une ou deux années. À l'issue de cette période et avant le démontage de cet aménagement des sacrifices animaux et des libations furent accomplis. Les guerriers survivants durent partager avec les morts les chairs des animaux sacrifiés en un véritable

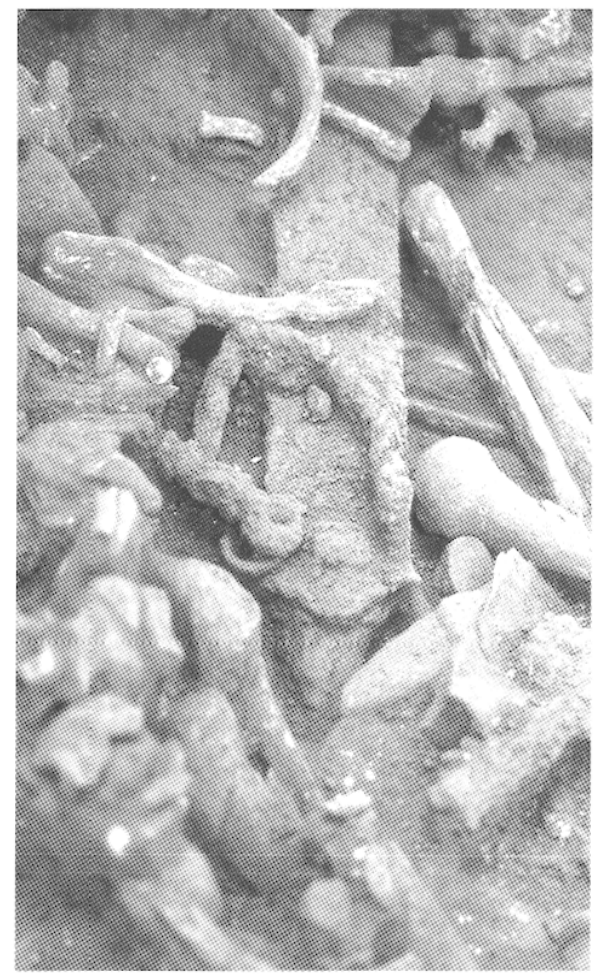

Fig. 20 - Ribemont-sur-Ancre (Somme), Le Champ Crezette. Restes de squelettes humains et d'armes découverts à l'emplacement des bâtiments périphériques du trophée (photo J.-L. Brunaux, CNRS).

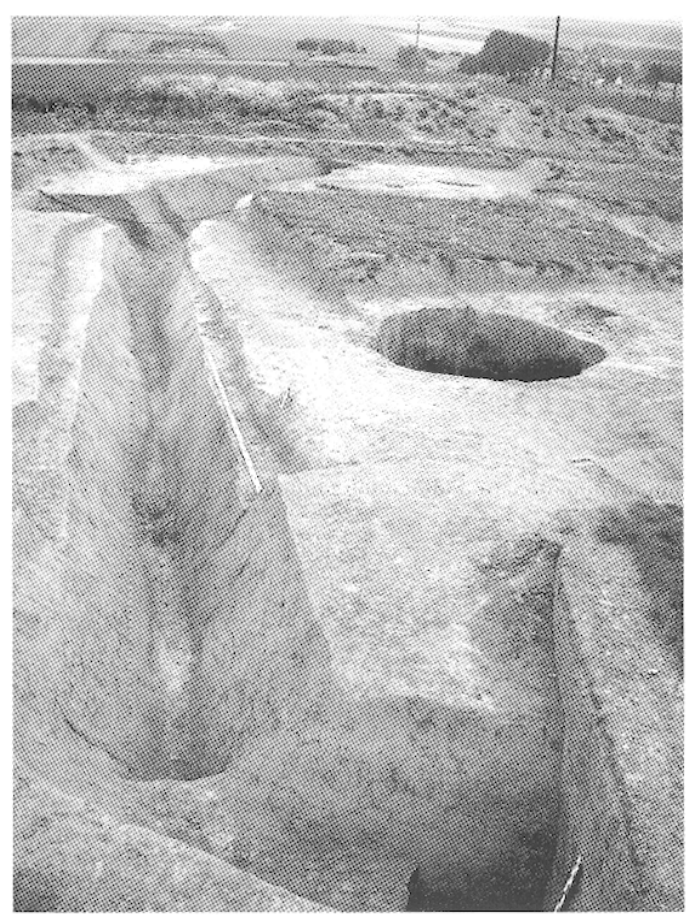

Fig. 21 - Ribemont-sur-Ancre (Somme), Le Champ Crezette. Fossé de fondation de la palissude de l'enclos polygonal (hérôon) (photo J.-L. Brunaux, CNRS). 


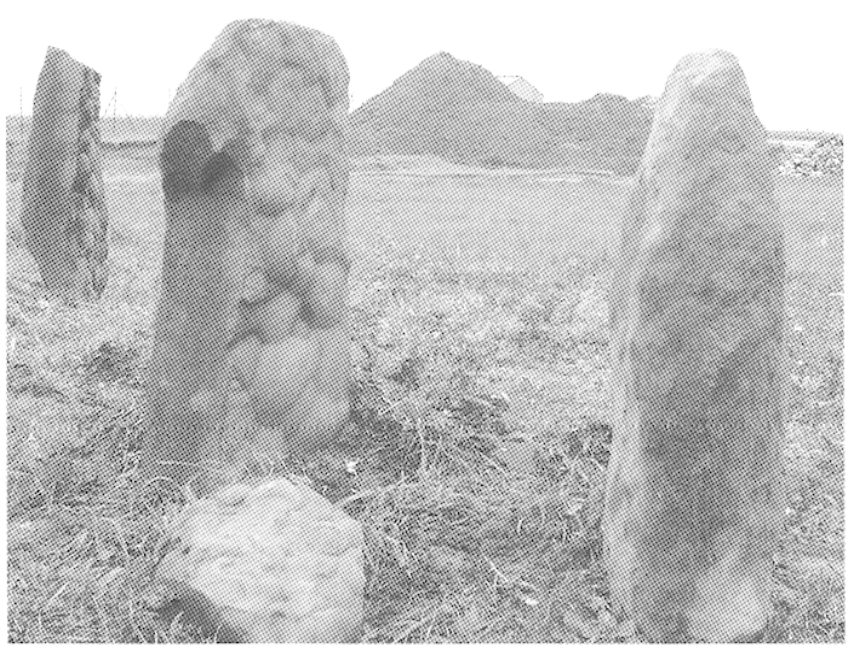

a

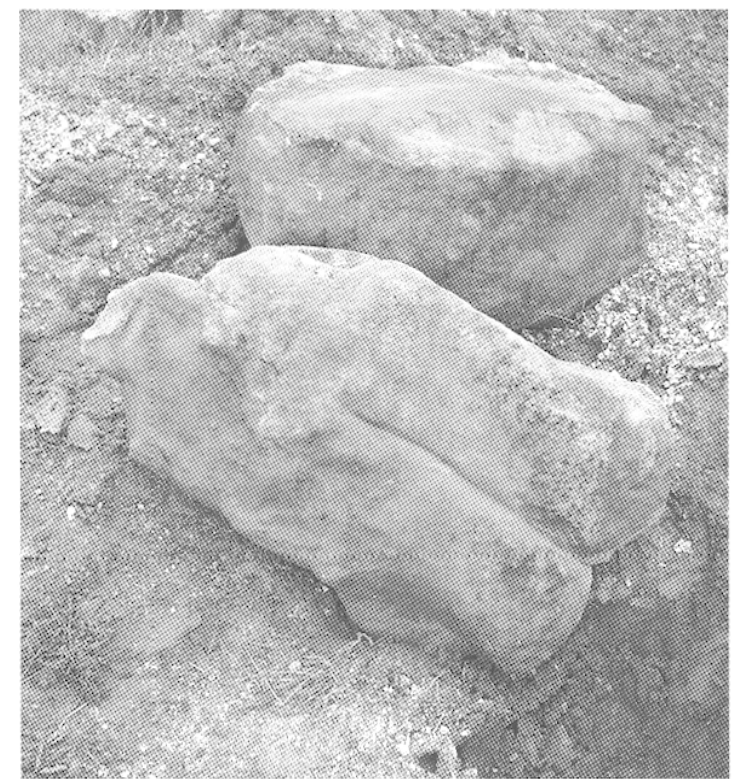

b

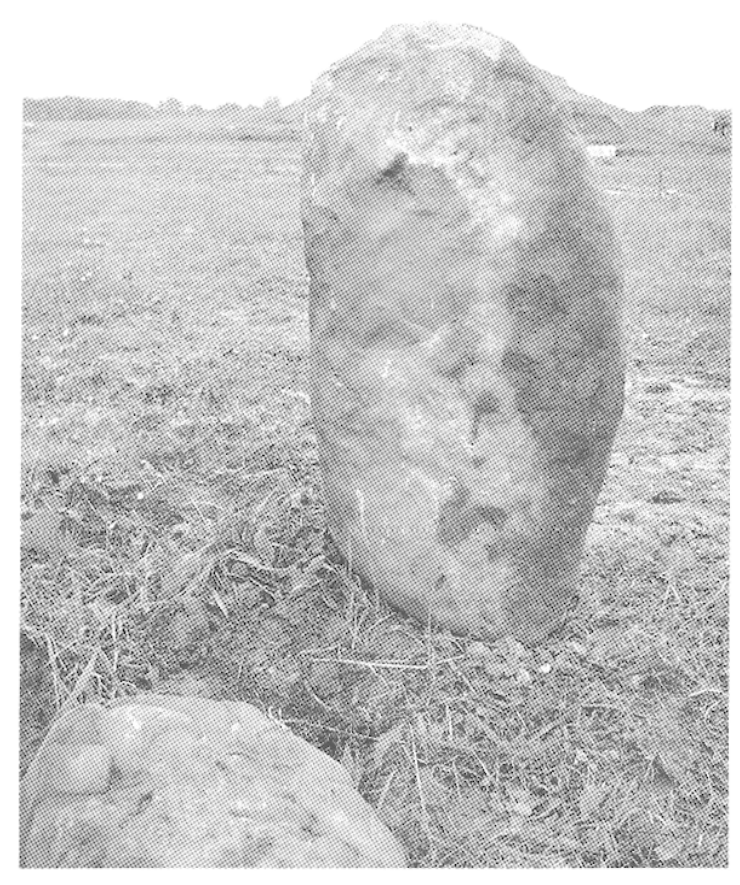

d

Fig. 22 - Ribemont-sur-Ancre (Somme), Le Champ Crezette.

Stèles de grès découvertes près de l'enclos polygonal (photo J.-L. Brunaux, CNRS). 
banquet funéraire. C'est à ce moment que furent dressées une cinquantaine de stèles de grès, autant qu'il y avait de guerriers morts (fig. 22). Elles demeurèrent plus tard les seuls témoins de ces morts et de cet aménagement, et suscitèrent un culte, de nature héroïque, s'accompagnant de sacrifices de commensalité et d'offrandes d'armes jusqu'à la conquête romaine.

La fonction de ces monuments - et plus particulièrement du second - demeurerait totalement énigmatique, si nous ne disposions pas d'une documentation littéraire, heureusement étonnamment explicite sur les pratiques qui nous occupent ici et sur les conceptions religicuses qui les sous-tendent. En fait, les gestes qui sont mis en évidence à Ribemont paraitraient non seulement difficilement explicables mais seraient susceptibles d'être interprétés en termes de sacrifice humain, si on se livrait à une analyse trop rapide. Le témoignage de Silius Italicus dans sa Punica (III, v. 340-343) ne laisse cependant aucun doute sur la signification de ces pratiques, puisque, de façon exceptionnelle dans la littérature concernant les Celtes, il décrit les faits mais en donne aussi les raisons: "Pour eux [les Celtes engagés dans les armées d'Hannibal] c'est une gloire de mourir au combat et il est sacrilège de brûler le corps de celui qui a connu une telle mort. Ils croient qu'ils seront transportés au ciel auprès des divinités supérieures, si le vautour affamé déchire les morccaux de leurs corps gisant au sol ». Silius Italicus qui a rédigé son poëme dans les années 80 de notre ère, dans cette description qui se démarque de celle de TiteLive, a trouvé sa source chez un annaliste, Valerius Antias, peut-être lui-même directement redevable de Fabius Pictor qui avait rencontré les Gaulois cisalpins et transalpins sur un champ de bataille, celui de Télamon en 225 où il avait pu voir de telles pratiques. La même information se retrouve chez l'encyclopédiste grec Élien (De natura animalium, X, 22) à propos des Vaccéens. Ce dernier, auteur tardif, a pu copier Silius Italicus. Plus intéressante est une autre information due à Pausanias qui concerne cette fois les Celtes qui envahirent la Grèce au III ${ }^{c}$ s. après la bataille des Thermopyles : «Les Gaulois ne firent pas demander par un héraut la permission d'enlever leurs cadavres : il leur était bien égal qu'on donnât à ces cadavres un peu de terre ou que s'en repussent les bêtes sauvages et ceux des oiseaux qui font la guerre aux morts ". Ce témoignage est évidemment beaucoup moins intéressant que le premier, mais il a le mérite de constituer une autre source, issue d'une tradition différente et concernant d'autres peuples celtiques, indiquant par là que cette coutume fut largement généralisée au monde celtique entre les $\mathrm{IV}^{\mathrm{c}}$ et le $\mathrm{II}^{\mathrm{e}} \mathrm{s}$.

C'est ce que confirment par ailleurs plusieurs documents iconographiques, l'un d'origine falisque, les autres dus à la main même des Celtes d'Ibérie. Dans le

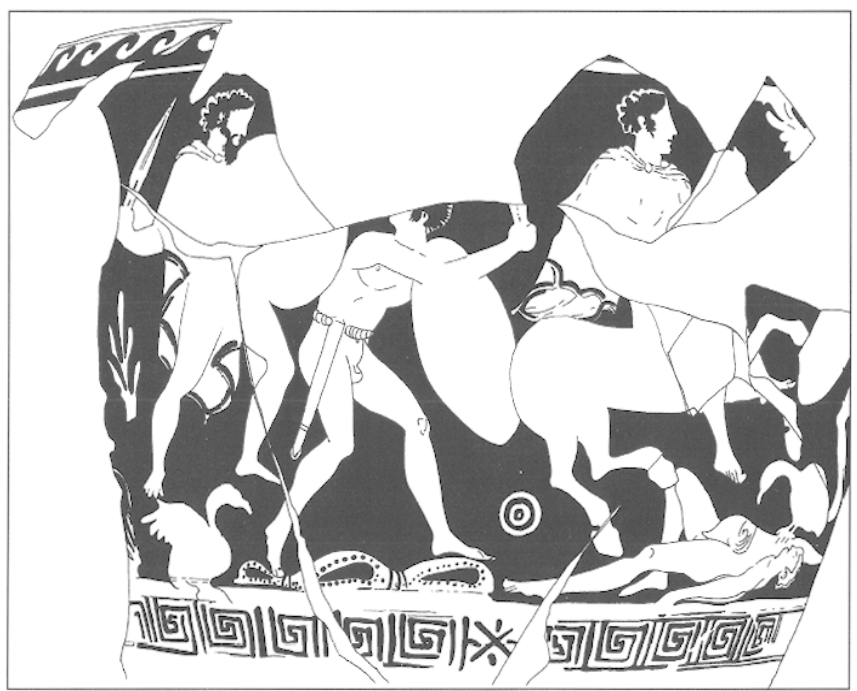

Fig. 23 - Stamnos étrusque du IV"s. avant J.-C. Scène de bataille entre Celtes et Italiques; un vautour arrache les viscères d'un guerrier mort (Bonn, Akademisches Kunstmuseum).

premier cas, il s'agit d'un stamnos à figure rouge datant du premier quart du $\mathrm{IV}^{\mathrm{c}}$ s., la plus ancienne représentation de Gaulois (Bonn, Akademisches Kunstmuseum) (fig. 23). On y voit deux guerriers gaulois s'affrontant à des guerriers italiques, l'un à pied l'autre à cheval. L'un des deux Gaulois gît au sol et un vautour arrache les viscères de son ventre. Un autre vautour se trouve à proximité, comme s'il attendait la mort du second. Des représentations similaires mais moins réalistes se trouvent sur des céramiques peintes découvertes à Numance ou sur unc stèle de El Palao en Espagne (Sopena Genzor, 1995).

Cette documentation, très diversifiée puisqu'elle provient à la fois des voisins des Celtes, Étrusques, Romains et Grecs mais aussi des Celtes eux-mêmes, suffit à convaincre de la véracité des faits qui s'accordent parfaitement aux croyances eschatologiques des Gaulois, sur lesquelles nous possédons une littérature relativement abondante (Brunaux, 2000a, p. 61-68). Mourir en héros permettait au guerrier de quitter le cycle des réincarnations et d'accéder à un paradis auprès des dieux. Seule une telle idéologie, suffisamment forte et attirante, pouvait permettre à des guerriers de se jeter à corps perdu dans les corps à corps effroyables que les récits de bataille nous rapportent.

Le fait est que le culte qui se développe sur le lieu de traitement de ces guerriers morts du camp vainqueur belge prend les allures d'un culte d'héroissation. Après que leur âme se soit délivrée de leur corps dans le huis clos d'une imposante " tour de silence ", ce sont des stèles qui ont pour mission d'en assurcr la mćmoirc, dc la même manière que les kolossoï de Grèce, ainsi que J.-P. Vernant en a si bien décrit 
le fonctionnement (Vernant, 1978) : elles n'ont pas pour mission de représenter le héros, mais elles sont une sorte de double qui témoigne de leur présence. Au pied de ces stèles se développe une activité cultuelle qui n'a pas grand chose à envier à celle qui animait les bois sacrés: sacrifices animaux et offrandes d'armes y scandent une mémoire qui, au fil des temps, ne faiblit pas.

\section{CONCLUSION}

Le traitement des dépouilles de guerriers rend plus évident encore ce que laissaient entrevoir les sépultures de la fin de La Tène ancienne à la fin de La Tène finale. En Gaule du Nord, à partir du début du III' s., l'individu n'est pas systématiquement promis, au moment de sa mort, à recevoir une sépulture. En réalité, comme le montreraient certainement des recherches démographiques plus approfondies, c'est certainement une part assez faible de la population qui bénéficiait d'un traitement funéraire. La mise en évidence de ce phénomène ne constitue nullement une découverte. Mais à la faveur de la multiplication des fouilles et des études plus systématiques des sépultures, on en mesure mieux l'ampleur. Et le déficit des tombes par rapport à la population que l'on estime occuper les habitats contemporains ne cesse de se creuser. On avait cru pouvoir expliquer l'absence de sépulture par un statut social défavorable : seuls peut-être les citoyens - au sens large que l'on peut donner à ce mot pour les habitants de la Gaule protohistorique avaient droit de sépulture, comme ils avaient droit de siéger dans les assemblées, à certains cultes et de figurer dans l'armée d'élite. Assurément cette explication ne paraît plus suffisante : s'il y a bien différentes catégories d'hommes auxquelles correspondent différents traitements funéraires, il y a aussi différents types de morts qui appellent chacun sa forme spécifique de traitement du cadavre. Les choses ne sont pas aussi simples que les modes de pensée, hérités de la culture gréco-romaine, le laissent imaginer. Face au corps humain mort, les Celtes ont des comportements qui diffèrent radicalement de ceux des Grecs ou des Romains. Ils n'ont pas l'obsession de l'inhumation, fût-elle symbolique. Le traitement du cadavre ou l'absence de traitement répond à d'autres préoccupations mais aussi à l'absence de préoccupations que peuvent avoir d'autres peuples.

Contrairement à ce que l'on voit surtout dans le monde romain, la sépulture chez les Gaulois du Nord ne vient pas marquer par sa monumentalité ou de façon symbolique l'univers des vivants. À Rome, le mausolée témoigne de la puissance d'un personnage et, au-delà, de celle de sa famille. Les Gaulois ne ressentent pas le besoin d'utiliser une telle sémiologie, parce que chez eux l'aura d'un personnage se transmet par la renommée et la mémoire, sur un mode épique. C'est pourquoi à partir du $\mathrm{III}^{\mathrm{e}} \mathrm{s}$. on ne voit plus de guerriers dans les nécropoles : ou bien ils n'y figurent pas ou bien ils n'ont pas besoin de se représenter physiquement comme tels. Aussi doit-on s'interroger sur l'interprétation en termes de mausolée que l'on donne aux bâtiments imposants qui surplombent quelques tombes. Le mausolée paraît contradictoire avec la simplicité, voire la pauvreté de ce que contiennent les fosses sépulcrales. On peut tout aussi bien imaginer qu'il s'agit de monuments cérémoniels dont la fonction était à la fois pratique mais aussi symbolique de la puissance du défunt et qui ne servaient que le temps des pratiques funéraires, comme les catafalques en forme de maison du pays toradja (Indonésie).

Si la sépulture occupa une place aussi dérisoire dans l'univers visuel des Gaulois, c'est que ces derniers, contrairement aux Romains notamment, avaient des conceptions élaborées et solides de l'au-delà. La religion ou philosophie druidique ont popularisé dès le III ${ }^{\mathrm{e}} \mathrm{s}$. la croyance en un cycle perpétuel de renaissances, auxquelles ne pouvaient échapper que certains êtres dans certaines conditions. La seule que nous connaissons précisément est la mort héroïque du guerrier. Mais il devait exister d'autres formes de "belle mort ", qui permettait aux prêtres, peut-être à certains paysans, aux hommes vertueux de bénéficier également d'une perspective eschatologique plus encourageante. Dès lors, les os dans la sépulture ne sont plus que le souvenir d'un état transitoire. Et il semble que dans la plupart des cas, pour cette raison, un culte des reliques ne se soit pas développé. Il ne correspondait à aucune nécessité, puisque la plupart du temps l'âme s'était rapidement échappée, presque toujours en direction des puissances inférieures, très rarement vers un éden situé dans les cieux.

Aussi les circonstances de la mort jouaient-elles peut-être un rôle aussi important que celui de la place sociale de l'individu, au moins dans les régions et pendant la période où les doctrines druidiques ont connu leur plus grand développement. C'est pourquoi certainement la sépulture et le lieu où elle se trouve présentent tant d'affinités avec le lieu de culte et son autel.

Ces constats doivent nous inciter à aborder le phénomène funéraire avec d'autres méthodes peut-être, avec des grilles interprétatives différentes sûrement.

\section{LES AMÉNAGEMENTS SYMBOLIQUES ET CULTUELS DANS L'HABITAT}

La formule célèbre de César (B. G., VI, 16), selon laquelle: "Tout le pcuplc gaulois se passionne immodérément pour les choses de la religion », laisse penser que les 
traces de cette passion doivent se retrouver dans toutes les manifestations de la vie quotidienne et dans tous les lieux que l'homme fréquente. L'habitat est non seulement de ceux-là, il est de très loin le plus fréquenté. Aussi devrait-on y découvrir les témoins les plus abondants de ces activités religieuses multiples. Le tableau que nous en livre la recherche archéologique reflète mal ces évidences. La raison principale est que très longtemps de tels phénomènes n'ont pas été l'objet d'une recherche spécifique et attentive: l'habitat était censé livré des fondations de demeures et un mobilier archéologique directement en relation avec les occupations quotidiennes des Gaulois, agriculture, élevage, artisanat, alimentation. Ce n'est que depuis une dizaine d'années, à la suite de découvertes suffisamment significatives, que l'attention des chercheurs s'est portée sur tout ce qui y paraît inhabituel voire incongru. La seconde raison, plus problématique, est que ces vestiges aussi bien matériels que structurels ne se distinguent pas souvent de façon évidente de ceux que produisent des activités domestiques banales.

Il s'agit donc d'un questionnement nouveau qui, comme celui qui touche aux phénomènes funéraires, s'appuie surtout sur la comparaison que fournit l'analyse des lieux de culte. C'est dire qu'il n'existe pas encore de méthode d'analyse propre. Et peut-être la comparaison avec les faits observés sur les sanctuaires n'est-elle pas, dans ce cas, la plus appropriée. Dans le cadre de cette approche nouvelle, il n'est pas toujours possible de distinguer les faits qui seraient à définir comme purement cultuels d'autres qui seraient de l'ordre du symbolique voire d'un décoratif alimenté de références mythologiques.

\section{LES ENCLOS DANS L'HABITAT}

Dans l'habitat, parmi les faits archéologiques qui paraissent les plus aisément attribuables à la sphère cultuelle, figurent en première place certains enclos. Il s'agit d'aménagements architecturalement mal définis et à la fonction énigmatique à l'intérieur d'une agglomération, d'une ferme ou d'une résidence aristocratique. L'interprétation cultuelle de ces structures et d'un matériel qui ne se distinguent pas de façon flagrante de ce que l'on rencontre habituellement sur l'habitat doit beaucoup à l'influence de l'étude des sanctuaires. Les archéologues ne craignent pas de rapprocher ces enceintes des enclos sacrés. Les zoologues de leur côté mettent en relation des restes osseux inhabituels ou spectaculaires (carcasses plus ou moins entières, crânes dc bovidés) toujours rencontrés dans le fossé de clôture avec ceux que livrent, parfois en grande quantité, les sanctuaires. Les sites les plus représentatifs à avoir été interprétés de cette manière sont ceux de Braine (Auxiette et al., 2000), Le Champ des I Lavoirs à Vermand (Lemaire et al., 2000) et Thaon (inédit).

Dans ces cas, l'interprétation cultuelle pose beaucoup de problèmes. En fait, contrairement à ce que pensent les archéologues, ces enclos en pleine zone d'habitation se distinguent plus des sanctuaires qu'ils ne s'en rapprochent. Par leur environnement tout d'abord, purement domestique pour les premiers, seulement naturel pour les seconds (même si les zones cultivées ne s'en trouvent jamais éloignées). Par la clôture ensuite : pour les premiers il ne s'agit que d'une clôture fonctionnelle (simple fossé) destinée seulement à séparer des espaces; pour les seconds il s'agit d'une clôture symbolique mais efficace et faite pour durer dans le temps (large et profond fossé, doublé d'une palissade puissante). Par leur aménagement intérieur enfin : indistinct pour les premiers, matérialisé fortement pour les seconds (autels creux, système de couverture, porche d'entrée monumental).

Ces différences ne suffisent pas cependant à écarter de tels ensembles de toute interprétation cultuelle. S'il est évident qu'en ces lieux ne s'est pas développé un culte authentique dédié à une divinité particulière et pour une période longue, on peut imaginer que s'y soient déroulées occasionnellement des pratiques situées en marge de la sphère religieuse : banquets peut-être, activités réglementées de boucherie, etc. Mais il y a beaucoup plus de chances pour que les vestiges découverts dans les fossés, notamment les crânes de bovidés, ne soient que les restes d'une décoration symbolique qui avait pour but de caractériser les espaces, de glorifier l'importance du cheptel et, par là, de celui qui le possède. Le renoncement à l'usage de l'écriture obligeait à user ainsi d'autres codes, à mettre en place un système de communication qui ne pouvait que valoriser des symboles directement puisés dans la vie quotidienne.

On voit bien néanmoins qu'ici l'interprétation cultuelle, au sens large, n'est plus opérante. Il paraît nécessaire de mieux caractériser l'aspect extérieur de ces espaces (s'agit-il de réelles clôtures ? quel était leur aspect ? imposaient-elles un accès réglementé ?, etc.), d'essayer de mieux identifier les activités qu'ils permettaient, notamment au moyen des aménagements dont on les avait pourvus, au moyen également de tous les restes découverts dans toutes les structures creuses. L'absence d'unité d'habitation dans l'enclos, la fréquentation de celui-ci par des animaux sélectionnés qui ont pu y connaître un traitement particulier, la présence d'installations pouvant être liées au culte (fosses et foyers de type autel) paraissent des critères assez décisifs pour reconnaître dans ces espaces des lieux qui n'étaient pas voués aux activités domestiques habituelles. 
Dans la région étudiée ici, un seul site a révélé au cours de sa fouille un espace indéniablement voué à des pratiques cultuelles, probablement liées à d'autres activités édilitaires ou politiques. Il s'agit de la résidence aristocratique de Montmartin (Brunaux, Méniel, 1997 et infra notice 12, p. 61-63).

Les restes découverts dans le fossé de l'enceinte dc Montmartin ne laissent guère de doute sur la nature partiellement religieuse de ce lieu. Crânes humains, armes en fer, os animaux nous renvoient directement à l'image donnée par les sanctuaires. Cependant, si l'on examine ces restes avec attention, des différences s'imposent. Notamment en ce qui concerne le sacrifice animal. Les os de Montmartin indiquent qu'il y a eu une consommation abondante, plutôt de type banquet. S'il y a bien eu culte chthonien, comme le suggère le caractère très spécifique de l'autel creux, parfaitement similaire à celui de Ribemont, celui-ci s'accompagnait de repas auxquels les humains participaient. Mais la différence la plus flagrante est la part que représentaient en ce lieu le culte et la divinité qu'il était censé servir. À l'évidence c'est une ou plusieurs autres activités qui y prenaient une part prépondérante. Le culte ne servait qu'à accompagner, voire à justifier des actes que l'on peine encore à identifier. Cependant plusieurs caractéristiques de l'enceinte nous livrent quelques pistes. La plus évidente, traduite par la présence d'un certain nombre d'armes et de crânes humains, suggère qu'on se trouve cn un licu rćscrvć aux guerriers ou tout au moins dans une enceinte où les vertus guerrières étaient particulièrement exaltées. La deuxième, s'appuyant sur la grandeur de l'espace enclos et l'absence de toute installation, laisse supposer qu'il s'agit d'un lieu de réunion. Ainsi, dans la publication, il a été proposé d'y voir le lieu d'assemblées politiques ou guerrières, les deux peut-être. Depuis, la découverte du second enclos de Ribemont permet d'envisager une dernière hypothèse qui n'exclut pas nécessairement celles qui ont été avancées. L'allure générale de l'enclos de Montmartin (son plan, ses hautes palissades de torchis également peint, la position et la forme de l'autel) et la présence d'os humains avec des traces d'un dépeçage poussé rendent aujourd'hui tout à fait évident le rapprochement avec l'aménagement funéraire de Ribemont. Ainsi n'est-il pas impossible que cette cour fermée de hauts murs ait, entre autres, servi à traiter les cadavres de quelques guerriers morts dans des combats plus ou moins lointains.

Cette dernière hypothèse trouve un prolongement inattendu avec une découverte récente, malheureusement non publiée exhaustivement, à Roissy-en-France (Boulestin, Séguier, 2000). Il s'agit d'un ensemble de cinq silos datés de la fin de La Tène ancienne. L'un d'eux a livré deux morceaux de calotte crânienne humaine présentant des traces d'écorchement, mais aussi d'un agrandissement du foramen magnum et, plus exceptionnel, de quatre petits trous circulaires. La trouvaille serait relativement anecdotique si elle n'était accompagnëe de plusieurs armes (umbo de bouclier, fer de lance, éléments de ceinture, le tout pouvant constituer quelques éléments d'une panoplic complète de guerrier de la fin du IV ${ }^{\mathrm{e}} \mathrm{s}$.) et de plusicurs céramiques qui présentent les plus grandes affinités avec celles de l'enclos circulaire de Ribemont. On est également frappé par une similitude des structures : les deux silos accolés ressemblent étonnamment à l'autel de Montmartin et à celui de Ribemont. L'absence de données sur le contexte structurel et mobilier ne permet malheureusement pas d'affiner plus les interprétations.

\section{LA MAISON}

Les difficultés à reconnaître des faits cultuels sur l'habitat sont encore accentuées lorsqu'on se livre à l'examen de la seule maison. Les vestiges de cellc-ci sont généralcment limités à de simples trous de poteaux dont le remplissage ne peut être que pauvre et forcément peu représentatif de ce que contenait l'édifice. Lorsque les structures sont plus conséquentes (fosses-dépotoirs, maisons semi-enterrées, etc.), la nature des déchets domestiques (os animaux ct cćramiques pour l'essentiel) ne les rend pas facilement distinguables de ceux livrés par l'activité cultuelle sur les sanctuaires.

Il n'est donc pas possible de savoir si les maisons et plus vraisemblablement celles, luxueuses, des personnages les plus éminents, comprenaient des aménagements pour une pratique individuelle ou familiale du culte, comme cela se rencontre couramment dans les autres civilisations antiques. Les textes n'évoquent pas de telles installations mais laissent plutôt croire que la plupart des activités cultuelles se déroulaient à l'extérieur des habitats, en public, tout au moins celui du cercle familial élargi ou d'une élite.

Le seul mobilier qui puisse être rapporté à la sphère religieuse est le crâne humain qui a déjà été évoqué à plusieurs reprises. On le trouve fréquemment dans les silos. Mais il n'est alors guère possible de savoir quelle était sa situation originale: se trouvait-il dans une maison, était-il fixé aux parois d'un enclos? La seule découverte significative nous est encore donnée par le site de Montmartin. Là une maison semi-enterrée $\left(n^{\circ} 50\right)$ a livré quatre éléments crâniens parmi un riche mobilier (céramique abondante et de luxe, parures, armes et outils mais surtout un torque en bronze qui pouvait être associé à ce crâne) qui témoignent du statut social élevé des habitants. I a bonne conservation des éléments crâniens exclut l'hypothèse que ceux-ci aient pu 
être accrochés à l'extérieur de la maison. Ils peuvent, au contraire, avoir fait partie de ces biens de prestige que conservait jalousement le guerrier, crâne des ennemis qu'il avait tués et qu'il conservait, si l'on en croit Diodore de Sicile (Bibliothèque historique, V, 29), chez lui et dans un coffre.

\section{LES GRANDS AMÉNAGEMENTS COLLECTIFS}

La découverte dans les années 1970-1980 des premiers grands sanctuaires a mis en évidence un élément essentiel pour la compréhension de la société gauloise, la capacité des Celtes du Nord de la Gaule, dès la fin du IVe s., à concevoir de grandes installations collectives, rigoureusement structurées dans l'architecture comme dans le fonctionnement. Ces réalisations supposent un pouvoir fort, une organisation sociale solidement établie et des conceptions religieuses déterminées constituant un contre-pouvoir spiritucl à la loi du plus fort. Dans la plupart des civilisations antiques, cette ćtape précède, parfois de peu, le moment où apparaissent d'autres formes de réglementation sociale, droit et justice, constitution politique. Il est donc légitime de chercher quelles formes matériclles ces nouvelles institutions ont revêtues. D'autant que le récit de la Guerre des Gaules atteste formellement que dans la première moitié du $\mathrm{I}^{\mathrm{er}} \mathrm{s}$. avant J.-C. les peuples gaulois disposaient de constitutions politiques, parfois sophistiquées, reposant sur une ou deux assemblées législatives, que le droit avait été formalisé et que la justice était régulièrement rendue. Il y avait donc des lieux où se tenaient les assemblées, des places de tribunal, telle que celle qui est décrite à propos de l'affaire Orgétorix, enfin des emplacements assurément très vastes qui permettaient recensement et vote.

Les recherches dans cette direction n'ont été, jusqu'à présent, guère fertiles. La raison principale est imputable aux archéologues eux-mêmes qui, d'une façon générale, délaissent les questions de société et n'interrogent que les faits matériels : mobilier et vestiges de construction. L'autre raison est d'ordre pratique: les archéologues aériens ne sont pas habitués à rechercher des ensembles aussi vastes, par ailleurs les fouilles, qu'elles soient programmées ou préventives, par leur emprise généralement faible, sont assez inaptes à révéler des aménagements de grande envergure, de l'ordre de plusieurs hectares de superficie. En Gaule du Nord, jusqu'à présent deux sites seulement ont fait l'objet d'une interprétation de type juridique ou politique ; ils s'ajoutent à l'enceinte de Montmartin dont on a vu que la fonction a pu être polyvalente. Ces sites présentent une même difficulté d'analyse qui tient justement à cette polyvalence ou à une double identité, religieuse et politique ou juridique. L'aspect religieux, même sous une forme assez symbolique, est, en effet, indissociable d'institutions qui n'ont dû leur émergence qu'à cette caution que leur donnait la religion.

Le site le plus emblématique à cet égard est certainement celui de Fesques qui présente indéniablement une double vocation (Mantel et al., 1997 et infra notice 8, p. 56-59). L'immense enceinte de 12 ha de superficie entourant le petit sanctuaire qui se trouve à son sommet n'avait, selon toute probabilité, aucun rôle propre dans le culte. Elle permettait le rassemblement d'importants groupes humains pour des activités que le matériel découvert dans le fossé d'enceinte et à sa périphérie permet d'éclairer. Ainsi peut-on présumer que se sont tenus là des banquets auxquels étaient conviés les membres d'une large collectivité disposant d'importants troupeaux leur permettant de sacrifier des centaines de jeunes bovidés. Mais c'est surtout la présence de cadavres humains exposés debout à l'extérieur de l'enceinte qui donne une explication à ces rassemblements (voir infra notice 8, p. 56-59) : à l'évidencc ces individus, certainement mis à mort, ont été l'objet d'une peine capitale. Le lieu de leur supplice, hors de l'enceinte réservée à la communauté civique qui s'arroge le privilège de banqueter, témoigne de cette condamnation qui est aussi un rejet de la communauté humaine. La grande enceinte tenait donc lieu probablement de tribunal. Le petit sanctuaire servait à assurer une caution divine à l'activité juridique et à laisser peut-être croirc que la peine capitale était encore une forme de sacrifice humain. Le site de Fesques est actuellement le seul qui témoigne assez clairement d'un exercice de la justice qui a pu se développer au cours du II $\mathrm{s}$. La grandeur de ses aménagements le rend compatible avec les descriptions de César.

Le site de Ribemont peut également être cité dans le cadre de cette recherche avec un enclos qui n'a pas ćté évoqué précédemment et qui apparaît probablement dans les premières décennies du $\mathrm{I}^{\mathrm{er}} \mathrm{s}$. avant J.-C. Il s'agit d'une enceinte quadrangulaire, fermée de palissades, de 1 ha de superficie, accolée à l'enclos sacré et englobant le cercle des stèles en grès (voir infra notice 14, p. 64-68). La superficie importante de ce nouvel espace et le matériel qui s'y rapporte (amphores et ossements de porcs pour l'essentiel) suggèrent une fois encore la tenue en ce lieu de grands banquets en relation certaine avec l'activité guerrière, puisque se tenait là le culte des héros. L'aménagement nouveau traduit assurément une nouvelle fonction: réunions à caractère guerrier, peut-être le " concilium armatum " que mentionne César (B. $G ., \mathrm{V}, 56)$ et qui jouait un si grand rôle dans la préparation et la décision de la guerre.

Le troisième site, celui de Villeneuve-Saint-Germain, doit être retenu pour une fonction politique ou judiciaire, les 


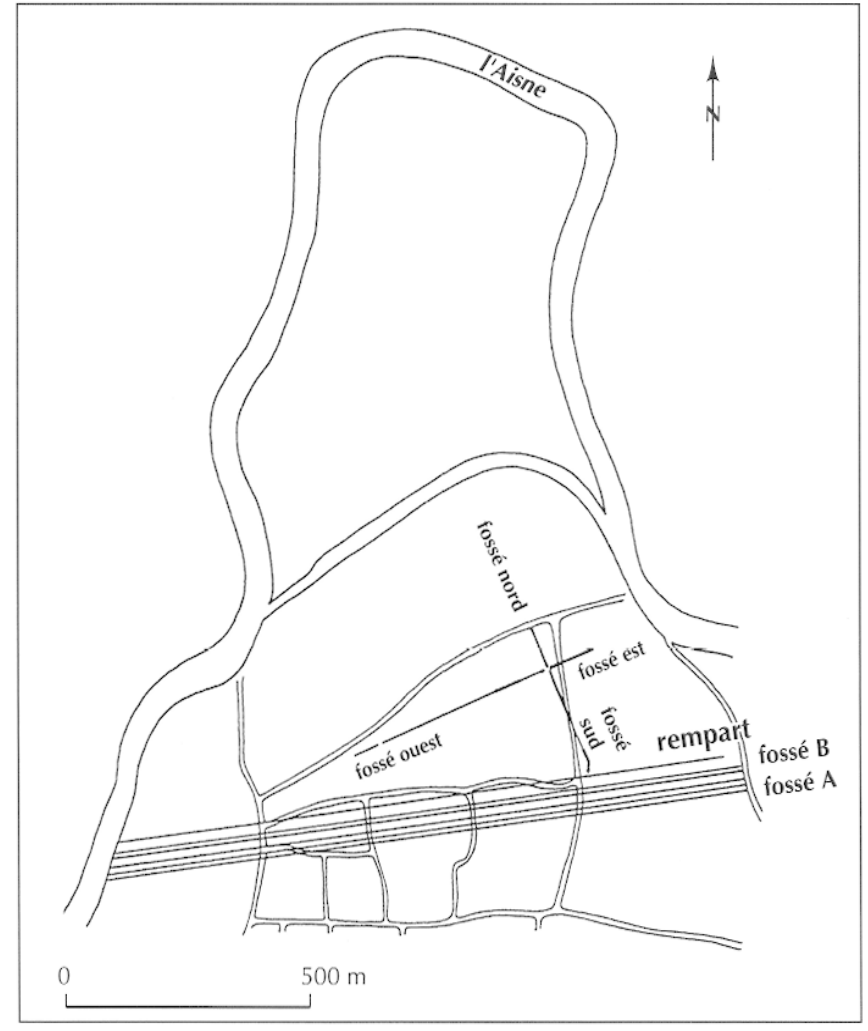

a

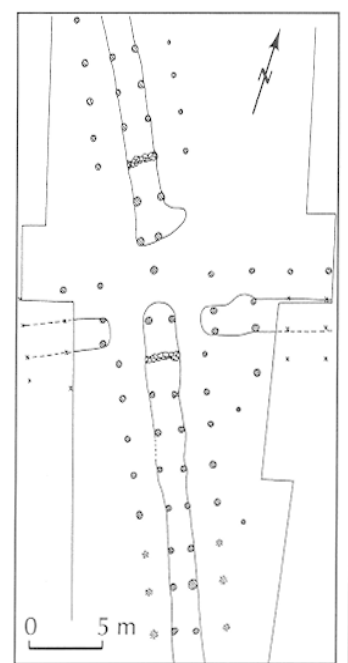

b

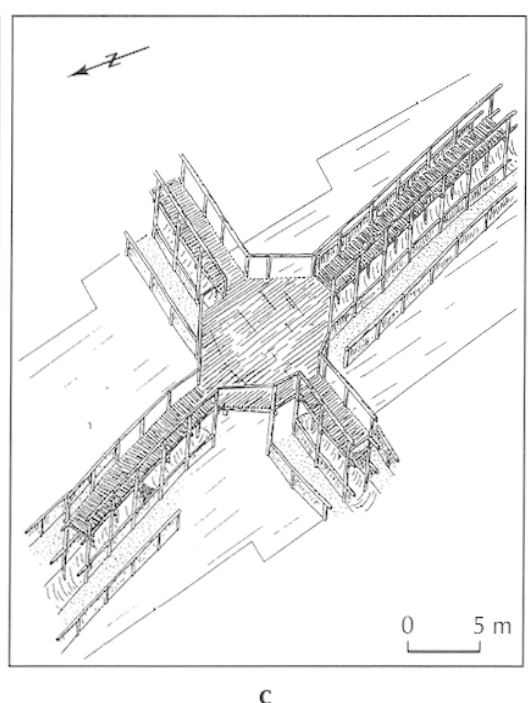

d'environ 70 ha, mais seule une vingtaine d'hectares à l'emplacement d'une terrasse fluviatile était réellement habitable. L'aménagement qui nous intéresse est un ensemble de quatre longs fossés formant une croix parfaitement orthogonale, divisant en quatre quartiers inégaux la moitié de la surface de la terrasse (fig. 24a). Les fossés n'ont été que partiellement explorés, puisque le plus long a été repéré sur plus de $400 \mathrm{~m}$. L'intérêt de la structure tient au plan parfaitement géométrique, ayant nécessité un véritable travail de géomètre, et à son aménagement très particulier. Les fossés, de faible profondeur, sont en effet bordés de chaque côté par deux rangées de trous de poteaux, parfaitement alignés et formant transversalement au fossé des travées de quatre poteaux (fig. 24b). Cette installation, contemporaine de la création du site, c'est-à-dire dans les premières décennies du ${ }^{e r} \mathrm{~s}$. avant J.-C., a livré un mobilier intéressant, parmi de nombreux restes animaux et déchets domestiques et artisanaux, près de trois cents rouelles. Le fouilleur, J. Debord, avait proposé de reconnaître dans ces vestiges ceux d'une sorte de galerie marchande, en fait une immense halle dont les fossés auraient servi de vide sanitaire (Debord et al., 1988). L'immensité de ces constructions, occupant au moins 10 ha, rend cette hypothèse peu crédible. L'hypothèse de $\mathrm{C}$. Peyre est plus convaincante, même si le manque de données imputable à une fouille trop partielle la rend fragile. Pour cet auteur il s'agirait d'un bâtiment destinć au votc ct/ou au ccns, un cnscmblc de couloirs fonctionnant à la manière des septae de la Rome antique (fig. 24c). Dans cette perspective, les rouelles sont interprétées comme des jetons de vote, à la manière des rouelles du tribunal des Héliastes à Athènes. Dans cette hypothèse, c'est une fois encore l'exemple du procès d'Orgétorix qui est invoqué : les participants étaient plus de 10000 , ce qui suppose un espace pour les accueillir tout à fait hors norme, plus d'une dizaine d'hectares, comme c'est le cas à Fesques. Malheureusement les fouilles partielles de Villeneuve-Saint-Germain ne permettent pas de savoir si la fonction politico-judiciaire de l'aménagement s'accompagnait d'une construction religieuse et peut-être d'un décorum symbolique, comme c'est le cas sur les autres sites.

Fig. 24 - Villeneuve-Saint-Germain (Aisne), La Crande Grève : $a$, plan du site avec l'emplacement des grands fossés rectilignes; $b$, plan des vestiges des fossés au niveau de leur intersection; $c$, hypothèse de restitution de l'utilisation des fossés (d'après Peyre, 2000).

deux peut-être à la fois, si l'on retient l'hypothèse qui a récemment été proposée par C. Peyre (2000). Il s'agit d'un habitat de type proto-urbain, qui peut être classé dans la catégorie des oppida de méandre de rivière. Sa superficie est

\section{PREMIÈRES INFLUENCES ROMAINES}

Dès le début du I ${ }^{\text {er }}$ s. avant J.-C. (dans certaines régions de façon encore plus précoce) se font ressentir les premières influences romaines. Même si les premières manifestations du poids de la civilisation romaine se traduisent avant tout dans un domaine strictement matériel (vin, monnaies, images), celles-ci en circulant relativement rapidement s'épanouissent préférentiellement dans les activités 
communautaires, autrement dit dans le lieu même des activités rituelles. Assez vite se développe un premier syncrétisme qui préfigure bien ce que sera la religion à l'époque gallo-romaine. Il n'est donc pas inintéressant de chercher à bien spécifier les pratiques, les rites, les conceptions et leurs traductions matérielles qui sont directement issus du monde romain.

\section{NOUVELLES FORMES DE COMMENSALITÉ}

Le vin est introduit en Gaule dès le $\mathrm{II}^{\mathrm{e}}$ s. avant J.-C., mais ce n'est qu'au début du I Ir $s$. qu'il gagne le Nord de la Gaule dans une chronologie et dans des quantités variables en fonction des différents peuples. Les habitants des bords de la Seine, les Rèmes et les Suessiones ont les premiers accueilli cette nouvelle boisson. Les peuples du Belgium ont été plus rétifs à cette intrusion, comme à celle de toute forme de commerce méditerranéen. Sur ce point les découvertes archéologiques confirment les propos de César (B. G., I, 1, 3) : " les marchands y [chez les Belges] vont très rarement et n'y introduisent pas ce qui est propre à amollir les cœurs».

Le vin, parce qu'il est une boisson chère et parce que sa consommation dans l'Antiquité nécessitait une préparation et des accessoires propres, se prêtait naturellement à engendrer un véritable rituel. Celui-ci a trouvé une place évidente dans les rites de commensalité aristocratiques, si bien décrits par Poseidonios (chez Athénée, IV, 15le-152d). Contre toute attente, il semble que ces véritables cérémonies, bien qu'éphémères et n'exigeant pas de lourds aménagements, se soient déroulées souvent dans un cadre qui a laissé des témoignages archéologiques. Ces recherches, conduites sur l'ensemble du territoire de la Gaule essentiellement par M. Poux, se trouvent encore dans une phase exploratoire, mais dès maintenant se dégagent deux ensembles de sites qui témoignent de ces pratiques (Poux, 2000a). Le premier est représenté par des espaces clos qui semblent n'avoir connu que cette activité. Le second comprend des espaces également clos mais situés dans des ensembles plus complexes, domaine agricole généralement.

Dans notre région il n'existe actuellement qu'un représentant typique du premier ensemble, il s'agit de Balloy (inédit). C'est un petit enclos, de plan carré, de $16 \mathrm{~m}$ de côté. Une entrée de $2 \mathrm{~m}$ de largeur s'ouvre à l'est. Le fossé, probablement demeuré ouvert, de 1 à $2 \mathrm{~m}$ de largeur pour $80 \mathrm{~cm}$ de profondeur environ, paraît n'avoir connu qu'une fonction symbolique de clôture. L'espace intérieur était vide de toute structure et le matériel découvert provient du fossé. Ce sont quasi exclusivement des tessons d'amphores, plus de $140 \mathrm{~kg}$ provenant d'au moins 15 amphores, soit l'équi-

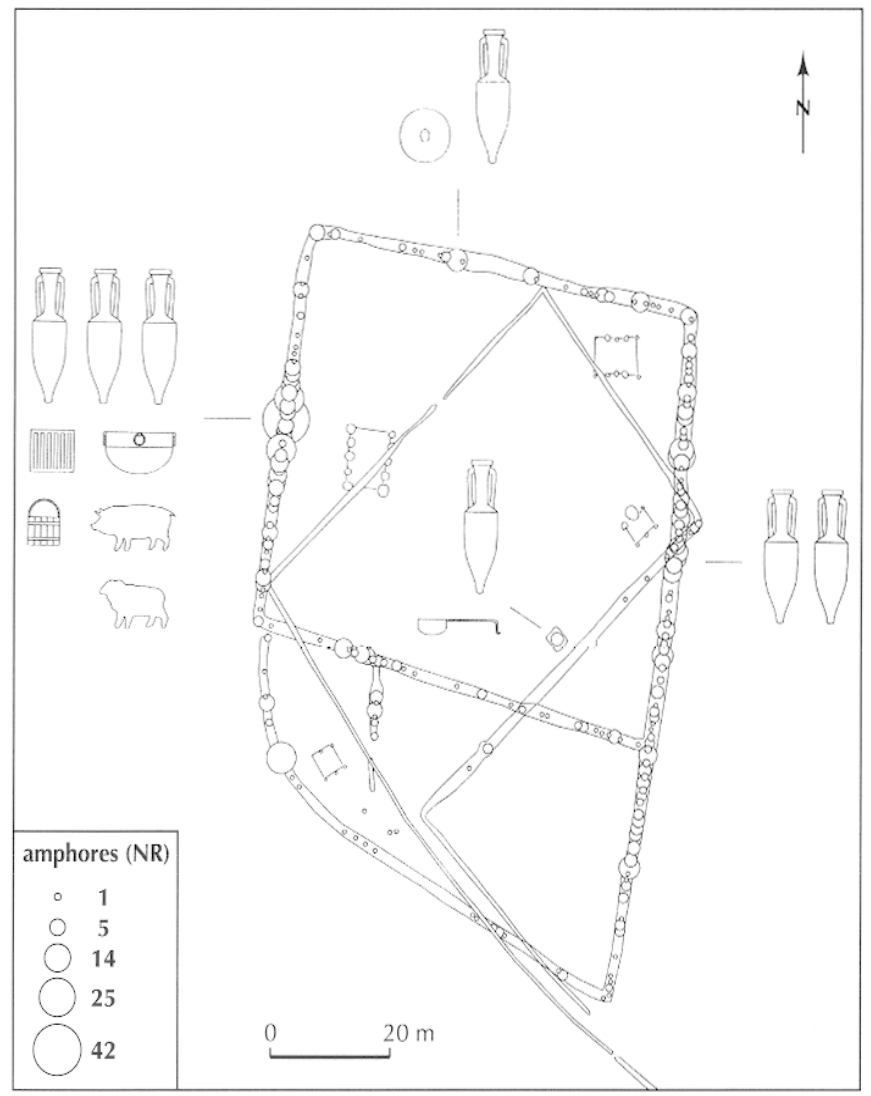

Fig. 25 - Braine (Aisne), La Grange des Moines. Enclos avec schématisation des principaux types de matériel rencontrés (d'après Poux, 2000b).

valent de près de 3001 de vin. À l'aménagement exceptionnel correspond un traitement de ces amphores qui n'est pas moins étonnant. Elles ont été volontairement brisées, souvent semble-t-il avec une lame d'épée. Une partie a été brûlée dans un feu très violent. Enfin le tout a été laissé à l'air libre pendant une période assez longue, suffisante en tout cas pour éroder visiblement leur surface.

Le second ensemble est représenté par des sites plus nombreux mais moins instructifs, à cause de la multiplicité d'activités qu'ils ont accueillies et qui brouillent la vision que l'on peut avoir de la commensalité proprement dite. Elle est présente sur les fermes de type aristocratique de Montmartin et de Montiers (inédit) et surtout sur celle de Braine (Auxiette et al., 2000), où les vestiges paraissent plus parlants. Là, sur une vaste zone d'habitat, deux enclos quadrangulaires successifs, d'environ $1 / 2$ ha de superficie, témoignent d'une pratique rituelle de consommation du vin dans un cadre où le caractère aristocratique se traduisait par la consommation de grands animaux et l'utilisation d'objets de luxe (simpulum, grill, chaudron, fourchette à viande) et d'armes. L'enclos le plus ancien, daté de la fin du II $^{\mathrm{e}} \mathrm{s}$. 
avant J.-C., comprend deux bâtiments d'habitation (fig. 25). Il s'agit peut-être de la demeure aristocratique proprement dite avec sa cour où se déroulaient des festins soit familiaux, soit édilitaires. Le second enclos, daté des années - 80, est édifié sur le même emplacement mais avec une orientation différente. Il semble ne pas contenir de bâtiments domestiques mais dans un angle se trouve une petite structure construite au-dessus d'une curieuse fosse quadrangulaire dont les parois étaient empierrées et bloquaient quatre petits poteaux qui supportaient vraisemblablement un plancher. Cet enclos, entièrement palissadé à la différence du précédent, a pu n'avoir pour fonction que d'abriter des festins.

Les pratiques que révèlent ces différents sites ont été interprétées par leurs fouilleurs comme "cultuelles». Le qualificatif ne va pas sans poser de problème. Il n'est pas seulement trop général, il introduit une double confusion entre rites et pratiques cultuelles d'une part, entre culte celtique et phénomènes d'acculturation d'autre part. Si l'on a bien affaire ici à de véritables rites qui se déroulent la plupart du temps dans un cadre qui leur est approprié, on ne saurait pour autant parler de culte, le mot n'étant adapté qu'aux dévotions rendues à une divinité, forcément présente sur le lieu. Il est donc moins question de religion que d'un rituel profane trahissant une double acculturation : un produit et des instruments provenant du monde romain sont mis en scène dans des gestes issus de la sphère religieuse. Il n'est dès lors pas étonnant de constater que ces faits n'apparaissent qu'à la fin du $\mathrm{II}^{\mathrm{c}} \mathrm{s}$. et au cours du $\mathrm{I}^{\mathrm{er}} \mathrm{s}$. avant J.-C., une époque où le pouvoir religieux décline au profit du pouvoir oligarchique.

\section{OFFRANDES}

L'introduction en Gaule d'objets aussi emblématiques que les figurines ou les monnaies romaines s'est accompagnée du dévcloppement d'une pratique cultuclle quasi inexistante en Gaule du Nord à l'âge du Fer, l'offrande. Celle-ci, nous l'avons vu, ne connaissait qu'une forme bien particulière, celle d'armes dont l'utilisation cultuelle est plus assimilable aux anathemata de Grèce qu'au simple don. $\mathrm{Au} \mathrm{I}^{\mathrm{er}}$ s. avant J.-C., l'offrande d'un objet plus ou moins précieux (une figurine de terre cuite, une monnaie, une fibule peut-être) présentait l'immense avantage de permettre une pratique, individuelle et ouverte à des couches plus larges de la population, dans l'enceinte même des sanctuaires. Auparavant les principales activités cultuelles étaient toujours de nature collective. Mais surtout elles ne s'exerçaient que par l'intermédiaire de prêtres, représentants directs de la noblesse. Même si, selon toute probabilité, les premières offrandes ne furent réalisables que par l'intercession du prêtre qui seul pouvait accéder à la divinité, elles permettaient un contact plus direct, plus personnalisé en tout cas, entre l'individu et le dieu qu'il honorait.

À quel moment ces objets commencent-ils à apparaître dans les sanctuaires? Il est actuellement difficile de le dire parce que l'essentiel du matériel découvert provient de structures creuses (fossés de clôture souvent), dont il constitue presque toujours une couche de rebouchage tardive. Chez les peuples du Belgium, là où les sanctuaires sont les plus nombreux et ont été le plus exhaustivement fouillés, on ne les rencontre jamais avant la conquête césarienne. En revanche, ils abondent à partir des années - 40 . Leur introduction semble donc massive et avoir connu un large succès populaire. Mais il n'est pas exclu que le rite de l'offrande ait pu être pratiqué plus tôt chez les peuples de l'est, plus ouverts au commerce. Seule une meilleure connaissance de la chronologie et des conditions de dépôt permettra l'étude du fonctionnement de ce rite et de son évolution.

\section{PREMIERS TEMPLES ET PREMIÈRES REPRÉSENTATIONS DIVINES}

Le temple, au sens méditerranéen, est intrinsèquement lié à la représentation divine. Dans les régions du Nord de la Gaule, celui-ci comme le rite de l'offrande n'apparaissent que tardivement, en tout cas après la conquête. Les premiers révèlent une profonde influence italique dont il est encore difficile d'imaginer les modes de transmission. Pendant la période augustéenne, l'acculturation de l'architecture des sanctuaires a été très forte et, faute d'exemples bien datés et, d'une façon plus générale, bien documentés, il est difficile de faire la part de l'indigène et du modèle italique. Il semble cependant qu'on ait surestimé la part proprement gauloise, à la faveur d'a priori trop enracinés, tel celui de la circumambulation, considérée comme un rite gaulois et qui aurait conditionné le plan du temple à galerie périphérique (pour traduire l'appellation germanique de Umgangstempel bien préférable à celle de fanum). La circumambulation, largement répandue dans le monde, n'est nullement propre aux Gaulois et on ne saurait affirmer que chez eux elle ait été généralisée. C'est certainement vouloir trop faire dire aux deux seuls textes qui pourraient l'évoquer, celui de Strabon (Géographie, IV, 4, 6) qui décrit une pratique visiblement extatique en l'honneur d'un dieu assimilé à Dionysos, et celui d'Athénée (IV, 15ld-152e) indiquant que les Gaulois honoraient leurs dieux en tournant (sur eux-mêmes peut-être, ainsi que le faisaient les Romains) vers la droite. Quoi qu'il en soit, comme vient de 


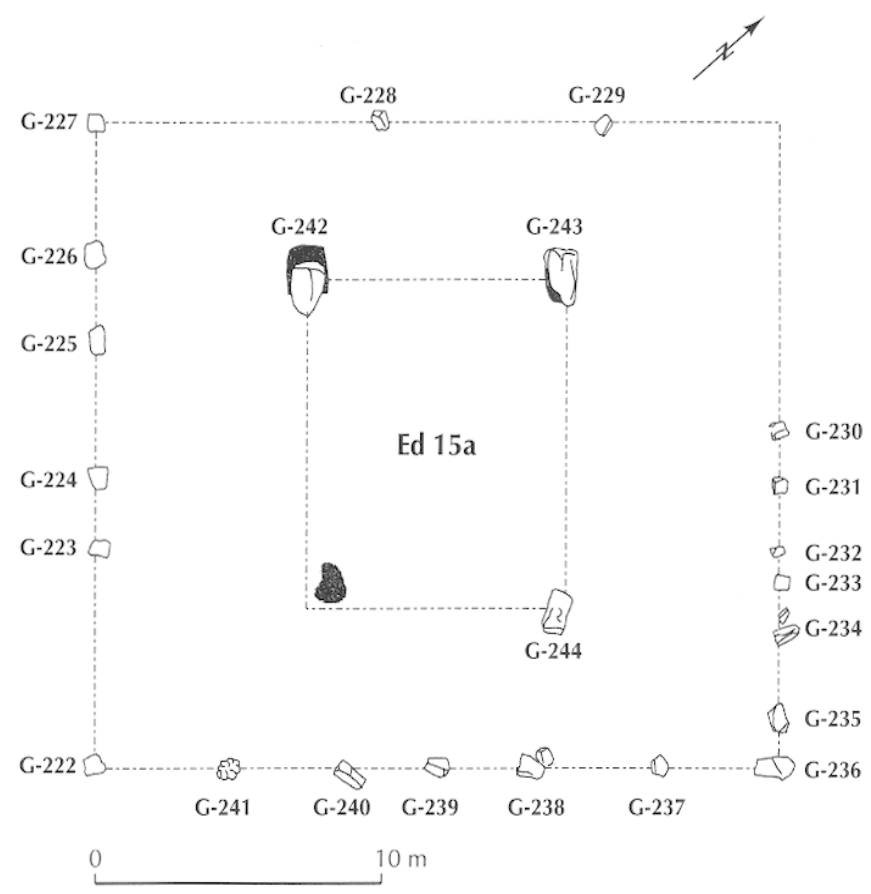

Fig. 26 - Ribemont-sur-Ancre (Somme), Le Champ Crezette. Plan du premier temple de lépoque romaine

(G. Fercoq du Leslay, Centre archéologique de Ribemont).

le montrer récemment W. Van Andringa, il semble bien que la galerie répondait à une autre fonction, celle d'abriter les imagines (Van Andringa, 2000).

Le seul temple de conception méditerranéenne qui soit bien daté se révèle pourtant étonnamment précoce. C'est celui de Ribemont dont le premier état doit être placé aux environs de 30 avant J.-C. (Brunaux dir., 1999). Son plan est celui d'un rectangle très proche du carré : $15 \mathrm{~m} \mathrm{x} 13 \mathrm{~m}$ (fig. 26). Ses parois sont matérialisées par une série de blocs de grès, découpés dans les stèles provenant de l'enclos circulaire gaulois qui ont servi de support et d'isolant à des murs en pans de bois. Au centre, quatre blocs de grès, plus volumineux (des stèles entières), dessinent un rectangle de $6,50 \mathrm{~m} \times 6 \mathrm{~m}$; il pourrait s'agir de l'emprise d'une cella. Le plancher de celle-ci se trouvait à un niveau supérieur à celui de ce qui pourrait être la galerie périphérique, il reposait donc sur un vide sanitaire qui a été conservé et qui se révèle surtout dans la phase suivante où il repose sur une série de sablières parallèles supportant des potelets, comme dans les horrea des camps militaires. L'emploi de blocs de grès dans la construction et les techniques employées n'ont évidemment rien d'indigène et sont probablement l'œuvre d'un architecte militaire qui accompagnait les militaires auxiliaires, auteurs de cette construction. Tous les niveaux contemporains dc cc tcmplc ont, en effet, livré un assez abondant matériel militaire, de type mixte, romain et ambien. À ce temple est associé un enclos sacré matérialisé par une palissade. L'autel devait se trouver devant la façade du temple, à $4 \mathrm{~m}$ de distance sur l'axe de symétrie de celui-ci.

Dans ce cas précis, on voit bien que le temple ne doit apparemment rien aux traditions indigènes. Pourtant ce n'est pas une création purement romaine, il est l'œuvre d'Ambiens qui ont côtoyé les Romains pendant plusieurs années et qui ont décidé d'adopter sinon leur religion du moins l'expression de celle-ci. L'exemple de Ribemont permet de mieux comprendre et de situer à sa juste place celui du premier temple (fig. 27) de Gournay (Brunaux, Méniel, Poplin, 1985). On avait pu croire un temps, en effet, que cet édifice était révélateur d'une transition sans heurt entre l'autel couvert laténien et le temple à galerie galloromain. En fait il n'en est rien, il s'agit d'un exemple hybride, peut-être unique, conciliant une nouvelle architecture de type romain à un fonctionnement cultuel, partiellement de tradition gauloise. La technique de construction (parois en pans de bois reposant sur des murs-bahuts), l'apparence extérieure (colonnade de bois en façade) sont d'inspiration romaine. Seul l'emplacement de l'autel (foyer installé sur l'ancien autel creux comblé) à l'intérieur du bâtiment témoigne du fonds indigène.

Ces deux exemples nous donnent une bonne idée des solutions diverses qui ont pu être adoptées sur chaque lieu de culte. Les formules architecturales ont pu souvent garder peu ou prou des techniques de construction gauloises antérieures. Mais ce qui fut un profond facteur de transformation, ce fut le changement du mode sacrificiel. C'est le culte de type chthonien qui imposait l'utilisation d'une fosse creuse associée à un foyer et le recours à la mise à mort de mammifères souvent de grande taille, tel que le bœuf. Or, dès les premières années de l'occupation romaine, ce type de sacrifice lourd, impliquant chaque fois une communauté plus ou moins vaste n'hésitant pas à sacrifier littéralement une part non négligeable de son cheptel, tombe en désuétude, au moins en milieu indigène, pour être réservé plus exclusivement aux premières formes de culte public de type romain. Les pratiques deviennent plus individuelles et plus diversifiées. L'autel, sous la forme d'un foyer, souvent surélevé, se prête mieux aux nouveaux modes de dévotion.

Les rites où l'individu trouve une liberté d'action plus grande sont rendus possibles par les premières représentations divines que chaque croyant pouvait probablement voir (lors de certaines fêtes par exemple). Ces représentations sont intimement liées, comme on l'a vu, à la nouvelle conception du temple et aux nouveaux rites qui se font jour. On doit donc penser que les unes et les autres se sont épanouies pendant les troisième et quatrième quarts du $\mathrm{I}^{\mathrm{er}} \mathrm{s}$. 


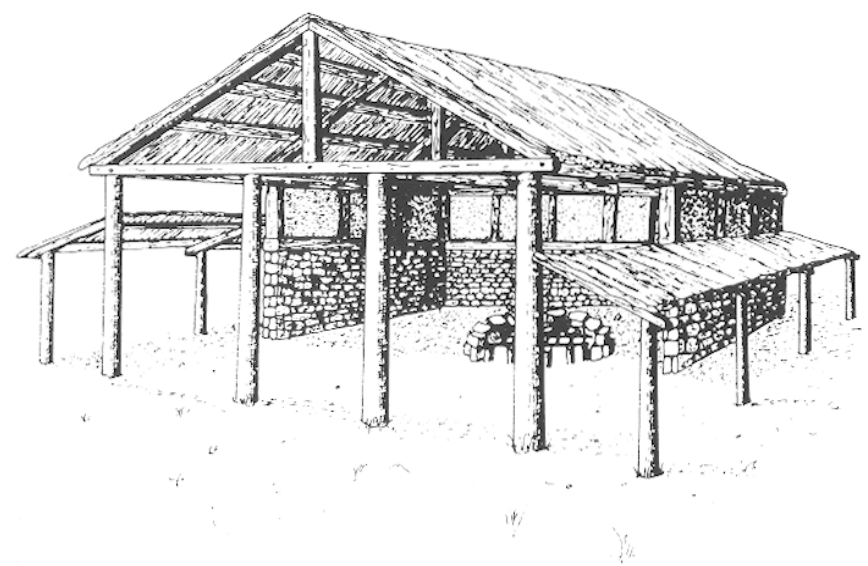

Fig. 27 - Gournay-sur-Aronde (Oise), Le Parc. Hypothèse de reconstitution du premier temple romain (d'après Brunaux, Méniel, Poplin, 1985).

avant J.-C. Il est souvent mal aisé de différencier les statues divines de simples représentations humaines, les attributs divins n'apparaissant qu'assez tardivement. Il est tout aussi difficile de dater ces objets. L'une des seules représentations divines précoces semble être la statue du dieu dit de SaintMaur, découverte sur le sanctuaire même et qui semble représenter l'équivalent de Mars. Elle pourrait dater du dernier quart du $\mathrm{I}^{\mathrm{cr}} \mathrm{s}$. avant $\mathrm{J}$.C.

\section{NOUVEAUX RITES ET NOUVELLES FONCTIONS DU SANCTUAIRE}

La forme nouvelle qu'adoptent les sanctuaires dans les premiers temps de la romanisation s'accompagne de nouveaux rites et de nouvelles activités. Ce sont ceux qui viennent d'être évoqués, l'offrande individuelle, le sacrifice d'animaux (notamment volailles), offerts par des personnes privées ou des familles, des formes de commensalité plus larges où le vin joue un rôle important.

L'usage des monnaies dans le sanctuaire est également attribuable à l'influence romaine. Celles-ci n'ont, en effet, jamais été découvertes en situation d'offrandes véritables dans des niveaux antérieurs à la guerre des Gaules. Il semble - mais cela reste à préciser - que les militaires romains et surtout les auxiliaires aient joué le plus grand rôle dans l'introduction de ces nouvelles pratiques. On sait par Arrien
(La chasse, 34) que les monnaies pouvaient entrer dans des petits trésors destinés à payer de grands sacrifices annuels dans le cadre de certaines corporations (en l'occurrence les chasseurs). Elles pouvaient constituer des ottrandes individuelles, voire des oboles, destinées à l'entretien du prêtre, comme cela existe dans de nombreuses religions. Malheureusement, rares sont les découvertes qui permettent de comprendre les usages qui étaient faits de ces pièces dans les lieux de culte. Le seul document intéressant à ce sujet est livré par le sanctuaire de Saint-Maur (Delestrée, 1996, p. 65). Deux fosses situées de part et d'autre de l'entrée du temple ont livré un nombre similaire de monnaies, avec chaque fois un nombre égal de représentants des différents types. On a donc ici la preuve d'un dépôt systématique de nombres de pièces égaux dans chaque fosse. Ce dernier constituait, à n'en pas douter, un authentique rite de passage.

Dans le Belgium, pendant la seconde moitié du $\mathrm{I}^{\mathrm{er}} \mathrm{s}$. avant J.-C., les monnaies dans les sanctuaires occupent une place quasi envahissante. Ce sont de très loin les objets les plus abondants, souvent par milliers, quelquefois par dizaines de milliers (sanctuaire de Morvillers-SaintSaturnin). Les recherches numismatiques conduites par L.-P. Delestrée ont montré que certains sanctuaires « étaient numismatiquement actifs ", autrement dit qu'un atelier monétaire se trouvait dans l'emprise même du sanctuaire (Dclcstrćc, 1996). C'est le cas à Morvillers-Saint-Saturnin, Eu (Delestrée, 1996), Fesques, Dompierre-sur-Authie (Piton, Dilly, 1990), Chilly, Saint-Maur et Estrées-Saint-Denis (Woimant, 1991). De quelle nature était la relation entre lieu de culte et atelier monétaire ? Le premier exerçait-il un rôle de caution et de contrôle ? Est-ce l'usage de l'offrande monétaire qui a engendré l'installation émettrice ? Il est pour l'instant impossible de répondre à ces questions, tant que les fouilles n'auront pas livré une documentation plus évocatrice.

Ces innovations dans les pratiques cultuelles montrent en tout cas que le sanctuaire joue désormais un rôle nouveau dans lá société gauloise. Il n'est plus l'image même d'une hiérarchie très forte qui donne l'accès au culte aux seules classes élevées de la société et exclut les autres. Au contraire, il devient un lieu d'unification sociale et de reconnaissance de l'individualité civique. Son expression populaire est certainement la caractéristique la plus forte de la religion gauloise à l'époque romaine. 


\section{NOTICES}

\section{NOTICE 1}

\section{ACY-ROMANCE (ARDENNES)}

\section{LA WARDE}

Au terme de la fouille du village gaulois de La Warde et des nécropoles contemporaines, les aspects cultuels reconnus sont divers et variés. Lors de l'installation, vers 180 avant J.-C., la religion conditionne l'organisation spatiale du village sur les 16 ha bâtis. L'abandon de l'habitat cst complet ct définitif vers 30-40 de notre ère. La variété des structures cultuelles, isolées ou groupées, et la diversité des rites imposent une présentation individuelle par type de manifestation religieuse.

\section{La place communautaire et cultuelle}

Cette vaste place de $3500 \mathrm{~m}^{2}$ occupe le sommet du plateau, au centre de l'habitat (fig. 28, place). Elle est délimitée par un fossé palissadé à l'origine, dont le tracé en forme de $\mathrm{D}$ épouse à l'est la dernière courbe de niveau. Le grand côté ouest rectiligne mesure $85 \mathrm{~m}$ de longueur et sa plus grande largeur est de $56,50 \mathrm{~m}$. L'entrée était aménagée sur le petit côté sud de 24,50 m de longueur. Un chemin d'accès bordé d'une palissade pénètre de $10 \mathrm{~m}$ à l'intérieur de la place. La récupération des bois de la palissade a laissé des dépressions qui ont piégé principalement des os animaux. Le bœuf avec $70 \%$ du nombre de restes et le cheval avec $18 \%$ représentent l'essentiel de ces os, le reste étant composé de porc, mouton, chevreuil et de quelques éléments humains cantonnés dans le secteur nord. Le bœuf se trouve principalement dans la partie sud de la place, le cheval dans la partie nord. Cette bipartition indique clairement que la place a vu l'abattage et la découpe de ces animaux dans des secteurs leur étant réservés. On ne peut évoquer l'existence de banquets ou de festins dans cette enceinte, la représentativité des espèces et le spectre des os étant fort différents de ceux des sanctuaires où se sont tenus de tels repas, mais plus certainement des abattages ritualisés.

\section{Les bâtiments cultuels}

Parallèlement au côté ouest de la place ont été élevées cinq constructions à angles coupés (fig. 28, temples et puits). Leurs dimensions, de la plus petite au sud $(6 \mathrm{~m}$ de long) à la plus imposante au nord (11 m de long), et leurs espacements augmentent régulièrement dans la même progression. La distance entre ces constructions passe de $17,50 \mathrm{~m}$ à $27,50 \mathrm{~m}$ d'axe en axe, ce qui correspond à un coefficient multiplicateur de 1,25. Cette géométrie parfaite répond à un plan préconçu mettant en œuvre des connaissances arithmétiques et un tracé préalable au sol. La hauteur de ces structures devait répondre aux mêmes normes et l'ensemble peut s'apparenter à une anamorphose, la perspective étant gommée dans le sens sud-nord et, au contraire, augmentée dans le sens inverse. Il ne fait aucun doutc que cet ensemble devait être spectaculaire et de nature à frapper le visiteur. Deux bâtiments annexes jouxtaient les constructions à angles coupés au sud et au nord et un autre s'élevait précisément au milieu de l'alignement, parfaitement dans l'axe de la place. Ces dispositions renforcent la symétrie déjà remarquable de l'ensemble.

Le plus grand de ces bâtiments, à l'extrémité nord, d'une superficie de $110 \mathrm{~m}^{2}$ abrite un puits carré de 7,60 m de profondeur. Sa réalisation soignée et ses divers aménagements témoignent qu'il ne s'agit en aucun cas d'un puits avorté (nappe phréatique à $60 \mathrm{~m}$ ). Une margelle en bois s'élevait hors sol et deux poutres reposaient sur des ressauts à $2 \mathrm{~m}$ du fond. Ce puits a été comblé volontairement avec les matériaux d'extraction, un siècle environ après son creusement. Le mobilier découvert dans ce comblement est rare et correspond à des balayages de sol sur lequel se trouvaient quelques os rongés par les chiens.

\section{Les inhumés recroquevillés}

Seize individus ont été inhumés dans de petites fosses circulaires devant le grand bâtiment appelé «temple". Deux autres inhumations ont été installées dans l'axe des voies de circulation longeant la place et une autre dans l'axe du puits et de l'entrée du bâtiment. Ces défunts sont enterrés en position assise, la tête entre les jambes, celle-ci reposant sur les pieds. L'étude anthropologique conclut, pour les ensembles anatomiques suffisamment bien conservés, qu'il s'agit essentiellement de jeunes adultes masculins. Les corps avaient dû être desséchés, momifiés naturellement, ce qui explique leur faible encombrement vertical. La prise en compte du contexte environnemental, l'étude minutieuse des squelettes et des anomalies des relations anatomiques ont conduit à décrire un cheminement de ces défunts passant par un séjour dans le puits. Après une mise ä mort ritualisëe, le corps du jeune homme était placé dans une caisse de bois et descendu dans le puits 


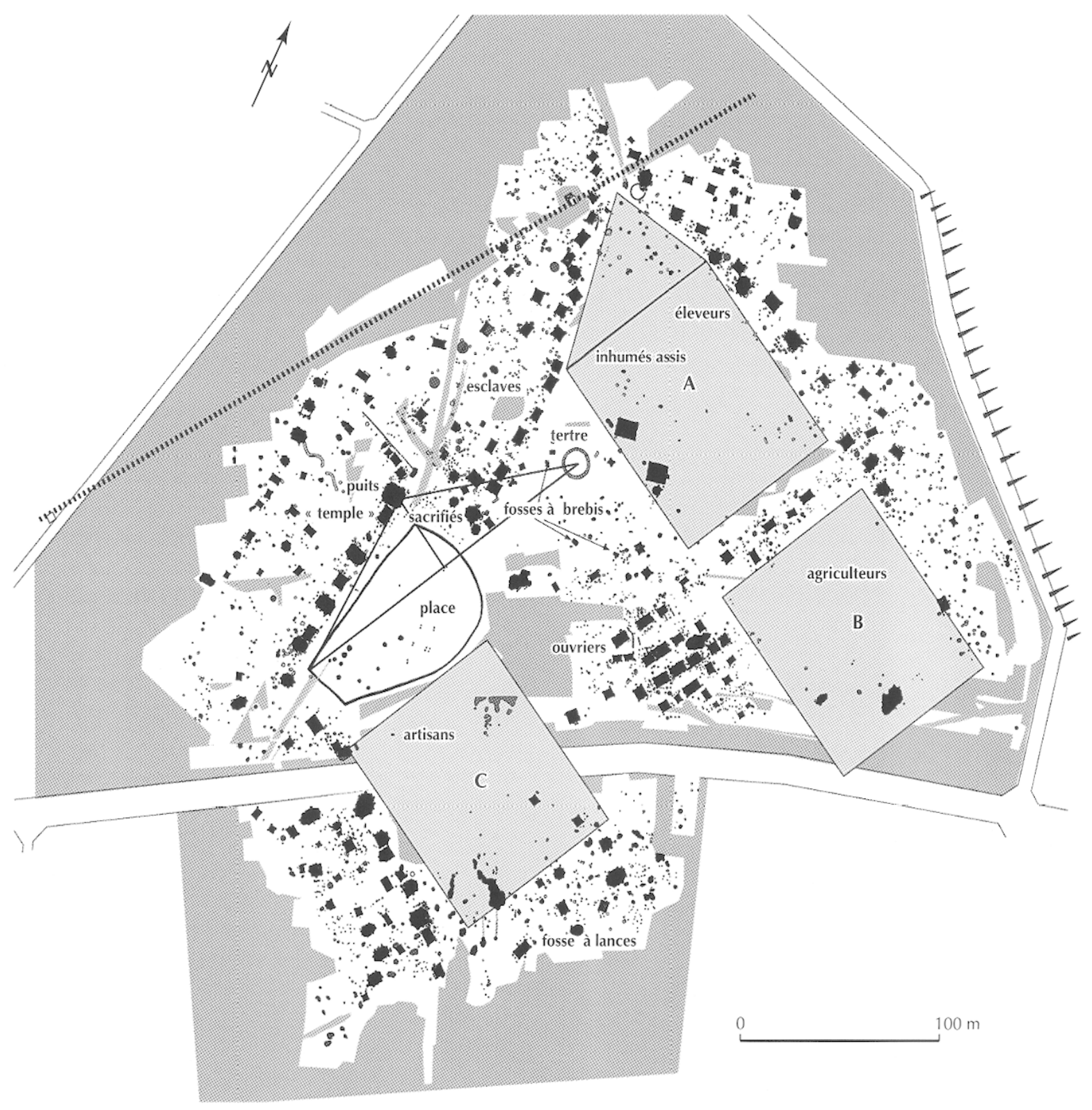

Fig. 28 - Acy-Romance (Ardennes), La Warde. Plan du village, état 2001. Identification des cours et des structures cultuelles. Tracé géométrique de l'installation du centre communautaire et cultuel prenant comme point de référence le tertre de l'âge du Bronze (dessin B. Lambot).

où il séjournait un temps suffisant à la dessiccation naturelle des tissus. Il était ensuite remonté, probablement mis à sécher complètement dans un endroit venté, avant d'être enfin enterré sur l'esplanade. Cette pratique ne pouvait se faire que pendant la saison froide pour des raisons évidentes de blocage du processus de putréfaction.

Un autre jeune homme, inhumé le long de la paroi nord d'un bâtiment proche, illustre probablcment la séquence de la mise à mort. Il est enterré allongé, légèrement sur le côté gauche, les poignets croisés dénonçant la ligature des mains dans le dos. Il est mort d'un coup de hache porté sur le temporal droit. La fosse funéraire empiète légèrement sur un silo en partie comblé et les faits sont datés par une fibule du type de Nauheim et une monnaie en potin, du début du $\mathrm{I}^{\mathrm{er}}$ s. avant J.-C.

\section{Les défunts assis}

Dans la plus vaste cour identifiée comme étant celle des éleveurs (fig. 28, A), au nord-est, trois individus ont été 
enterrés assis, jambes croisées, face au soleil levant. Ils ont également été momifiés naturellement, puis ont été installés dans des fosses de forme carrée de moins de $1 \mathrm{~m}$ de côté. Ce "séchage " a probablement eu lieu dans un espace proche comptant un bâtiment rectangulaire à parois de poteaux, une enceinte quadrangulaire palissadée et un petit bâtiment à angles coupés. Au cours de cette exposition, l'un des défunts a perdu le bras droit. Tout comme les autres sacrifiés, ces personnages étaient probablement nus. Aucun objet métallique n'a été retrouvé et aucun viatique impérissable, si minime soit-il, ne les accompagnait. Il est impossible de dire s'il s'agit là aussi de sacrifiés ou de décès naturels. Le seul dont l'âge a pu être estimé est un adulte mature.

\section{Les fosses à moutons}

Quatre fosses rectangulaires, plus ou moins bien conservées, ont servi de réceptacles à des quartiers de moutons (fig. 28, fosses à brebis). La plus remarquable a reçu des gigots, épaules et grils costaux d'une cinquantaine de brebis, mais au total cent cinquante bêtes sont représentées par des os de pieds. Il s'agit essentiellement de brebis âgées de trois ans environ qui étaient gravides comme le montre les fœtus retrouvés. Ces derniers, de onze semaincs en moyenne, permettent de situer l'abattage de ces animaux à la fin du mois de décembre ou au début de janvier. L'imbrication des os et des fœutus révèle qu'il s'agit à chaque fois d'abattages massifs, véritables hécatombes effectuées à proximité des fosses. La quantité et la qualité des morceaux déposés excluent un banal rejet de surplus qui serait de toute façon incompréhensible chez des populations comptables de leurs ressources carnées et de la survie de leurs troupeaux. Il ne peut s'agir non plus d'une épidémie, d'un carnage provoqué par des loups ou d'un événement catastrophique inconnu en raison de l'homogénéité des caractères de tous les individus. Le choix et le nombre des animaux, des brebis gravides, impliquent l'existence d'un troupeau local fort de plusieurs centaines de têtes, environ 800 , pour rester viable, ou des apports extérieurs répondant à des critères précis. La masse de viande ainsi disponible évoque la tenue de festins dont une part, minime malgré les apparences, est consacrée aux dieux. Contrairement aux restes de la place centrale ne figurent ici aucune tête ni vertèbre cervicale. Comme ces restes n'ont pas été retrouvés dans les silos, on peut penser qu'ils ont été également abandonnés à même le sol ou accrochés en trophées comme les crânes de boufs. Les quelques objets recueillis dans le comblement de ces fosses permettent de dater l'enfouissement à une période comprise entre 80 et 50 avant J.-C.

\section{Des lances miniatures en ex voto}

La fosse conique (fig. 28, fosse à lances) résultant du tassement du comblement d'un puits a servi de réceptacle à environ 1600 lances miniatures. La fouille a été interrompue à $7,20 \mathrm{~m}$ et une sonde descend $6 \mathrm{~m}$ plus bas sans rencontrer d'obstacle. Les documents connexes les plus récents sont quelques fragments de céramiques galloromaines et notamment de petites cruches en terre blanche de Reims datées du début du I ${ }^{\mathrm{cr}}$ s. de notre ère. La base des rejets contient un certain nombre de monnaies du type au personnage courant avec lance et torque (La Tour 8124), des fibules du type de Nauheim, des fragments de bracelets en verre à section en $\mathrm{D}$, faisant remonter les premiers rejets au début du $\mathrm{I}^{\mathrm{er}} \mathrm{s}$. avant J.-C., probablement vers - 80. Le comblement inférieur très foisonnant, sur $5 \mathrm{~m}$, est essentiellement détritique et semblable à ce qui est connu dans les silos. L'abondant mobilier céramique est datable dans son ensemble de La Tène D1.

Il n'y a aucune normalisation de ces petits objets et une classification typologique est illusoire dans la mesure où ils sont aussi divers que nombreux (fig. 29). En revanche un classement technologique peut être envisagé et les premiers examens montrent que deux " mains " de forgerons pour des séries réalistes peuvent être reconnues. Le support utilisé est très variable et va de la petite barre métallique à la simple tôle repliée, à la réutilisation de fragments d'armes ou encore à des morceaux de bracelets en tôle de bronze simplement martelée. Il y a aussi toute une gradation dans la volonté de représenter de façon réaliste un fer de lance. Du simple cône de $15 \mathrm{~mm}$ à la copie crédible de $15 \mathrm{~cm}$ il y a une multitude de réalisations plus ou moins sommaires. Les fers de lance réels ne sont pas absents. Ils ont tous été mutilés par découpage des ailettes, par martelage ou bien encore par sectionnement de la flamme à sa base. Rares sont les fragments d'autres armes réelles, difficilement reconnaissables, comme des morceaux de fourreaux ou d'ailes d'umbo, mais il y a lieu de signaler la présence d'une bouterolle en bronze de fourreau d'épée, cassée en deux. D'autres objets ont souffert de cette mutilation rituelle comme une fibule en bronze de type de Nauheim, à l'arc plié et ressort cassé. À noter aussi parmi le mobilier d'accompagnement un dolium balancé rempli d'ex voto, des fragments d'amphores et plusieurs fragments de passoires en terre cuite.

Des vases miniatures, une trentaine environ, se trouvaient mêlés à ces lances. De fabrication assez grossière, ils sont tous de même type et imitent plus ou moins fidèlement les grands vases à liquide à profil en $\mathrm{S}$. Des restes minéralisés de bois, des charnières, de petits clous et de nombreuses agrafes proviennent de coffres ou coffrets et certainement de supports. 


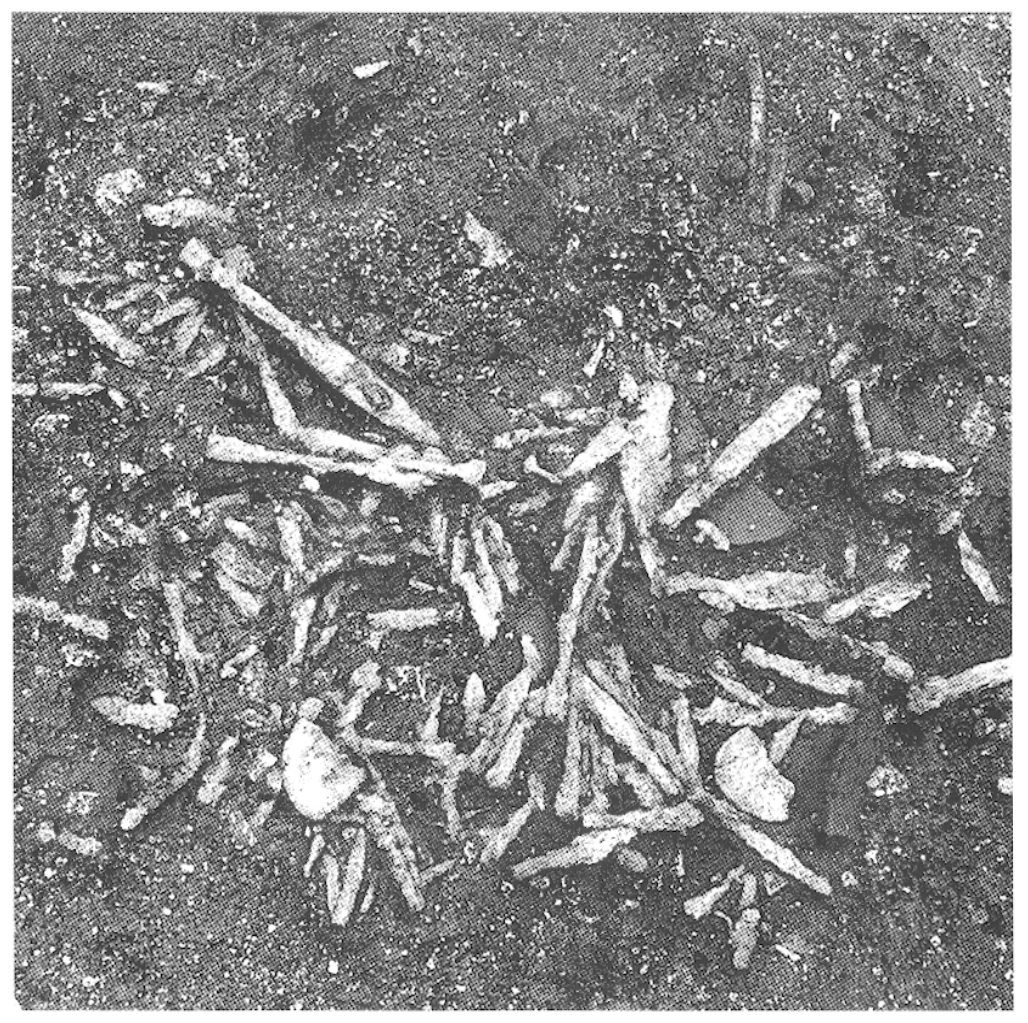

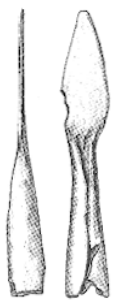

1775

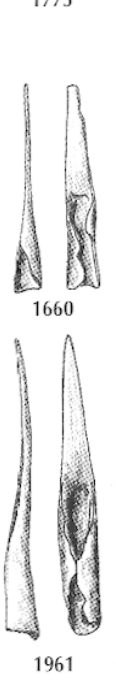

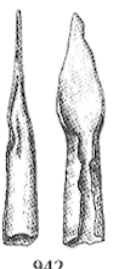

942

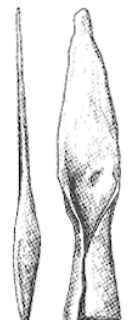

735
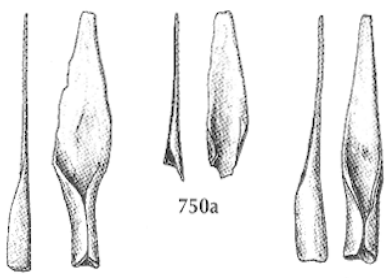

939

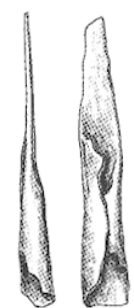

1473

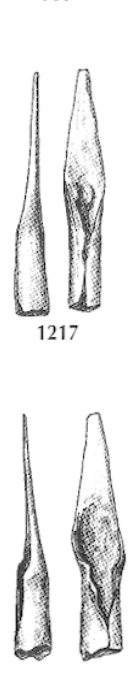

790

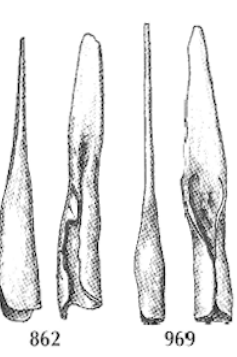

Fig. 29 - Acy-Romance (Ardennes), La Warde. Lances réelles et miniatures jetées dans le cône de tassement du comblement d'un puits ; dessins représentatifs des lances réelles et miniatures (photo et dessin B. Lambot).

\section{Une statue de divinité ?}

La seule sculpture connue sur le site est tardive. Elle provient du quartier des forgerons-dinandiers. Il s'agit d'un buste de personnage portant un vêtement plissé en $V$ sur la poitrine et aux cheveux coiffés ou couverts d'une résille. Le bloc de calcaire oolithique, d'une trentaine de centimètres de hauteur, est taillé en forme de ciste et deux tenons ont été réservés de chaque côté, la base est rainurée. La technique est assez fruste et s'apparente aux sculptures indigènes découvertes sur certains sanctuaires romains, à Verneuil-en-Halatte (Oise) par exemple, ou aux sources de la Seine. Cette sculpture s'enchâssait dans un support que l'on peut présumer de bois (poteau, socle ou même dans un arbre). Quelques fragments de tuiles sont, peut-être, les restes d'un petit édicule. Aucune fonction ne peut être proposée pour la perforation de $8 \mathrm{~mm}$ qui la traverse de part en part en diagonale et affleure la surface à hauteur de l'oreille gauche.

\section{Les restes humains de l'habitat}

Aux inhumés particuliers s'ajoutent plus de quatre-vingts os humains ou fragments découverts dans des structures variées, mais surtout dans des silos. Leur étude n'en est qu'au stade de l'ébauche mais il est clair qu'une grande partie de ces restes n'est pas " errante ». Les os du crâne et ceux des membres sont les mieux représentés. Sur les restes humains d'Acy-Romance les traces de découpe et de coups violents sont fréquentes mais aussi les traces de carbonisation, les stigmates d'ingestion et de rongements par les chiens. Si certains proviennent probablement de corps abandonnés à l'air libre, il n'en est pas de même pour ceux découpés ou fracturés comme ce frontal brisé, au-dessus des orbites, en forme de coupe. Il y a aussi ce coxal humain placé entre la tête et les pieds d'un inhumé "roulé en boule ", situation qui ne peut être anodine. Il en est de même d'un autre coxal trouvé dans une petite fosse, à quelques mètres de ces inhumés et du grand temple. Des fragments humains proviennent du fossé palissadé de ce secteur.

Dans cet espace il y a eu de toute évidence des manipulations de corps humains, ne seraient-ce que les inhumés placés sur l'esplanade, mais il est impossible de savoir quel rapport il y a entre eux. Les traces de découpe impliquent des traitements spćcifiqucs trc̀s scmblables à ce qui a été observé sur les sanctuaires. Certains os ou fragments sont 
dans un tel état de fraîcheur qu'il est évident qu'ils n'ont pas été exposés aux intempérics. Comme les restes de boufs et de chevaux de la place, c'est une infime partie des ossements humains présents sur l'habitat qui nous est parvenue.

\section{Des services à boisson pour le rituel domestique?}

Dans un certain nombre de silos, datés de La Tène C2 et Dla, se remarquent régulièrement trois vases bien particuliers par leur réalisation au tour, leur pâte claire, leur décor ondé et les restes de peinture lie-de-vin. Le premier est un vase à liquide, à piédouche et ressauts sur le haut de la panse. Le deuxième est une petite écuelle à paroi verticale et le troisième est une petite coupe à bord rentrant, type unique sur le site pour ces périodes. La répétition de cet assemblage est telle qu'elle correspond à une nécessité dans le cadre domestique. Il s'agit sans ambiguité d'un service à boisson. L'hypothèse d'une consommation ritualisée de certaines boissons au sein de familles relativement modestes est assez attrayante. Ces vases, luxueux en comparaison du reste du vaisselier, ne sont connus que chez les agriculteurs, aucune structure excavée importante, type silo ou cave, n'existant dans les autres catégories sociales. On peut penser que les vases à liquides étaient remplacés chez. les gens aisés par des seaux et des amphores, à partir de La Tène D1, ce que certaines de leurs sépultures semblent attester.

\section{Les tombes de " sacrificateurs"}

Cinq tombes présentent la particularité de contenir de l'armement mutilé. Dans l'une d'entre elles l'arme est symbolisée par une simple entrée de fourreau en bronze. Les autres ont des panoplies comprenant l'épée dans son fourreau, l'umbo de bouclier, et dans deux cas le fer de lance. Toutes ces armes sont pliées, martelées, mutilées de manières identiques à celles des sanctuaires à armes du Nord et de l'Ouest de la Gaule. D'autres mobiliers en fer sont présents comme des ensembles d'outils utilisés en ébénisterie, en menuiserie ou encore dans le travail du cuir. Ces caractéristiques déjà remarquables sont encore accentuées par d'autres objets particuliers et fortement connotés : petits seaux de $16 \mathrm{~cm}$ de diamètre maximum à cerclages de fer ou de bronze, poêles en bronze, fragments d'amphores, mais surtout couteaux à découper (feuille de boucher) et haches à perforation transversale. Une des trois haches connues s'adapte parfaitement à la perforation du temporal droit du jeune homme assassiné. La chronologie de ces tombes correspond à celle des divers rituels sanglants observés sur l'habitat, sacrifices humains et hécatombes de moutons.

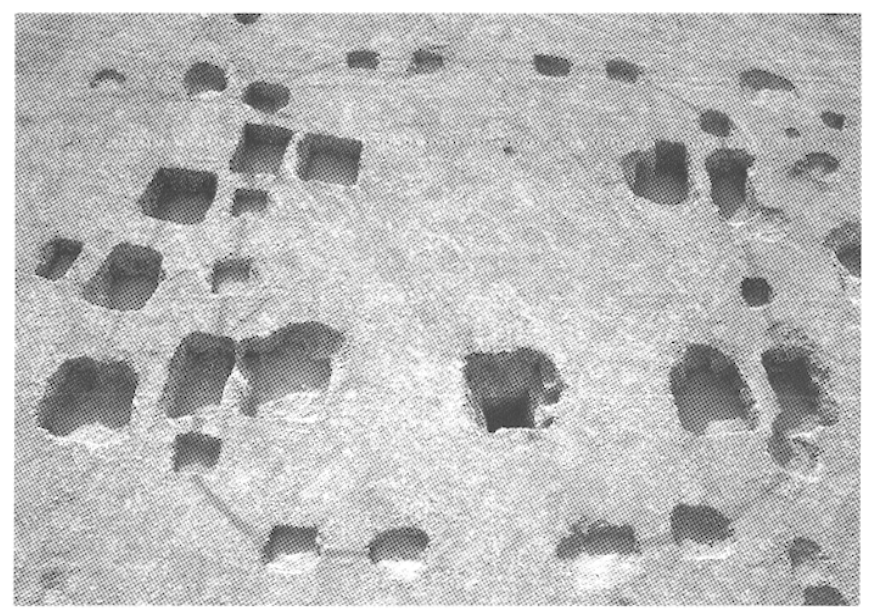

Fig. 30 - Acy-Romance (Ardennes), La Warde. Le grand temple et le puits. Les parois du bâtiment ont élé tracées à la peinture. La partie centrale était surélevée comme l'indiquent les quatre énormes fosses à poteaux internes (photo B. Lambot).

\section{Les activités religieuses dans le village d'Acy-Romance}

C'est un grand tertre de l'âge du Bronze final qui a été pris comme repère pour tracer au sol l'implantation générale et plus précisément le complexe religieux associant la place publique et l'alignement de constructions dont le temple fait partie (fig. 30). Cet hérôon a d'ailleurs été protégé pendant toute l'existence du village. C'cst dans son environnement que se trouvent deux des fosses à brebis, ainsi que les bâtiments et l'enceinte en rapport avec les trois inhumés assis dans la cour des éleveurs. Une zone dense de chablis indique la conservation probable d'un bosquet au sud-est de ce tertre, encore bien visible lors de l'arrivée de la population. La perpendiculaire dressée du milieu de la ligne droite tirée du centre de ce tumulus à l'angle sud de la place arrive au centre du puits. De ce tracé primaire a été mené tout le découpage en parcelles et en lots de la superficie du village. C'est ainsi que, malgré la topographie du terrain, les trois grandes cours sont parfaitement similaires et de même orientation. Même si ce travail ne demande pas de grands moyens matériels, il nécessite un minimum de connaissances arithmétiques et géométriques, et une cohérence d'exécution. Ajoutons à cela le choix du sommet du plateau pour aligner les bâtiments religieux, véritable acropole même si l'élévation est minime.

Les jeunes hommes recroquevillés enterrés sur l'esplanade devant le grand temple (dont la mort a été ritualisée et avec un séjour au "centre de la terre » dans un puits où ils ont nourri de lcurs humcurs lcs dieux infernaux pendant près d'un siècle) évoquent ce que les textes 
antiques rapportent sur les sacrifice humains. Il ne peut y être vu essentiellement l'exécution ritualisée de sentences judiciaires : ce serait en contradiction avec les données anthropologiques qui, comme pour les hécatombes de brebis, ne concernent que des individus de même âge et de même sexe. En outre le jeune assassiné - il ne peut être dénommé autrement - a été tué d'un coup de hache sur le temporal droit et non sur la nuque, ce qui aurait été plus efficace, garrotté et agenouillé avant d'être dissimulé dans une fosse creusée à la hâte le long du mur d'une maison, vraisemblablement celle d'un prêtre. Ce sont des homicides qui ont été commis en hiver, tout comme l'abattage massif de brebis dont on peut difficilement contester l'aspect religieux.

Une relation entre ces prêtres, ces sacrificateurs et les restes humains épars sur l'habitat existe-t-elle ? Au premier abord on peut ne pas en voir. C'est oublier que les " funérailles grandioses " mentionnées par César résident essentiellement dans le cérémonial et non dans le viatique déposé sur le bûcher et dans la tombe. L'incinération différée et la mise en terre est un privilège réservé aux personnes aisées, éleveurs notamment. L'abandon probable des corps des gens du peuple aux charognards, corbeaux et autres oiseaux de proie n'exclut pas l'intervention des prêtres. Ils sont les grands organisateurs des sacrifices humains et ils président à la sortie des corps du puits et à lcur cnfouisscment sur l'esplanade. Le coxal accompagnant une des victimes n'a pu se retrouver accidentellement entre sa tête et ses pieds.

La singularité de l'ensemble des lances votives d'AcyRomance réside dans la présence d'un nombre important de fers de lance réels, certainement le chiffre le plus élevé connu actuellement pour la période de La Tène C2 et D1. Aucune de ces lances n'a été trouvée intacte. Toutes ont été mutilées, de façon profonde, rendues méconnaissables ou transformées en armes de jet de type romain. D'où proviennent ces lances réelles? Il est tentant d'évoquer le sanctuaire proche de Nanteuil-sur-Aisne (Ardennes), sanctuaire de "type belge » regorgeant d'armes brisées, d'os humains, de rouelles et de monnaies. Lne autre origine est plus probable. Les troupes gauloises composées de milliers de soldats ne comptaient pas que des porteurs d'épée, loin s'en faut. Nous aurions là l'équipement de la piétaille militaire gauloise, en fait l'armement consacré au sein même du village. Les miniatures seraient un substitut symbolisant quelques faits d'armes anciens dans une dévotion à un dieu local. Cette hypothèse n'est pas sans conséquence et l'interprétation comme armes des vaincus des panoplies des sanctuaires est à nuancer. Il peut s'agir, plus prosaïquement, des armes des guerriers du peuple, tombe commune symbolique en quelque sorte.
Bibliographie : Hatt, 1979 ; Lefèvre, 1987 ; Lambot, 1999, 2000 ; Lambot, Méniel, 2000.

B. LAMBOT

\section{NOTICE 2}

\section{BAILLEUL-SUR-THÉRAIN (OISE)}

\section{LE MONT-CÉSAR}

Bien que ce site ait fait l'objet d'une fouille fort peu scientifique à la fin du XIX ${ }^{c}$ s. (Renet, 1879), le site est exemplaire. Il est situé au sommet et précisément au centre d'une butte-témoin du Tertiaire, entourée de tous côtés par de vastes marécages. Le lieu a, de ce fait, été fortifié à l'âge du Bronze, puis régulièrement été occupé à toutes les époques. Il est cependant abusif de parler à son propos d'« oppidum ", puisque ni les structures ni le matériel courants sur ce type de site n'ont été rencontrés.

Le très probable sanctuaire celtique n'est connu que par le mobilier archéologique qui y a été récolté, il est également confirmé par la superposition habituelle d'un fanum gallo-romain. Les aménagements architecturaux de l'époque protohistorique n'avaient que peu de chances d'être observés, à cause de la nature du sédiment (un sable qui nécessite des observations stratigraphiques très fines) et de la présence des aménagements gallo-romains abondants. Le matériel archéologique est très varié. On reconnaît dans la publication des fers de lance de La Tène Cl, tout à fait similaires à ceux de Gournay, des épées et des fourreaux de La Tène moyenne (un des fourreaux est attribuable à La Tène C2), de grandes fibules en fer de schéma La Tène moyenne, des crochets de ceinture de La Tène C2, un fragment de torque de type ternaire, des perles en ambre et en pâte de verre, de la céramique, des os animaux et 27 monnaies gauloises, de type bellovaque dont des potins antérieurs à la conquête romaine. Des os humains ont été rencontrés, ils sont interprétés comme des restes de sépulture, mais il s'agit évidemment d'une explication habituelle à l'époque des fouilles.

Le nombre et la variété des vestiges, ainsi que l'évolution du site à l'époque gallo-romaine sont des arguments irréfutables pour une interprétation en termes de sanctuaire. Bailleul-sur-Thérain s'inscrit parfaitement dans la série la plus homogène de ces sanctuaires celtiques que l'on pourrait qualifier de «bellovaques » et qui comptent Gournay-sur-Aronde, Estrées-Saint-Denis, Saint-Maur, Vendeuil-Caply.

Bibliographie : Renet, 1879 ; Woimant, 1995.

J.-L. BRUNAUX 


\section{NOTICE 3}

\section{BEAUVAIS (OISE)}

\section{Les Aulnes du Canada}

Cette enceinte quadrangulaire se trouve au fond de la vallée marécageuse du Thérain. À l'époque protohistorique, le milieu était déjà très humide et le fond du fossé de clôture devait être régulièrement rempli d'eau. La structure a été à moitié détruite par une gravière avant de faire l'objet en 1981 et 1982 d'une fouille de sauvetage très partielle. Seules des sections de fossés ont été fouillées ; l'intérieur de l'enceinte, malgré un très bon état de conservation, n'a fait l'objet que de sondages aléatoires dont les emplacements ne figurent pas sur le seul plan très sommaire publié (Woimant, 1990). Pourtant, au cours de l'extraction des graviers, sont apparus en coupe dans cet espace intérieur des foyers visiblement bien aménagés, constitués de rognons de silex et de blocs de grès portant des traces de feu. Sont apparus également des vestiges gallo-romains dont une fosse datée de l'époque augustéenne.

C'est donc la clôture de cette enceinte qui est le mieux connue. Le fossé oriental a été observé sur la totalité de sa longueur, soit $82 \mathrm{~m}$. Sur le plan publié, au milieu de ce côté, figure une interruption qui paraît correspondre à une entrée, laquelle n'est pas précisément décrite dans le texte. L'enclos pourrait avoir un plan carré rectangulaire. La surface est estimée entre $6725 \mathrm{~m}^{2}$ (Woimant, 1990) et $5725 \mathrm{~m}^{2}$ (Woimant, 1995). La clôture est matérialisée par un large fossé, de 3,50 m environ de largeur pour 1,50 $\mathrm{m}$ de profondeur. Il est resté visiblement ouvert longtemps, suffisamment pour que les parois s'effondrent régulièrement et qu'une formation tourbeuse se développe au fond. Cette dernière a magnifiquement conservé un matériel archéologique abondant parmi lequel se trouvaient des restes de végétaux et des insectes. La céramique surtout est nombreuse et présente beaucoup de vases complets : 6 vases peints, 90 formes hautes (types situle, dolium) et 77 écuelles. Les outils et ferrures diverses sont courants. Ce sont surtout 66 barres dont une extrémité se termine en douille ou cornet et l'autre en spatule. Ces objets sont caractéristiques des sites cultuels picards de La Tène $\mathrm{D}$ et semblent liés à l'usage du feu (soit armatures de torches, soit éléments de grils). Les représentants de la faune se trouvent en assez grande quantité ; ils proviennent en majorité de porcs abattus jeunes ( 2 ans), de bœufs, de moutons, de chiens et de chevaux. Trois crânes humains ont également été découverts, l'un d'eux présente une découpe de la partie sommitale de la calotte, tout à fait similaire à celle observée sur les pièces de Ribemont-sur-Ancre et de Montmartin.
Les trois fibules de schéma La Tène moyenne et les vases peints appartiennent à La Tène $\mathrm{C} 2$ et, vu leur état de conservation, ne peuvent faire figure de matériel résiduel, antérieur à la structure ou provenant d'un autre lieu. Les amphores de type Dressel $1 \mathrm{~A}$ et la plupart des vases hauts, ovoïdes, sans col, sont datables de La Tène Dl. En revanche, un grand nombre de céramiques, les trois monnaies gauloises découvertes et les barres dites "à douille " se rencontrent dans les ensembles de La Tène D2. L'enceinte paraît donc avoir été utilisée avec son fossé ouvert pendant plus d'un siècle, avant d'être transformée au début de l'époque gallo-romaine sous une forme que l'on ignore.

Le nombre, la conservation et la qualité des vases découverts, associés à une soixantaine de fragments d'amphores gréco-italiques, précoces et exceptionnelles dans le Nord de la France, ainsi que la présence de plusieurs crânes humains et d'éléments de fer, habituellement rencontrés sur les lieux de culte, suffisent à persuader qu'on a affaire à un lieu de culte dont la fonction malheureusement demeurera à jamais inconnue. La surface de l'enceinte et le matériel découvert font songer aux enceintes dites " à banquet "; dont le rôle est tout aussi obscur. On peut seulement affirmer que sur ces lieux comme celui-ci se sont tenus des banquets. Mais la raison de ces agapes demeure incertaine. Ici l'existence de foyers malheureusement non documentés par la fouille et celle de crânes humains, dont l'un au moins a subi un traitement particulier à finalité funéraire vraisemblable, suggèrent que ces banquets pouvaient s'inscrire dans l'ensemble certainement vaste des rites funéraires.

Bibliographie : Woimant, 1990, 1995.

\section{J.-L. BRUNAUX}

\section{NOTICE 4}

\section{BENNECOURT (YVELINES)}

\section{LA ButTe du Moulin à Vent}

Le sanctuaire de Bennecourt semble appartenir au type picard. Il a été édifié sur une colline dominant une courbe de la Seine et la confluence de cette dernière avec l'Epte. Les fouilles non extensives, réalisées de 1982 à 1988, ne permettent pas d'affirmer l'absence d'un grand enclos quadrangulaire de plusieurs dizaines de mètres de côté et matérialisé par un fossé. Les fouilles ont, en effet, porté principalement sur la zone de trois temples gallo-romains où se trouvait un petit aménagement architcctural laténicn. Ces travaux ont donné lieu à une publication mono- 


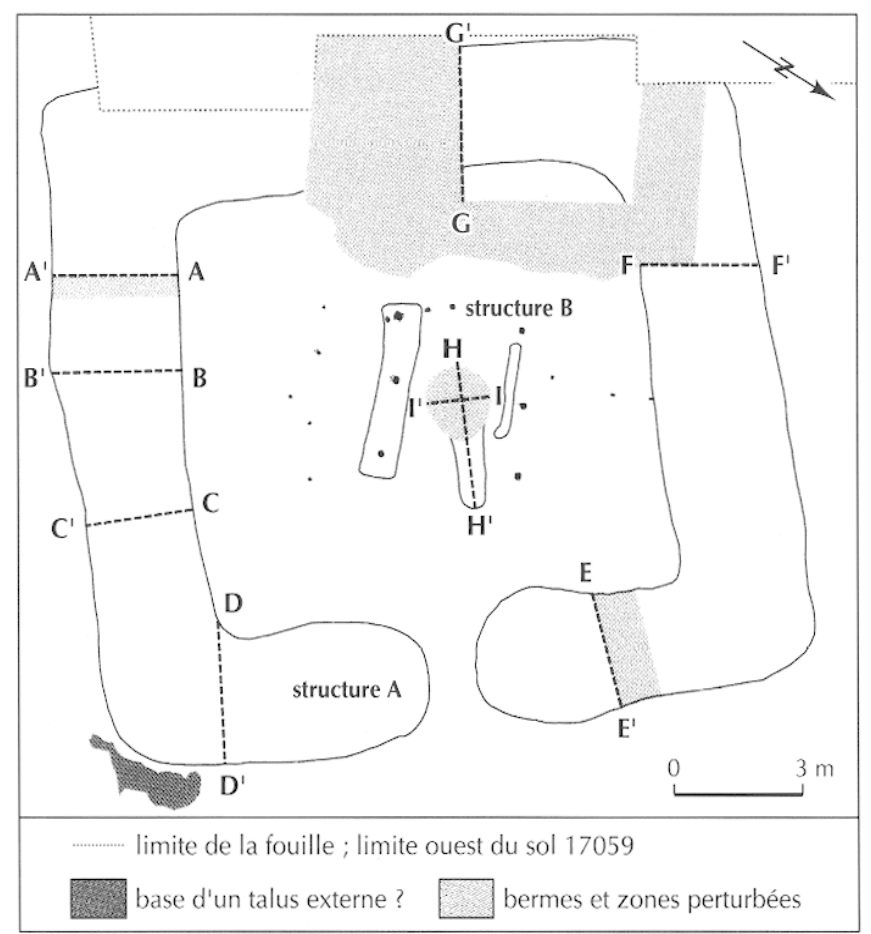

Fig. 31 - Bennecourt (Yvelines), La Butte du Moulin à Vent. Plan du sanctuaire laténien (d'après Bourgeois dir., 1999).

graphique où est présentée la totalité de la documentation (Bourgeois dir., 1999).

De la période proprement gauloise nous ne connaissons donc qu'un petit enclos carré de $17 \mathrm{~m}$ x $15 \mathrm{~m}$, matérialisé par un fossé de près de $3 \mathrm{~m}$ de largeur et d'environ $1 \mathrm{~m}$ de profondeur (fig. 31). Une interruption de celui-ci, au milieu du côté oriental, marquait une entrée étroite, d'un peu plus de $1 \mathrm{~m}$ de largeur. Ce fossé a subi de nombreux réaménagements, ce qui ne permet pas d'assurer qu'il est resté toujours ouvert. La petite taille de l'enclos, son entrée étroite et la présence au fond d'un fossé de 20 à $25 \mathrm{~cm}$ de largeur suggèrent plutôt qu'il dut, à une époque qu'il est difficile de préciser, recevoir des murs construits avec une armature de bois.

L'aménagement central est à l'échelle de l'enclos fossoyé : la fosse centrale ne mesure qu'1 $\mathrm{m}$ de diamètre pour une profondeur de $40 \mathrm{~cm}$. Un appendice à cette fosse de 1,50 $\mathrm{m}$ de longueur et de $60 \mathrm{~cm}$ de largeur, aménagé en pente douce, servait d'escalier. Un aménagement semblable a été observé à Gournay-sur-Aronde et à Montmartin. La fosse, totalement vidée au Haut-Empire, n'a livré aucun indice pouvant témoigner de son usage. Autour de cette fosse, deux saignées laissées par une sablière basse et des petits trous de poteaux révèlent l'existence d'un petit bâtiment, de plan quadrangulaire d'environ 3,50 m de côté et ouvrant vers l'est. Cette petite structure, couvrant très exactement la fosse, présente les plus grandes similitudes avec les bâtiments de protection des autels creux de Gournay et de Montmartin.

L'essentiel du mobilier archéologique provient du fossé de l'enclos. Ce dernier a été réutilisé à plusieurs reprises, le matériel découvert s'y trouve donc en situation résiduelle et n'apporte guère d'informations sur les rites qui ont pu s'y dérouler. Les objets, de petite taille, perdus ou oubliés, témoignent du séjour d'armes et d'horizons chronologiques qui n'ont laissé aucune autre trace. Les pièces les plus remarquables sont les fibules, nombreuses, parmi lesquelles on reconnait beaucoup d'exemplaires de La Tène moyenne mais aussi quelques représentants plus anciens (fin du $\mathrm{NV}^{\mathrm{c}}$ s.). Ine entrée de fourreau, une croisière d'épée campaniforme et un crochet de ceinture en fer reflètent un horizon chronologique de la fin de La Tène C1 et de La Tène C2. Des restes animaux nombreux (20 000) proviennent pour l'essentiel du porc, du mouton et du chien. Ils témoignent tous d'une consommation humaine. Les comparaisons effectuées par les zoologues en ce qui concerne les critères de sélection des espèces, des âges et des parties consommées rapprochent l'échantillon de Bennecourt de celui du remplissage principal du fossé quadrangulaire de Ribemont-sur-Ancre, remplissage daté de La Tène D2.

Bibliographie : Bourgeois dir., 1999.

J.-L. BRunauX

\section{NOTICE 5}

\section{CHILLY (SOMME)}

\section{Le BoIs du CARMe}

Ce lieu de culte est intéressant dans la mesure où il est parfaitement caractéristique des sanctuaires indigènes de l'époque gallo-romaine, dont l'origine gauloise est assurée mais n'a généralement laissé que très peu de vestiges. On s'aperçoit d'ailleurs ici, comme sur les sites similaires, que cette pauvreté du matériel protohistorique n'est que toute relative et s'explique avant tout par une exploration archéologique trop limitée dans l'espace.

Le lieu se trouve au milieu du vaste plateau du Santerre sur une très légère pente orientée au sud-est. Objet. de nombreux bombardements pendant la Grande Guerre, puis de pillages exécutés par des fouilleurs clandestins, enfin de sondages archéologiques intempestifs et trop exigus, ce sanctuaire n'est vraiment documenté qu'à la période gallo-romaine : on connaît le plan des fondations d'un fanum qui s'est installé sur un enscmblc complcxc dc structures allant de La Tène finale au Bas-Empire. Les seules 
structures antérieures à la conquête romaine connues sont un fossé et une fosse. Ie fossé a été reconnu sur une douzaine de mètres. Il est rectiligne et de dimensions importantes ( $3 \mathrm{~m}$ de largeur pour $2 \mathrm{~m}$ de profondeur), ce qui laisse penser qu'on a affaire à un élément de clôture d'une enceinte conséquente, similaire à celle de Gournaysur-Aronde, d'autant que le fossé est demeuré ouvert. La fosse, située à $17 \mathrm{~m}$ au nord du fossé, pourrait se trouver en position centrale à l'intérieur de l'enceinte. Elle n'est malheureusement pas connue dans sa totalité, son plan serait ovalaire. Ses dimensions en font cependant une structure conséquente: au moins $4 \mathrm{~m}$ de diamètre. Sa profondeur est d'une soixantaine de centimètres. Ses parois sont quasi verticales et forment un palier intermédiaire, comme on le voit dans les autels creux de Gournay, de Montmartin et de Saint-Maur. Il y a donc de fortes chances pour que cette fosse ait appartenu à l'installation cultuelle principale.

Le mobilier archéologique n'est que partiellement documenté : l'important ensemble monétaire qui a attiré les pillards et a suscité la fouille a obnubilé l'archéologue qui ne fait que mentionner la présence d'abondants os animaux (Collart, 1987). La céramique est représentée par de nombreux tessons et par un morceau d'amphore de type Dressel 1A. Une croisière d'épée campaniforme et une attache de fourreau témoignent de la présence d'armes. La parure est également présente : fibules et perles de verre.

Des vases ovoïdes sans col, la croisière d'épée, une fibule de La Tène moyenne, une autre de type Nauheim et l'attache de fourreau témoignent d'un incontestable horizon fin La Tène C2-début La Tène D1. À celui-ci se rapportent un certain nombre de potins que l'on date maintenant du tout début du $\mathrm{I}^{\mathrm{cr}} \mathrm{s}$. avant J.-C.

Ces éléments ne permettent évidemment pas de reconnaître le type d'activité rituelle qui s'est pratiqué ici. Ils nous autorisent seulement à reconnaître un authentique lieu de culte qui a dû fonctionner à partir du début du $\mathrm{I}^{\mathrm{er}} \mathrm{s}$., où la monnaie a joué un rôle non négligeable.

Bibliographie : Collart, 1987.

J.-L. BRUNAUX

\section{NOTICE 6}

\section{DOMPIERRE-SUR-AUTHIE (SOMME)}

\section{La Plaine aU-Dessus du Bois}

Ce sanctuaire occupe une position caractéristique : sur le plateau picard, au bord du versant sud de la vallée de l'Authie et à $400 \mathrm{~m}$ de la voie dite d'Agrippa, reliant Milan à Boulogne-sur-Mer, qui avait peut-être un antécédent celtique. À l'époque romaine, le site paraît vaste puisqu'il comprend au moins trois fana largement séparés les uns des autres, sur une surface de plus de 3 ha. Les vestiges gaulois sont importants par la quantité de matériel archéologique découvert et surtout par son état de conservation. Malheureusement, les fouilles programmées réalisées en 1987 et 1988 sont restées trop limitées dans l'espace pour que l'on puisse se faire une idée suffisante des aménagements architecturaux. Néanmoins la présence en ce lieu d'un authentique sanctuaire gaulois ne fait aucun doute.

Les fouilles ont mis en évidence deux aménagements. Le premier est le plus habituel sur ce type de site, c'est un fossé, fouillé sur une longueur de $5 \mathrm{~m}$. Il est rectiligne sur cette section, sa largeur est de $1,80 \mathrm{~m}$ pour près de $1 \mathrm{~m}$ de profondeur. Il semblerait qu'il soit demeuré ouvert. Le matériel découvert n'est guère significatif. L'autre aménagement est un sol constitué d'un épandage de rognons de silex et de galets. La surface conservée est de $150 \mathrm{~m}^{2}$ au minimum. En certains endroits s'observe au moins une recharge. Un matériel archéologique abondant y a été découvert, soit sous les pierres, soit parmi elles, mais aussi à sa surface. Ce matériel est constitué d'os animaux, d'objets de parure (fibules, bracelets), de nombreux crochets de ceinture en bronze mais aussi en fer, d'armes (épées, fourreaux, chaînes de ceinture), de céramique. Les ossements animaux ont été étudiés. Ce sont, pour près des deux tiers, des porcs abattus assez jeunes, des agneaux (19\%) et du bœuf (17\%). Les objets métalliques témoignent surtout d'un riche horizon La Tène C2-D1 (fin du II et début $\mathrm{I}^{\mathrm{er}} \mathrm{s}$.), mais quelques objets paraissent plus anciens (chaînes de ceinture et une bouterolle sont datables de La Tène Cl). L'abondance des fibules de La Tène D2 indique que le lieu a connu une occupation continue jusqu'à la romanisation.

Les fouilleurs analysent cet abondant matériel en termes d'offrandes déposées à même le sol. Cette interprétation est peu convaincante, au vu de la connaissance très limitée que l'on possède de ce site et de ce que l'on observe sur des sites similaires (à Ribemont-sur-Ancre par exemple). Il s'agit d'une hypothèse minimaliste qui oublie l'essentiel, la présence exceptionnelle d'un sol aménagé et conservé qui a gardé les témoins de rites complexes. Le séjour d'objets sur ce sol, s'il fut volontaire, n'a probablement constitué qu'une étape parmi d'autres. Mais il est beaucoup plus vraisemblable que ces objets, généralement de petite taille, témoignent d'une masse beaucoup plus importante dont ils ne seraient que des pièces perdues, d'ailleurs souvent imbriquées dans le blocage de pierres. Bibliographie : Piton, Dilly, 1990.

J.-L. BRUNAUX 


\section{NOTICE 7}

\section{ESTRÉES-SAINT-DENIS (OISE)}

\section{Le Moulin des Hayes}

Le lieu de culte d'Estrées-Saint-Denis nous intéresse surtout par son environnement le plus proche comme le plus large. Il a, en effet, la particularité de se trouver en pleine zone d'habitat. D'autre part, il est en relation culturelle et chronologique avec le sanctuaire de Gournay-surAronde (distant de $7 \mathrm{~km}$ ) et la résidence de Montmartin (distante de $6 \mathrm{~km}$ ).

Des fouilles programmées y ont été conduites entre 1983 et 1988, et en 1993, 1996 et 1998 des opérations de fouilles préventives ont été réalisées à sa proximité immédiate. Malheureusement la documentation disponible est quasi inexistante; elle se limite à des plans d'ensemble d'une grande confusion (Woimant, 1995, où l'orientation des plans est en contradiction avec Woimant, 1991). Le matériel archéologique découvert a fait l'objet d'évocations vagues, il est daté approximativement dans une chronologie relative désuète. Les travaux de sauvetage n'ont fait l'objet que de notes brèves sans documentation iconographique (Woimant, 1994 ; Derbois-Delattre, 1998).

Le site se trouve au milieu d'une grande plaine et au pied d'une petite butte-témoin sableuse d'où sourdent plusieurs petits ruisseaux. La zone cultuelle est marquée par une accumulation exceptionnellement dense de vestiges allant de la fin de La Tène moyenne au Bas-Empire. Cinq temples de type fanum, au moins trois constructions de type sacellum, deux ensembles de murs de péribole viennent, de surcroît, perturber la lecture délicate des aménagements protohistoriques. Néanmoins ces vestiges gallo-romains, eux-mêmes précédés d'un ou deux états antérieurs (de La Tène finale au sens large et de la fin de la période augustéenne), témoignent d'une forte tradition cultuelle sur une zone de près de $5000 \mathrm{~m}^{2}$.

Les vestiges les plus anciens se concentrent à l'intérieur et autour d'un bâtiment dont le plan a la forme d'un fer à cheval $(6 \mathrm{~m} \times 8 \mathrm{~m})$, matérialisé par une fondation de palissade. Ce bâtiment, ouvrant vers l'est par une sorte de colonnade ouverte, offre les plus grandes similitudes par la conception, le plan au sol et les dimensions avec le plan de la phase III de l'édifice protégeant l'autel creux de Gournay. À proximité de cette zone, quelques os humains, de la céramique gauloise et quelques armes ont été rencontrés. En l'absence de documentation graphique, il est difficile de préciser la chronologie. Ainsi il est question de chaînes de ceinture considérées "comme plus tardives que les premières structures ", elles-mêmes datées " de la fin de
La Tène II ", or l'on sait que ce type de chaîne disparaît à la fin du III's. L'hypothèse d'un dépôt de fondation plus ancien que les premiers aménagements n'est donc pas à exclure, mais pour en décider il faudrait pouvoir disposer d'une publication exhaustive des données de la fouille et du matériel. Les mêmes constatations concernent les monnaies gauloises dont il a été démontré que les potins se rapportent à une époque antérieure à la conquête romaine (Delestrée, 1993, 1996). L'état de la documentation (Delestrée, 1996, fig. p. 51) ne permet pas de savoir si ces pièces proviennent d'aménagements anciens ou sont simplement résiduelles.

Bibliographie : Woimant, 1991, 1994, 1995 ; DerboisDelattre, 1998 ; Delestrée, 1993, 1996.

J.-L. BRLNAUX

\section{NOTICE 8}

\section{FESQUES (SEINE-MARITIME)}

\section{Le Mont du Val aux Moines}

Il s'agit du plus vaste lieu de culte protohistorique rencontré dans la France du Nord, puisqu'il occupe une surface d'environ 12 ha (fig. 32). C'est un vaste enclos découpant et entourant un éperon naturel dominant d'une cinquantainc dc mc̀trcs les vallées environnantes. Il faut distinguer deux ensembles de structures (fig. 33) : le plus grand est un enclos de forme ovalaire qui suit les courbes du terrain, puis un enclos plus petit en position centrale, d'une surface de 25 ares. Entre ces deux enclos, le vaste espace d'une dizaine d'hectares n'a révélé aucune structure. D'importantes fouilles de sauvetage ont été réalisées en 1992 et 1993 qui ont fait l'objet d'une publication monographique (Mantel et al., 1997). Cette dernière, en ne présentant pas le mobilier structure par structure, ne permet malheureusement pas les distinctions chronologiques nécessaires, de même elle ne décrit pas les structures nombreuses et complexes de façon raisonnée.

L'enclos le plus vaste est matérialisé par trois ensembles de structures concentriques, deux fossés parfaitement parallèles sur toute la longueur du tracé connu et, entre les deux, un ensemble de fosses. Seul le fossé intérieur est documenté. Il apparaît comme un petit fossé ouvert, de $1 \mathrm{~m}$ à $1,50 \mathrm{~m}$ de largeur pour une profondeur d'environ $50 \mathrm{~cm}$. Dans sa partie supérieure a été rencontré un très abondant matériel: plusieurs milliers d'os animaux, beaucoup de céramique, plus deux cents os humains et quelques dizaines d'armes. À l'extérieur de ce fossé, sur une bande de 7 à $8 \mathrm{~m}$ de largeur se trouvent de nombreux trous de poteaux et fosses ne formant pas d'ensembles très cohérents, si ce n'est 


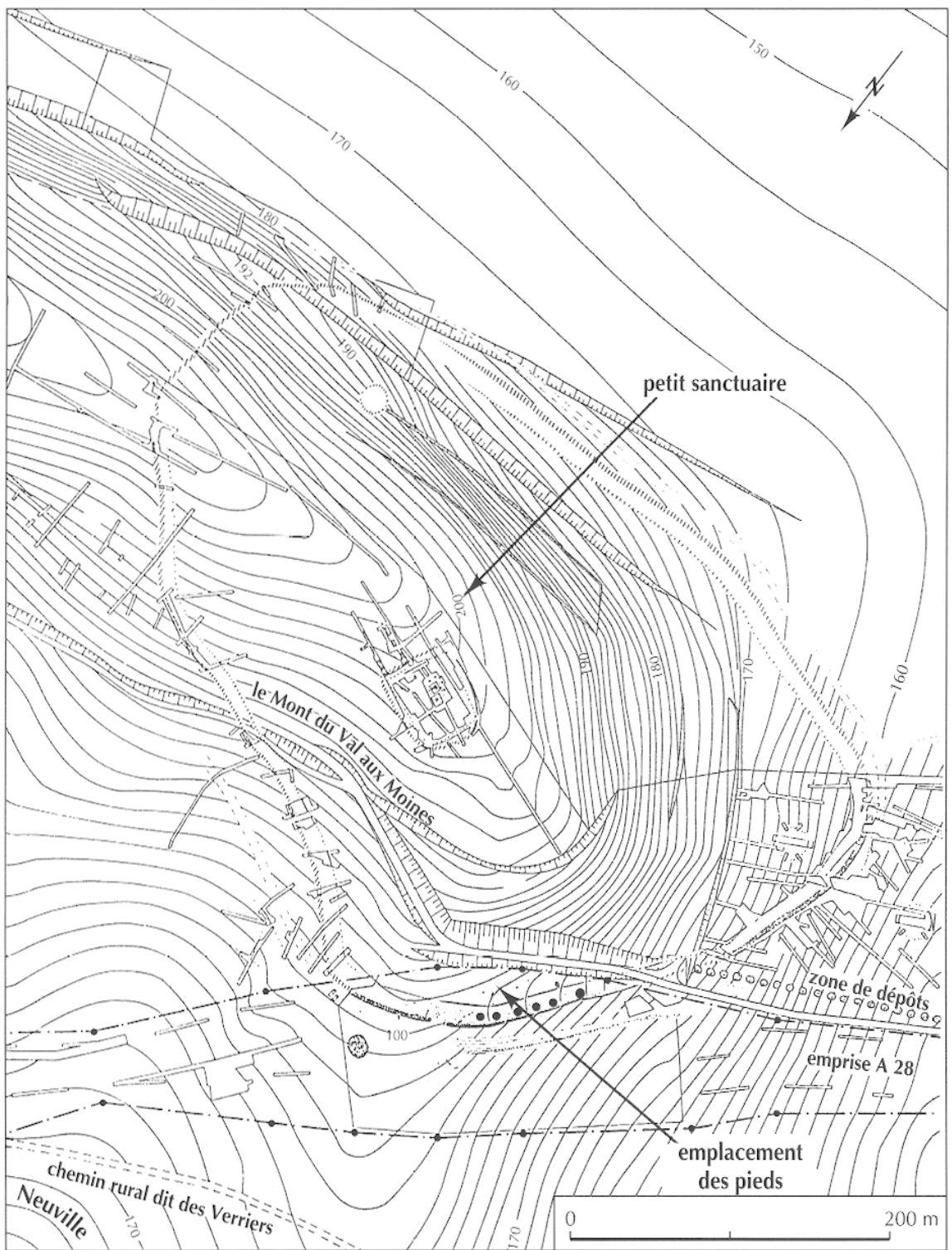

Fig. 32 - Fesques (Seine-Maritime), Le Mont du Val aux Moines. Plan général du site (d'après Mantel et al., 1997). par l'alignement. Parmi ces structures figurent 26 fosses remarquables. Ce sont des cuvettes de 50 à $60 \mathrm{~cm}$ de diamètre, plus ou moins circulaires, de 20 à $30 \mathrm{~cm}$ de profondeur. Chacune contenait les restes plus ou moins bien conservés de la partie inférieure (os du tarse et parfois tibia et fibula) d'un individu en position debout (fig. 34). Aucun matériel archéologique n'était associé à ces os. Enfin, la troisième structure, la plus extérieure, est un large fossé ouvert, de 3 à $4 \mathrm{~m}$ de largeur et $2 \mathrm{~m}$ de profondeur. La documentation ne permet pas de connaître sa chronologie exacte, il est seulement indiqué que ce fossé pourrait être légèrement postérieur au premier.

Les armes rencontrées dans le fossé interne se rattachent majoritairement à La Tène $\mathrm{C} 2\left(\mathrm{II}^{\mathrm{e}} \mathrm{s}\right.$. avant $\mathrm{J}$.-C. $)$. Un umbo à larges ailettes rectangulaires et une fibule de Nauheim indiquent qu'il est demeuré ouvert au moins jusqu'au début $\mathrm{du} \mathrm{I}^{\mathrm{er}} \mathrm{s}$.

L'enclos central est, par sa forme et ses dimensions, très semblable aux sanctuaires picards. L'enclos, de plan quadrangulaire avec le côté oriental légèrement curviligne, est matérialisé par un fossé ouvert ininterrompu. Sa largeur est presque de $2 \mathrm{~m}$ pour une profondeur d'à peine $1 \mathrm{~m}$. À l'intérieur, à 2-3 $\mathrm{m}$ du fossé, et parfaitement parallèle à celui-ci, un enclos de plan carré (40 m de côté) apparaît sous la forme d'un alignement régulier de trous de poteaux, séparés d'environ $2 \mathrm{~m}$. L'espace central est occupé par deux ensembles de fosses, chacun étant marqué par une fosse importante de $3 \mathrm{~m}$ de diamètre et de $1 \mathrm{~m}$ de profondeur 


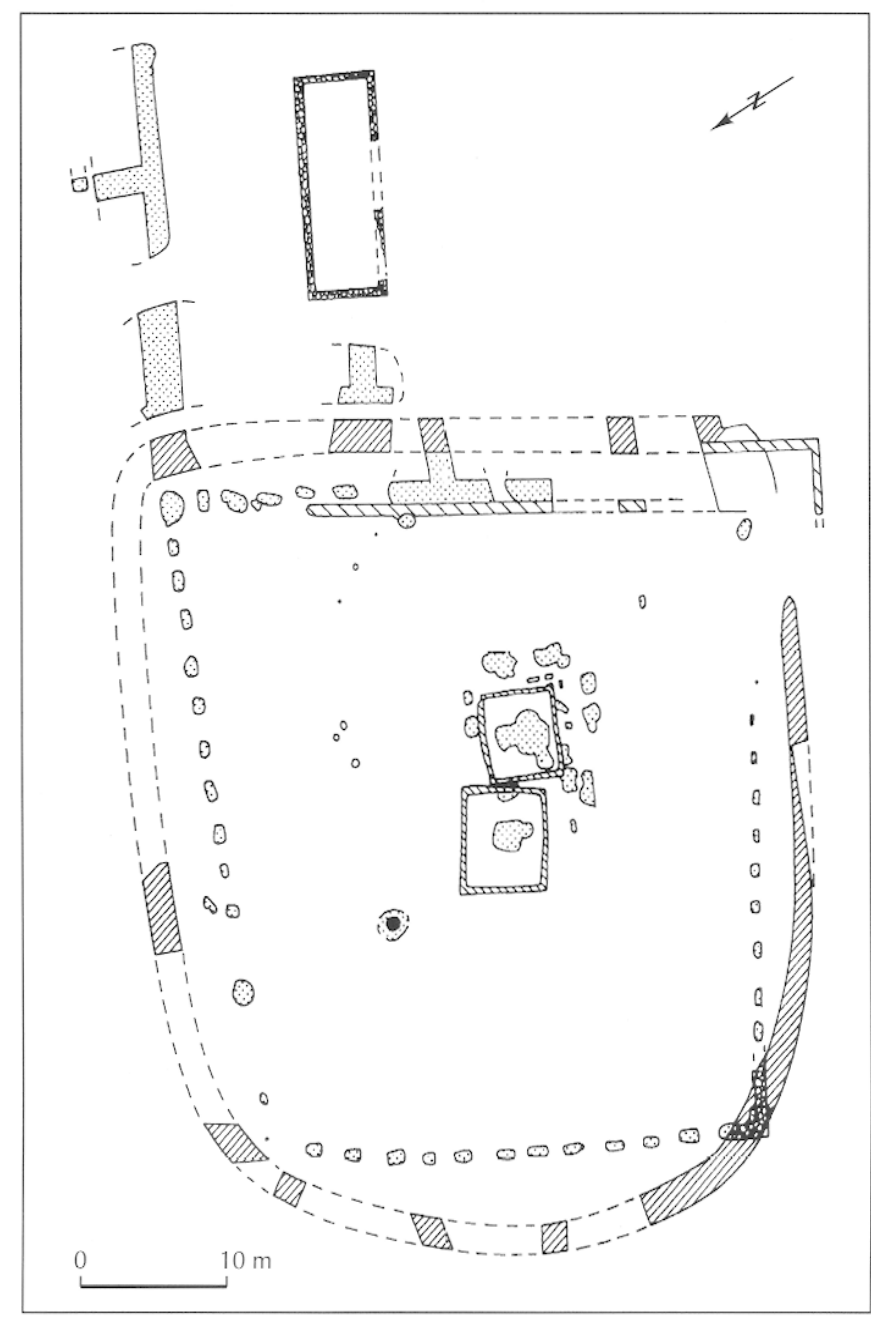

Fig. 33 - Fesques (Seine-Maritime), Le Mont du Val aux Moines. Plan du sanctuaire (d'après Mantel et al., 1997).

environ. L'ensemble le plus ancien comprend une fosse centrale plusieurs fois recreusée et entourée d'une dizaine de fosses rectangulaires à angles arrondis, de $1 \mathrm{~m}$ à $1,20 \mathrm{~m}$ de côté. Dans un deuxième temps, ces fosses ont été remplacées par un bâtiment de plan carré, de $6 \mathrm{~m}$ de côté, entourant la fosse. Le second ensemble est plus simple, il s'agit encore d'un bâtiment carré de mêmes dimensions, élevé sur sablières et entourant une fosse. Il aurait remplacé le bâtiment précédent.

Le matériel archéologique datant ce deuxième ensemble provient pour l'essentiel du fossé de clôture. Il a livré quelques armes et une céramique assez abondante qui appartiennent à coup sûr à La Tène D1 et pour quelques exemplaires à La Tène C2.

Les découvertes d'os humains en place dans les fosses extérieures ont suscité des interprétations diverses qui font
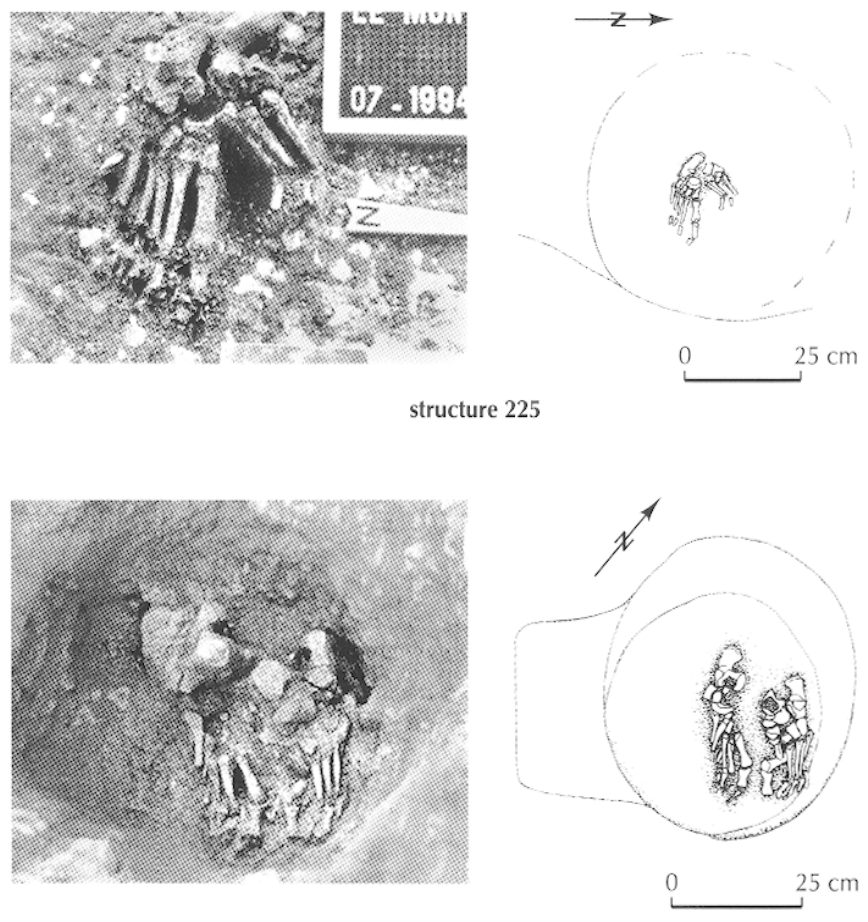

structure 33

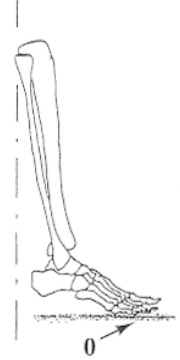

0 : appui

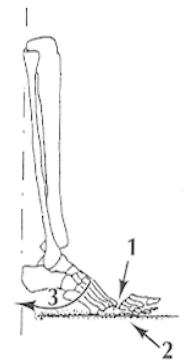

1 : détachements 2 : mis à plat 3 : recul

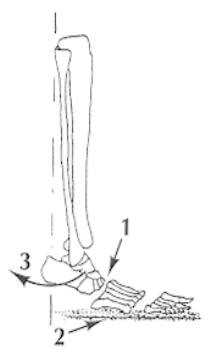

1 : détachements

3 : recul

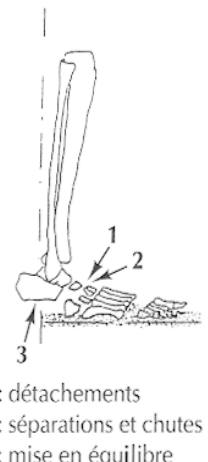

3 : mise en équilibre
Fig. 34 - Fesques (Seine-Maritime), Le Mont du Val aux Moines. Fosses contenant les restes osseux de jambes humaines (d'après Mantel et al., 1997).

l'objet d'une analyse détaillée dans la synthèse régionale. Il paraît cependant nécessaire de revenir sur quelques particularités de ce matériel archéologique riche et significatif. La plus instructive (malheureusement non documentée dans la publication) est la découverte d'un certain nombre de crânes entiers dans le fossé qui borde ces fosses. De tels crânes sont absents des sanctuaires, notamment de ceux qui ont un fort caractère guerrier. Ici, leur association avec des os longs (on aimerait connaître leur nombre et leur répartition anatomique) laisse supposer qu'ils proviennent des individus exposés à proximité et dont seuls les pieds sont demeurés en 
place. La disparition des éléments du tronc (Mantel et al., 1997, p. 26) fait évidemment songer au phénomène similaire observé à Ribemont-sur-Ancre, sur l'enclos circulaire notamment, et pourrait avoir la même cause. L'enseignement livré par les os animaux et la céramique n'est pas non plus anodin. La situation de leurs rebuts est nettement différenciée. La céramique (vases hauts pour l'essentiel) est abondante dans le sanctuaire proprement dit, alors que les milliers d'os de bovidés, vestiges de banquets considérables, sont rejetés dans le fossé du grand enclos.

Bibliographie : Mantel et al., 1997 ; Brunaux, 2000a.

J.-L. BRUNAUX

\section{NOTICE 9}

\section{GOURNAY-SUR-ARONDE (OISE)}

\section{Le PARC}

Le sanctuaire de Gournay-sur-Aronde a fait l'objet d'une publication monographique détaillée (Brunaux, Méniel, Poplin, 1985), ainsi que de nombreuses présentations récentes (par exemple Brunaux, 2000a) qui dispensent d'une description même rapide. Il est nécessaire cependant de faire le point sur l'état actuel des connaissances et de revenir sur quelques problèmes non résolus au moment de la publication.

Sur les aménagements architecturaux, l'apport principal des dernières études concerne le porche d'entrée. La mise en évidence de deux poteaux situés dans le fossé principal (Lejars, 1994, p. 103) permet de restituer un véritable bâtiment construit sur huit poteaux et enjambant les deux fossés. La taille de ces supports laisse imaginer un bâtiment conséquent qui pouvait comporter un étage et qui, sous cette forme, se prêtait mieux à accueillir la masse des armes, des éléments de char, des crânes de bovidés et d'humains qui a été découverte de part et d'autre dans le fossé. Il était difficile de replacer tout ce matériel sur les seules cloisons d'un porche simple. Un étage, d'une surface d'une vingtaine de mètres carrés, rend la chose possible. Le porche ressemblerait alors fort aux propositions d'élévations des portes des oppida mais aussi aux propylées des sanctuaires grecs, celui notamment du temple d'Athéna à Pergame qui justement était décoré de bas-reliefs représentant un matériel celtique assez similaire à celui de Gournay. On peut comprendre que l'informateur de Poseidonios, dont le passage est recopié par Strabon, ait pu parler de crânes humains accrochés à des «propylées".

Un autre aménagement du sanctuaire, qui n'est pas proprement architectural, mérite une attention particu- lière, c'est la zone boisée dite du « tiers nord ». La fouille maintenant ancienne, menée dans des conditions techniques difficiles et sans l'aide d'études environnementales, n'a pas permis de trancher entre deux hypothèses présentées dans la publication: soit il s'agit d'une sorte de parc à bestiaux, soit c'est un bois en partie artificiel. Les enseignements de la fouille de Ribemont, menée en un terrain quasi similaire à celui de Gournay (limon épais sur un socle crayeux), font plutôt pencher en faveur de la deuxième hypothèse: les perturbations du sol ancien de Gournay, heureusement préservé en cette zone, montrent les mêmes particularités que celles de la zone centrale de l'enclos carré de Ribemont. Quant à l'absence de toute trace dans le " tiers sud ", qui avait été interprétée en termes d'espace ouvert, pour des banquets par exemple, elle doit maintenant être interprétée tout autrement. Cette zone est, en effet, marquée par une érosion relativement importante qui va d'une dizaine de centimètres sur le bord sud de l'ensemble des fosses jusqu'à $60-80 \mathrm{~cm}$ sur le bord du fossé sud. Le sol ancien a donc disparu et, avec lui, très certainement des traces similaires à celles qui ont été observées au nord où sur une surface de $150 \mathrm{~m}^{2}$ le sol ancien est conservé.

Sur les rites proprement dits les nouveaux éléments de réflexion proviennent de l'étude de sanctuaires ou d'installations cultuelles plus ou moins similaires, en tout cas proches dans le temps. L'originalité du traitement du bœuf, bien signalée dans la publication, se voit confirmée, au-delà de tout espoir, puisque aucun autre ensemble de même nature n'a été découvert depuis. En revanche, une autre particularité se révèle aujourd'hui, c'est la rareté des céramiques, surtout dans les ensembles les plus anciens mais aussi, dans une moindre mesure, dans les couches les plus récentes. Il est difficile de choisir entre plusieurs explications : absence de libation et de consommation de boissons, nettoyage quasi systématique des récipients et de leurs restes?

Quant aux os humains, l'information livrée par les autres sites est heureusement plus instructive. François Poplin avait attiré l'attention sur deux faits intrigants, la présence d'au moins trois femmes parmi les douze individus identifiés et la pratique du dépeçage. Cependant les témoins éloquents de la découpe du crâne devant le porche d'entrée avaient incité les trois auteurs à la prudence, à ne pas aborder la question du sacrifice humain et à considérer l'ensemble des vestiges humains comme des dépouilles parmi d'autres provenant de quelque champ de bataille plus ou moins éloigné. Les enseignements de la fouille de Ribemont obligent à reconsidérer cette hypothèse. Tout d'abord il paraît arbitraire de considérer tous les os humains comme un même ensemble résultant d'une même pratique. On peut avoir affaire à des traitements de natures diverses qui 
ont livré cette petite collection d'os assez hétérogène. La présence de femmes (même si la diagnose sexuelle se fonde sur les indices de taille et de gracilité des os longs) ne peut raisonnablement être mise en doute. Or, sur les milliers d'os humains de Ribemont, aucun n'est attribuable à une femme. Il est donc difficile de reconnaître dans les os de Gournay les restes de cadavres de quelques guerriers rapportés au sanctuaire. Par ailleurs, la découpe du crâne sur ce site, bien décrite par F. Poplin et amplement confirmée par les découvertes de Ribemont, n'est concevable que sur un individu mort mais de fraîche date. Une interprétation qui voudrait absolument écarter le sacrifice humain ici suppose qu'il y eut une ou même plusieurs batailles à proximité immédiate du sanctuaire, et qu'à cellesci aicnt participć des fcmmcs. Dc tcllcs conditions sont hautement improbables et il est plus simple, en l'occurrence, d'envisager la pratique de quelques sacrifices sur un lieu de culte dont la nature apparaît, avec le recul, encore plus éminemment guerrière qu'elle ne le semblait lors de la publication.

Bibliographie : Brunaux, Méniel, Poplin, 1985 ; Brunaux, Rapin, 1988 ; Lejars, 1994 ; Brunaux, 2000a.

J.-L. BRUNAUX

\section{NOTICE 10}

\section{MEAUX (SEINE-ET-MARNE)}

\section{LA BAUVE}

L'existence d'un authentique sanctuaire gaulois sur le site de La Bauve à Meaux demeure encore problématique. Néanmoins ce site vaut la peine d'être évoqué, dans la mesure où il est largement représentatif d'un nombre non négligeable de lieux qui ont livré un matériel sans aucun doute d'origine cultuelle mais qui n'ont pas révélé, dans le même temps, les aménagements architecturaux qui leur sont normalement associés.

Le site se trouve, à mi-pente, sur le versant nord de la vallée de la Marne. Son extension spatiale maximale n'est pas connue : des vestiges protohistoriques ont été reconnus sur une surface d'environ 1 ha, à l'occasion de la fouille d'un grand sanctuaire gallo-romain. Ces vestiges consistent pour l'essentiel en plusieurs dizaines de pièces métalliques gauloises, armes surtout. Ce sont surtout des fragments de fourreaux, plutôt anciens (IV s. bien représenté) mais aussi de La Tène moyenne. Les épées, fers de lance et umbos sont plus rares. L'interprétation cultuelle tient, d'une part, à la présence de ces objets, d'autre part, à l'installation postérieure, sur le lieu même, d'un sanctuaire monumental gallo- romain. L'absence des vestiges architecturaux les plus habituels, fossés et fosses, est problématique. Les fouilleurs l'interprètent en termes de déplacement de dépôts qui n'auraient été découverts que sous une forme très résiduelle. Cette explication est assez convaincante mais elle ne lève pas totalement les interrogations que l'on peut avoir quant à l'état de conservation de pièces aussi fragiles que des fourreaux ou des bouterolles. S'il y a eu déplacement d'objets, il n'a pu se faire sur de grandes distances et le dernier séjour de ces objets (là où ils ont été découverts) s'est forcément accompagné d'une forme de protection. Bibliographie : Marion, 1998.

\section{J.-L. BRUNAUX}

\section{NOTICE 11}

\section{MCUVRES (NORD)}

\section{CANAL du Nord}

Il s'agit d'une découverte fortuite en 1913, lors du creusement du canal du Nord. C'est probablement le deuxième cas avec celui de Ribemont-sur-Ancre d'un lieu cultuel et/ou funéraire érigé après une bataille. Malheureusement la fouille en urgence dut être particulièrement brève et le mobilier recueilli semble avoir disparu. Cependant la découverte a été relatée dans un article succinct mais précis qui livre des informations suffisantes pour que l'on puisse rattacher ce lieu à ceux qui nous occupent ici (Salomon, 1913).

Il s'agit d'un fossé qui a été découvert sous une épaisse couche de colluvions ( $1 \mathrm{~m})$. Il se trouve, en effet, dans un thalweg proche du ruisseau de Mœuvres ; situation topographique inhabituelle pour les sanctuaires de type picard. La section reconnue du fossé mesure plus de $35 \mathrm{~m}$, sans que l'on sache si cette longueur correspond à l'emprise des travaux d'aménagement, si elle s'interrompait sur un des côtés ou si elle formait un enclos avec retour en angle du fossé. La largeur du fossé était de $2 \mathrm{~m}$ environ, voire un peu plus, et sa profondeur de $1 \mathrm{~m}$. La section est curieuse (en V à fond très arrondi, en $U$, ou encore avec un palier) mais il est possible que le fouilleur n'ait observé que la couche de remblai sans distinguer les parois originelles. La fouille n'a porté que sur $10 \mathrm{~m}$. Sur sa profondeur, telle qu'elle a été reconnue, le fossé était entièrement comblé d'os humains. Ceux-ci étaient le plus souvent en connexion anatomique mais concernant de petits ensembles, comme pour le « charnier» de Ribemont. Ces morceaux de squelettes présentaient des positions incongrues et surtout ils étaient intimement imbriqués. Alors que les os étaient bien conservés, 


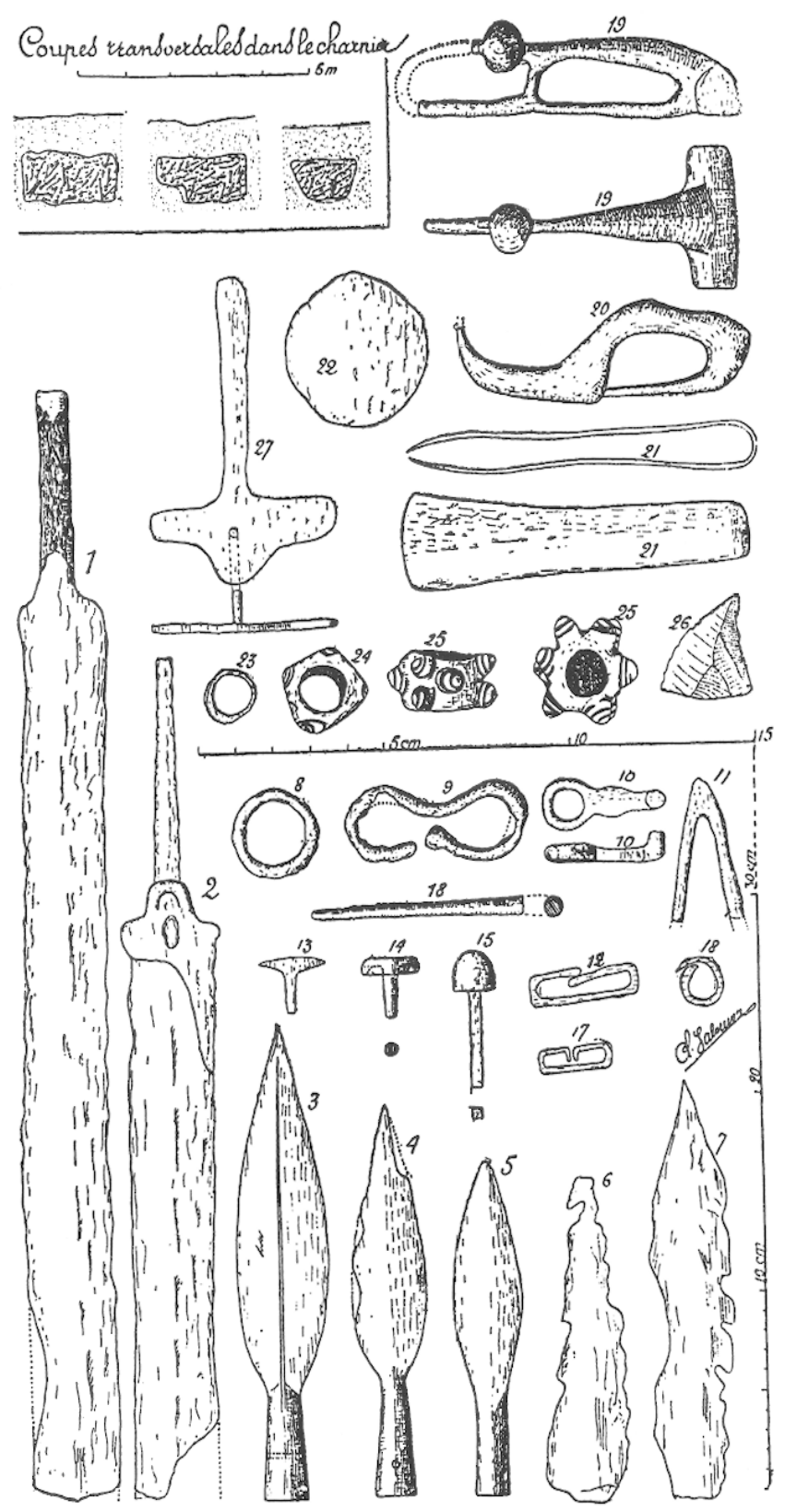

Fig. 35 - Mouvres (Nord), canal du Nord. Matériel découvert dans le fossé (d'après Salomon, 1913).

aucun crâne ne fut retrouvé. Le fouilleur avance le chiffre de 200 individus, mais le démembrement des cadavres qui vient d'être évoqué rend cette estimation très incertaine. À tous les niveaux de ce remplissage se trouvaient en abondance des armes, des pièces de harnachement et de parure. Malheureusement aucun chiffre n'est donné. Le matériel ferreux était dans un état d'oxydation normal mais qui a dû rebuter le fouilleur de l'époque. Celui-ci n'a donc dessiné que les objets qu'il a identifiés (fig. 35). On reconnaît deux épées du type de La Tène moyenne dont l'une possède encore l'entrée de son fourreau probablement datable de La Tène C2, cinq fers de lance (un à douille courte et nervure prononcée est typique de La Tène $\mathrm{Cl}$, les autres pourraient être plus tardifs), un élément de bouterolle, un talon de lance à soie, un rivet d'umbo de bouclier, un crochet de ceinture, un manipule de bouclier à patte tréflée, deux fibules de schéma La Tène moyenne, trois perles en verre bleu ocellées avec de la pâte de verre blanc ou jaune et divers éléments de harnachement. Ces pièces dont il est à craindre qu'elles ne soient pas totalement représentatives de la totalité de l'échantillon paraissent appartenir à la fin de La Tène C1.

Cet ensemble a été interprété par le fouilleur comme un « charnier " constitué après le prélèvement des crânes. Il ne parle pas explicitement de bataille dans sa courte note mais c'est bien l'interprétation qu'il donne et c'est, en tout cas, celle qu'expose très explicitement Joseph Déchelette qui avait eu connaissance de cette découverte (Déchelette, 1914, p. 1040-104l). Les ressemblances étonnantes avec les découvertes de Ribemont paraissent lui donner raison. Cependant beaucoup d'incertitudes demeurent quant à la nature des aménagements (le fouilleur a naturellement pensé qu'il s'agissait d'un " charnier » constitué dans la précipitation, ce qui n'est probablement pas le cas) et leur datation précise. Elles pourraient être levées par une nouvelle fouille dans une section du fossé encore conservée. Bibliographie : Salomon, 1913 ; Déchelette, 1914.

J.-L. BRunaux

\section{NOTICE 12}

\section{MONTMARTIN (OISE)}

\section{LA FOSSE MUETTE}

Cette petite installation cultuelle, découverte au centre d'un habitat de nature aristocratique, a fait l'objet d'une publication monographique qui nous dispense d'une présentation générale (Brunaux, Méniel, 1997). Cependant un certain nombre de points doivent être réexaminés ou tout au moins rappelés. C'est tout d'abord le contexte, au sens large. L'habitat de Montmartin se situe à $3 \mathrm{~km}$ seulement et sur la même rive de la rivière Aronde que le sanctuaire de Gournay-sur-Aronde, dont il est contemporain, et à $6 \mathrm{~km}$ du sanctuaire et de l'habitat d'Estrées-Saint-Denis. Les habitants de Montmartin ont à coup sûr fréquenté le sanctuaire de Gournay : on trouve, en effet, sur les deux lieux les mêmes représentants d'unc production cćramique bien caractéristique. L'histoire des trois lieux paraît liée. La 
chronologie permet de penser que les guerriers nobles de Montmartin ont participé à l'édification et au fonctionnement du sanctuaire de Gournay, que l'aménagement cultuel de Montmartin pourrait correspondre à une réplique de celui de Gournay dans une phase de "repli " marquée par la fermeture du sanctuaire de Gournay. Le sanctuaire d'Estrées-Saint-Denis, au contraire, se met en place après l'abandon du site de Montmartin, lors d'un réaménagement de la topographie politique et religieuse du territoire de la tribu des Bellovaques qui occupait la vaste plaine d'Estrées-Saint-Denis.

La fonction de l'enclos central et des fosses cultuelles qui y furent trouvées suscite toujours des interrogations (fig. 36). Cet enclos, au plan trapézoïdal dont deux côtés sont formés par la confluence de l'Aronde et d'une petite rivière aujourd'hui asséchée, paraît assez. éloigné des lieux de culte du type "sanctuaire ". La clôture de l'espace renforce encore cette impression: ce n'est ici qu'un puissant mur de palissade entièrement recouvert de torchis sans entrée monumentale mais disposant d'une simple porte probablement munie d'un vantail. La situation de la fosse cultuelle, très décentrée et repoussée sur le côté nord, est également intrigante. Dans la publication, les auteurs conscients de ces anomalies ont laissé le champ libre à plusieurs interprétations : espace voué à des réunions politiques ou édilitaires qui pouvaient se faire sous une égide religieuse ou bien possibilité d'un culte domestiquc. Cependant, l'un des faits les plus énigmatiques demeurait sans réponse : en effet, quel sens devait-on donner aux os humains rencontrés dans le fossé de fondation de la palissade, mêlés aux os animaux, à la céramique et aux armes ? La présence de crânes pouvait être interprétée en terme de trophée, logiquement associés à des armes. Mais pourquoi se trouvaient à côté d'eux une vingtaine d'os longs provenant, à l'évidence, de plusieurs individus? Les découvertes récentes de Ribemont-sur-Ancre, plus précisément celles de l'enclos circulaire, permettent d'avancer une nouvelle hypothèse. Les structures et le matériel archéologique mis au jour à Montmartin présentent de grandes similitudes avec ces dernières: on a le même type de clôture, le même type de fosse cultuelle (entre $2 \mathrm{~m}$ et $2,60 \mathrm{~m}$ de diamètre et de profondeur) associée à un foyer et la même position de la fosse, décentrée et rapprochée de la clôture. Le matériel archéologique est également assez similaire. Il le paraîtrait encore plus si l'on arrivait à distinguer les objets provenant de l'intérieur de l'enceinte de ceux qui viennent de sa périphérie immédiate où se trouvaient habitations et ateliers artisanaux. Quoi qu'il en soit, tel qu'il a été découvert, ce matériel montre d'étonnantes particularités. Dans la céramique se trouve une proportion tout à fait inhabituelle de vases hauts. Les armes montrent des déformations, des traces de coups qui sont parfaitement différentes de celles rencontrées sur le sanctuaire de Gournay. La représentation des espèces animales et de leurs différentes parties anatomiques diffère également de celles rencontrées sur les sanctuaires. Il en va de même des crânes humains : ici les cervicales sont absentes et il ne se trouve donc aucune preuve d'une décollation sur place; en revanche, les restes céphaliques présentent d'étranges traces de prélèvement de la peau et des méninges et surtout des perforations qui sont similaires à celles mises en évidence sur les crânes de l'enclos circulaire de Ribemont (Brunaux, Méniel, 1997, p. 167, fig. 146).

Tous ces éléments nous conduisent naturellement à envisager une nouvelle hypothèse qui ne remet pas forcément en cause celles déjà proposées mais qui s'ajoute à elles, celle d'un lieu de traitement funéraire dont les modalités sont cependant moins claires que celles mises en évidence à Ribemont.

Bibliographie : Brunaux, Méniel, 1997 ; Brunaux, 2002.

J.-L. BRUNAUX

\section{NOTICE 13}

\section{MORVILLERS-SAINT-SATURNIN (SOMME)}

\section{DIGEON}

Ce sanctuaire de type picard se rattache à la série des sanctuaires bellovaques avec lesquels il présente de nombreuses similitudes. Il se situe sur le plateau picard, sur une très légère éminence, mais surtout il se trouve sur la voie ancienne qui relie Beauvais à l'embouchure de la Somme, dans la même position donc que le sanctuaire de SaintMaur.

Abondamment pillé par des chercheurs de monnaies, le lieu a fait l'objet d'une fouille programmée très partielle en 1983 et 1984 qui n'a toujours pas fait l'objet de publication exhaustive. Le lieu de culte protohistorique a donné naissance, probablement assez tôt, à un important lieu de culte public gallo-romain voué au culte impérial, comme l'atteste une inscription. Ce dernier a fonctionné pendant tout l'Empire et a été réoccupé à l'époque mérovingienne, peut-être même jusqu'au Moyen Âge, comme semble l'attester le lieu-dit Le Catelet. Ces constructions répétées sur une même zone relativement exiguë ont entraîné de profonds bouleversements des structures et des niveaux laténiens.

Tel qu'il est restitué schématiquement par le fouilleur (Delplace, 1991), le lieu de culte protohistorique apparaît très semblable par son plan à celui de Saint-Maur. Il se 


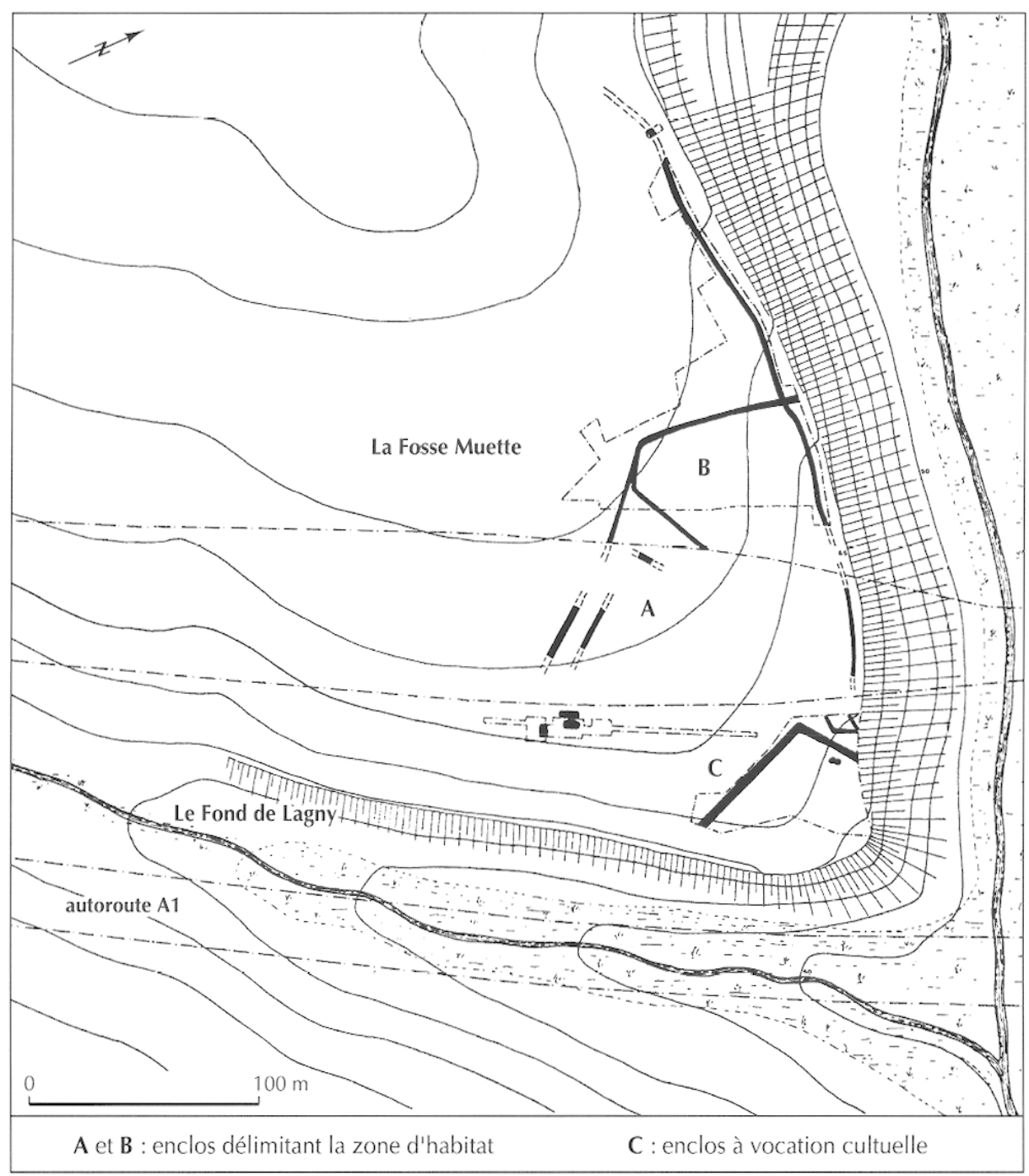

Fig. 36 - Montmartin (Oise), La Fosse Muette. Plan du site (d'après Brunaux, Méniel, 1997). présente sous la forme de trois enclos rectangulaires emboîtés, deux fossés (l'enclos extérieur mesure $32 \mathrm{~m}$ x $25 \mathrm{~m}$ et l'enclos intérieur $18 \mathrm{~m} \mathrm{x} 18 \mathrm{~m}$ ) et une palissade simple ( $15 \mathrm{~m}$ de côté environ). La documentation, très allusive, ne permet pas de connaître exactement la nature de ces fossés, s'ils étaient ouverts, s'ils ont servi de fondation à un mur de palissade. Les rapports chronologiques entre ces structures ne sont pas mieux établis. On peut seulement présumer qu'ils ont fonctionné en même temps, comme le suggèrent le plan d'ensemble et la comparaison avec SaintMaur. Les fosses qui se trouvaient au centre ont été presque totalement détruites par la cella du fanum qui s'est installé précisément sur l'emplacement des fossés gaulois et par une nécropole mérovingienne dont le noyau central se trouvait dans cette cella.

Lc mobilicr archćologiquc n'a fait, à l'exception des importants lots monétaires (Delestrée, 1996), l'objet d'aucune publication conséquente. Ce sont les armes en fer qui témoignent le mieux d'une occupation ancienne. Il a, en effet, été rencontré plusieurs épées, fourreaux, chaînes de ceinture qui témoignent d'une occupation ancienne qui n'a rien de résiduel. La conservation de certains fourreaux suppose la présence de lambeaux de sol en place qui, à l'époque du fonctionnement du sanctuaire, étaient protégés. Ces pièces remontent au moins au $\mathrm{II}^{\mathrm{e}} \mathrm{s}$. Des crochets de ceinture et des armes miniatures appartiennent très probablement à La Tène D1. Quant aux monnaies, fort nombreuses, leur usage sur le sanctuaire serait postérieur à la conquête romaine.

En l'absence d'un contexte stratigraphique et topographique, les représentants de la faune, assez abondants, ne sont d'aucune utilité dans l'étude des rites qui ont pu se dérouler ici. Sur ces derniers la fouille de ce sanctuaire n'apporte aucun élément. 
Bibliographie : Delplace et al., 1986 ; Delplace, 1987, 1991 ; Delestrée, 1996, p. 88-96.

J.-L. BRUNAUX

\section{NOTICE 14}

\section{RIBEMONT-SUR-ANCRE (SOMME)}

\section{Le Champ Crezette}

Le site celtique de Ribemont se trouve sur le versant nord de la vallée de l'Ancre, à $14 \mathrm{~km}$ au nord-est d'Amiens (Samarobriva Ambianorum, de l'époque gallo-romaine). D'une superficie d'au moins $3 \mathrm{ha}$, il occupe un méplat de la partie haute du versant (fig. 37). De nombreuses prospections aériennes, pédestres et géophysiques permettent une bonne connaissance de son environnement. Les seuls vestiges protohistoriques proches sont un ensemble de trois cercles funéraires (de la fin de l'âge du Bronze probablement), distants de $500 \mathrm{~m}$ vers l'ouest des vestiges gaulois et qui se trouvent sur le point dominant du versant. Dans un rayon de $2 \mathrm{~km}$ autour du site n'ont été repérés ni vestiges d'habitat ni traces d'installation funéraire. Pendant le second âge du Fer, le lieu était donc totalement isolé. Les vestiges postérieurs (de l'époque gallo-romaine notamment) sont au contraire abondants.

Pour le second âge du Fer les témoins les plus anciens sont un ensemble impressionnant de restes (plusieurs dizaines de milliers d'os humains, plusieurs milliers d'armes), datables du début du III' $s$. et dont une part importante gisait encore à la surface du sol ancien, pas seulement de façon dispersée mais souvent encore en connexion anatomique ou fonctionnelle pour les armes. Ce sol ancien a pu faire l'objet de nombreuses études environnementales. Il appert qu'une grande partie de la zone des 3 ha était cultivée depuis quelques années avant que le gisement archéologique ne se forme à sa surface, suffisamment longtemps pour qu'un début de colluvion se produise.

Ce premier horizon d'occupation est très resserré dans le temps : les trois ou quatre premières décennies du $\mathrm{III}^{\mathrm{e}} \mathrm{s}$., soit la période fin La Tène B2-début La Tène C1. Il est matérialisé non seulement par ces sols jonchés de vestiges mais aussi par de grands aménagements structuraux, tous contemporains, de grands enclos qui paraissent délimiter l'aire de dispersion des vestiges et qui déterminent des lieux de nature différente. Deux grands enclos quadrangulaires couvrent la totalité de la surface occupée, un carré auquel est accolé par son sommet un trapèze. La base de ce dernier mesure plus de $100 \mathrm{~m}$ et les côtés du carré très exartement $47,50 \mathrm{~m}$. Les deux enclos s'alignent sur un axe nord-sud.



Fig. 37 - Ribemont-sur-Ancre (Somme), Le Champ Crezette. Plan des structures gallo-romaines et laténiennes. Au sud du sanctuaire proprement dit, un immense quadriportique gallo-romair (esplanade) reprend l'espace réservé au culte héroïque (C. Malagoli, Centre archéologique de Ribemont). 
À l'intérieur de l'enclos trapézoïdal se trouvent deux autres enclos : très exactement dans la partie centrale un grand enclos curviligne et une section de fossé reliant cet enclos à l'enclos carré.

Les modes de clôture de ces espaces sont variés et certainement plus complexes que ne le laissent imaginer les vestiges conservés. L'enclos trapézoïdal et ses aménagements intérieurs sont matérialisés par des fossés de fondation pour palissade. La taille des fossés $(2 \mathrm{~m}$ de profondeur pour l'enclos curviligne, $1,50 \mathrm{~m}$ pour les autres) et le mode de construction font supposer des murs hauts de torchis appliqués sur des poteaux verticaux, eux-mêmes ancrés dans des sablières basses placées dans les saignées constituant le fond des fossés. Des éléments de torchis portant des traces d'enduit noir et blanc suggèrent que les murs de l'enclos curviligne étaient peints et peut-être gravés. À l'inverse, l'enclos carré est révélé par un large et profond fossé (3,50 m de largeur pour $3 \mathrm{~m}$ de profondeur) qui est demeuré depuis son creusement, au début du III ${ }^{\mathrm{e}} \mathrm{s}$, jusqu'à son comblement aux environs de -20 . Ce fossé était doublé, tant sur son bord extérieur que sur son bord intérieur, de constructions en élévation (bâtiments, auvents, sections de palissade peut-être) qui devaient le fermer complètement et assuraient une liaison avec les murs de l'enclos trapézoïdal. Ces différents espaces ont livré un mobilier archéologique de même nature et de même situation chronologique. Ce sont essentiellement des os humains et, dans une grande majorité, des os longs (les crânes sont quasiment absents et les éléments du thorax sont assez peu nombreux) accompagnés d'armes en fer (surtout les éléments de la lance, du bouclier, des fourreaux et de leur harnachement) appartenant à la transition La Tène B2La Tène Cl. Cependant leur état de conservation diffère d'un enclos à l'autre (fig. 38).

L'enclos trapézoïdal, dont la présence est reconnue seulement depuis 2002, demeure encore un peu mystérieux. Le comblement du fossé, au moment de la destruction des palissades, recèle des objets métalliques d'une nature particulière, grands éléments d'orle et différentes pièces appartenant à des boucliers d'allure archaïque. Ces pièces, souvent entières mais extrêmement corrodées, ont très certainement été exposées, peut-être sur les parois mêmes. D'assez. nombreux os humains témoignent d'un traitement des cadavres dans une relative proximité. Enfin des fosses découvertes dans la périphérie de l'enclos curviligne, comblées d'un sédiment cendreux, d'os animaux et de céramiques, suggèrent que se sont tenus dans cet espace des sacrifices d'animaux, suivis de repas qui pouvaient avoir une finalité funéraire et/ou cultuelle.

L'enclos curviligne a, au contraire, fait l'objct d'unc fouille presque complète. Le sol de la surface intérieure

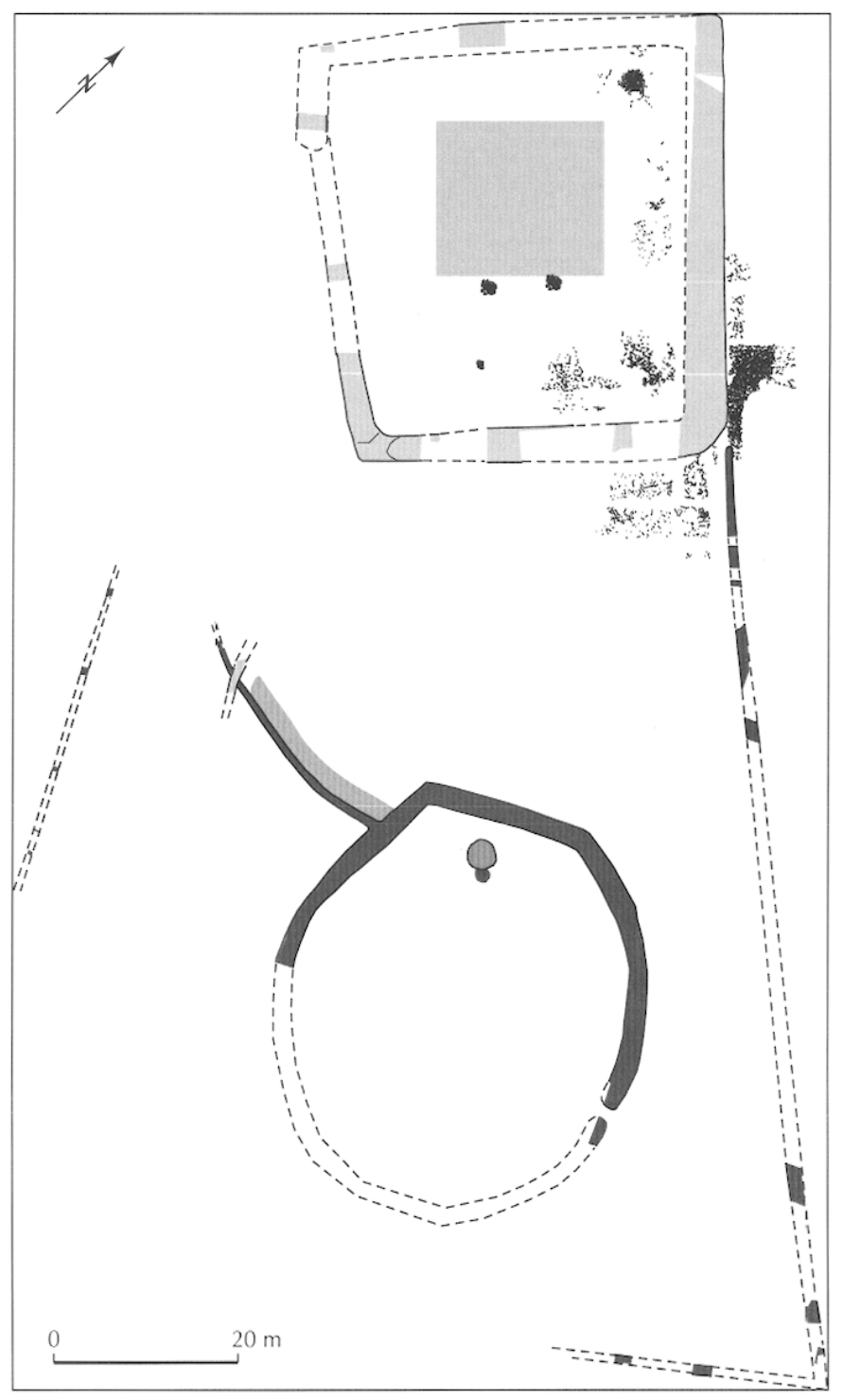

Fig. 38 - Ribemont-sur-Ancre (Somme), Le Champ Crezette. Plan des enclos laténiens (C. Malagoli, Centre archéologique de Ribemont).

n'était pas conservé. Les aménagements principaux sont une grande fosse à laquelle sont accolés un foyer, un ensemble de fosses et de trous de poteaux. Mais ce sont surtout les objets découverts dans le remblai du fossé qui renseignent sur l'utilisation de cet espace. Trois cents ossements humains et deux cents éléments d'armement témoignent du séjour d'une quarantaine d'individus dont presque tous les os longs et les bassins, ainsi que toutes les lances et les boucliers ont été conservés. De nombreux blocs de silex découverts avec ces restes et portant de multiples traces d'oxydation suggèrent que ces dépouilles furent dćposćcs sur un dallage dans la partie centrale de l'enceinte sur une aire de 100 à $150 \mathrm{~m}^{2}$. Cette exposition s'est 


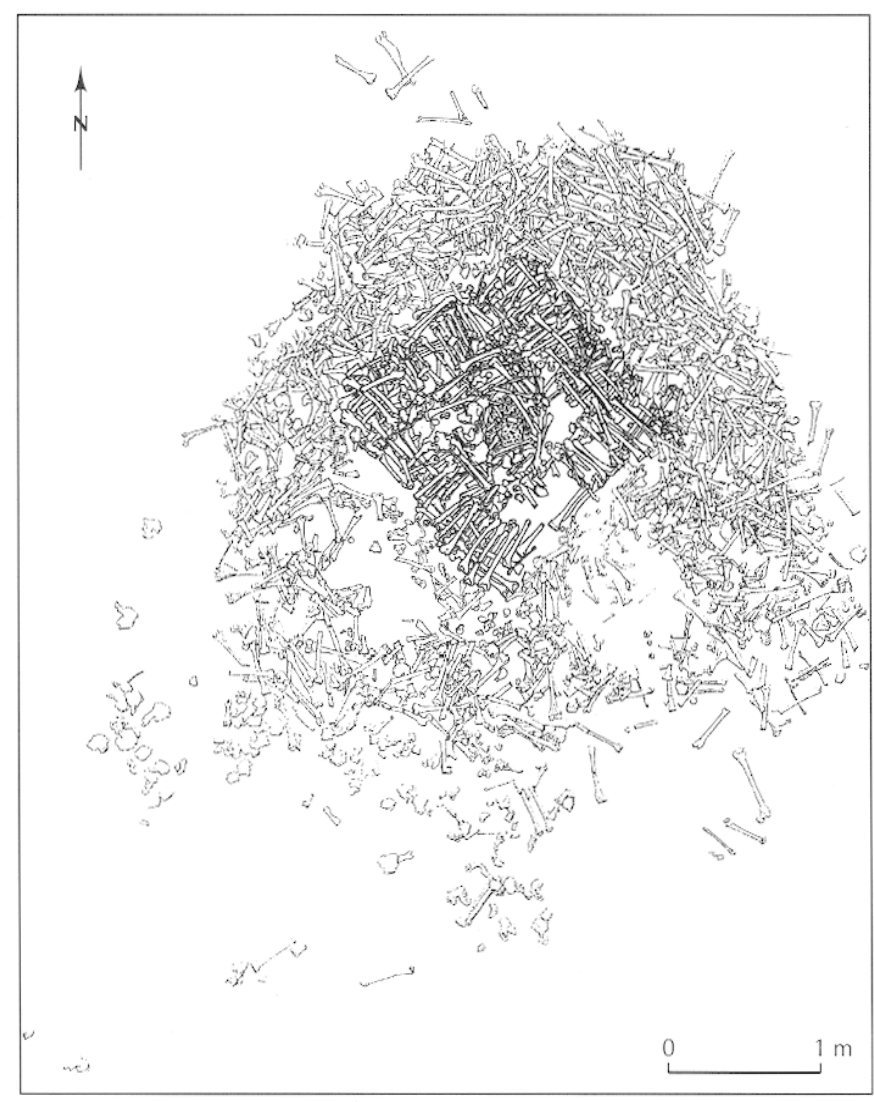

Fig. 39 - Ribemont-sur-Ancre (Somme), Le Champ Crezette. Autel fabriqué en os humains (d'après J.-L. Cadoux, 1984).

prolongée pendant plusieurs mois ou quelques années. De nombreuses traces de coups sur les os, d'origine humaine mais surtout d'origine animale, indiquent que les cadavres furent grossièrement dépecés avant d'être dévorés par les charognards. C'est au cours de cette exposition prolongée que durent être introduits dans cette enceinte des blocs parallélépipédiques en grès, de 1,20-1,40 m de hauteur, d'un poids de $1 \mathrm{t}$ environ. Il s'agit de stèles extraites d'un affleurement naturel distant de $10 \mathrm{~km}$. La grande fosse cylindrique de 3,50 $\mathrm{m}$ de diamètre et $2 \mathrm{~m}$ de profondeur, sur les bords de laquelle se trouvait un foyer aménagé en silex, présente les plus grandes similitudes avec les autels dits "creux " des sanctuaires contemporains. Elle était entièrement comblée de poches de limon pur provenant de l'éboulement des parois mais surtout d'importantes couches cendreuses où se trouvaient en abondance des os animaux et de la céramique ainsi qu'un certain nombre d'armes et d'os humains. Cette installation n'a été réalisée qu'à l'issue de la période d'exposition des dépouilles et juste avant le démontage des murs et le remblayage des fossés. Le démontage de toutes les installations a été exécuté avec méticulosité : pour arracher les poteaux verticaux des murs, les fossés ont dû être recreusés jusqu'à leur fond où se trouvaient les sablières basses. Dans cette cavité furent rejetés l'essentiel des restes humains et métalliques, ainsi que les restes des rites cultuels et/ou funéraires marquant la fin du traitement des dépouilles. Il est à noter que le matériel archéologique significatif trouvé dans cet enclos (objets en fer et céramique) se démarque radicalement de celui découvert dans l'enclos carré. La céramique est ici abondante alors qu'elle est absente dans les gisements de l'enclos carré; de tradition de La Tène ancienne, elle se rattache à des productions septentrionales. Les armes, bien que contemporaines de celles des autres ensembles, montrent également des formes et une technologie anciennes.

La section de fossé curviligne qui relie probablement l'enclos circulaire et l'enclos carré est également une tranchée de fondation pour une palissade un peu moins puissante que celle précédemment décrite. Elle a fonctionné en même temps : sa construction et sa destruction sont synchrones de celles de l'enclos circulaire. Un alignement de fosses parallèles à la tranchée de fondation et une grande quantité de blocs de silex découverts dans le remblai de celle-ci gardent la trace d'un chemin empierré qui longeait la palissade et devait permettre une circulation entre les deux enclos majeurs du lieu. À l'intersection de l'enclos circulaire et de cette section de palissade devait, en effet, se trouver une entrée.

L'enclos carré est, de loin, le plus complexe par ses aménagements architecturaux et par son fonctionnement. L'emprise de ses aménagements est plus large que celle délimitée par le fossé : sur le bord externe de celui-ci se trouvent sur une bande d'une largeur de 4,50 m les gisements d'os humains et d'armes les mieux conservés - notamment celui qui a été désigné dans les publications antérieures sous le nom de " charnicr "- (fig. 39). Les limites de ces gisements sont très nettes, rectilignes et dessinent en plan des structures fantômes, des rectangles dont la longueur n'est pas toujours connue. Le long du fossé cette limite prend parfois la forme d'une sablière basse dont le vide laissé par le bois pourri a piégé les ossements. La qualité de la conservation des vestiges reposant sur le sol ancien ne peut être expliquée que par une protection architecturale, un bâtiment reposant entièrement sur des sablières basses, comme l'ensemble des installations construites sur le site à cette époque. Ce gisement se présente comme un épandage de restes, plus ou moins dense et donc plus ou moins épais, jusqu'à $30 \mathrm{~cm}$. Dans tous les cas cependant, il se caractérise par des ensembles anatomiques plus ou moins étendus présentant encore des connexions strictes ou lâches (quelques squelettes presque entiers sans jamais le crâne, des moitiés inférieures ou supé- 
rieures, des os des membres ou de leurs extrémités), ainsi que par des armes dans un état de conservation étonnant (coques d'umbos, fourreaux non écrasés) et présentant dans de nombreux cas des relations fonctionnelles (épée dans son fourreau, celui-ci encore fixé à sa chaîne). L'autre aspect remarquable est l'absence de stratification, même là où le gisement semble former des tas. En effet, tous les ensembles anatomiques (pour les os) ou fonctionnels (pour les armes) s'entrecroisent et témoignent donc d'un dépôt synchrone. Par ailleurs ces derniers montrent des positions tout à fait inhabituelles : corps recroquevillés, membres repliés ou largement ouverts. Les fourreaux d'épée dans de nombreux cas ont perdu leur bouterolle et les pointes des tôles, non protégées, sont alors légèrement ployées. Ces positions désordonnées et ces déformations accidentelles témoignent moins d'un dépôt volontaire (sur la logique duquel il y aurait alors à s'interroger) que d'une chute depuis un support situé à une hauteur non négligeable.

Pour ce qui est plus précisément du gisement appelé "le charnier " ce sont 20000 os humains qui ont été exhumés, ils appartiennent à plus de 120 individus, tous masculins, adolescents ou jeunes adultes, plutôt grands (moyenne d'environ 1,75 m). Beaucoup de cervicales témoignent d'une décollation effectuée au couteau sur l'individu mort. Un certain nombre d'os présentent des traces de coups attribuables au combat et souvent mortels. Trois cents pièces d'armement les accompagnaient. Elles appartiennent toutes au début de La Tène $\mathrm{Cl}$ et forment un équipement remarquablement homogène marqué par des pièces d'une haute technologie. Les fibules sont peu nombreuses et les seules parures sont des bracelets de lignite, mais il est vraisemblable que des parures plus précieuses en or et en bronze aient été récupérées au moment du démontage des installations dans les années trente avant J.-C. En effet, un torque en or massif et une bourse contenant des hémistatères et des quarts de statères en or ont été découverts sous une poche de terre, interprétable comme du torchis liquéfié. Pareillement quatre pièces en or ont été découvertes isolées, masquées par des os humains. Ces pièces sont toutes attribuables à un même monnayage armoricain que l'on situe dans la région de Lisieux-Le Mans (Delestrée, 2001).

L'intérieur de l'enclos carré comprend trois zones disposées concentriquement. Sur le bord intérieur du fossé se trouve une bande qui présente les mêmes caractéristiques que celle qui longe le bord extérieur: sur une surface de 3,50 m de largeur environ, ossements humains et armes sont parfaitement conservés et témoignent de l'existence de bâtiments moins importants que ceux de l'extérieur, moins hauts ct pcut-ĉtrc ouvcrts vers l'intćricur. Un alignement d'umbos de boucliers et d'éléments de lances matérialisant la bordure intérieure de ces bâtiments suggère que de nombreuses armes devaient y être accrochées. Le long de ces gisements où les restes sont bien conservés se trouve la deuxième zone qui présente également la forme d'une bande dont les limites sont moins nettes du côté du centre de l'enclos : la largeur serait d'environ $4 \mathrm{~m}$. Là, os et armes apparaissent isolés et dans un mauvais état de conservation. À l'évidence, cet espace n'était pas couvert. Sur cette même bande de terrain, dans chacun des angles de l'enceinte, se trouve un curieux aménagement d'os humains. Dans deux cas (angles nord et est), la structure était conservée, dans un cas (angle ouest), elle ne l'était que très partiellement et, dans le dernier cas, elle avait totalement disparu lors du décaissement de cette zone. Ces différents états permettent de reconstituer la construction d'origine: une sorte de margelle cubique au-dessus d'un trou cylindrique de $30 \mathrm{~cm}$ de diamètre et de $1 \mathrm{~m}$ de profondeur creusé dans le sol. Les murets de celle-ci, de $1,75 \mathrm{~m}$ de côté environ et d'une soixantaine de centimètres de hauteur avaient été confectionnés avec des membres humains décharnés, repliés et alignés par lits alternés. Cette sorte d'armature était probablement liée par de la terre ou torchis et la construction protégée des intempéries peut-être par les bâtiments longeant le bord intérieur du fossé. L'intérieur de cette sorte de margelle, ainsi que la cavité cylindrique étaient totalement comblés d'esquilles d'os humains brûlés. La troisième zone, centrale, d'une superficie d'environ $500 \mathrm{~m}^{2}$, se distingue radicalement des autres espaces. Là, sur le sol ancien, se rencontrent très peu de vestiges. Les stratigraphies révèlent de nombreuses perturbations qui sont attribuables à la présence de souches d'arbres et à l'arrachement de certaines. Les études environnementales confirment une forte présence de végétaux de type arbre et arbuste.

On ne reviendra pas ici sur les interprétations qui ont été proposées pour ces aménagements du III $^{\mathrm{e}}$ s. avant J.-C., on en trouvera la substance dans la synthèse régionale (Brunaux dir., 1999 ; Brunaux, 2000a). Il est, en revanche, nécessaire d'évoquer l'histoire de ces aménagements et de leur disparition. L'enclos carré, comme l'enclos circulaire, ne présentent aucune trace d'une occupation ou d'une utilisation postérieure jusqu'à sa destruction au tout début de la période augustéenne : on ne constate l'existence d'aucune couche de remblai, d'aucun nouveau sol ni de nouvel aménagement. On ne peut cependant exclure l'hypothèse que l'enclos trapézoïdal, structure englobante, ait connu quelques activités au cours du $\mathrm{II}^{\mathrm{e}}$ et au début du $\mathrm{I}^{\text {er }}$ s. avant J.-C. Quelques armes attribuables à cette période ont été découvertes dans le remblai du fossé de l'enclos carré. Néanmoins, si activité cultuelle ou funéraire il y eut pcndant cette période elle dut être ni régulière ni importante. À l'inverse, on constate la présence sur l'ensemble du 
site d'un horizon de La Tène D2, presque aussi manifeste que celui du début de La Tène Cl. Ce sont à nouveau des centaines d'armes gauloises du type Alésia, d'autres de conception romaine (pilum, javelot, gladius, épieu), de nombreuses monnaies gauloises locales (attribuées aux Ambiani) ou dites d'auxiliaires, de nombreux éléments de cuirasse ou de harnachement de cheval, une masse considérable d'os animaux et de céramique. Ces objets sont généralement mêlés à d'autres plus anciens et se trouvent dans des niveaux de remblai ou de comblement des structures creuses. On les trouve également associés à des foyers et des installations culinaires, ainsi qu'à la base du premier temple galloromain.

Bibliographie : Lejars, 1998 ; Duday, 1998 ; Brunaux dir., 1999 ; Brunaux, 2000a ; Fercoq du Leslay, 2000.

J.-L. BRUnauX

\section{NOTICE 15}

\section{SAINT-JUST-EN-CHAUSSÉE (OISE)}

\section{LE Rossignol}

Ce site a fait l'objet, en 1994 et 1995, d'une fouille de sauvetage très partielle en une zone qui semble quelque peu marginalc. Lcs vcstigcs protohistoriques découverts permettent cependant la comparaison avec les sanctuaires bellovaques et témoignent de rites exceptionnels.

La situation topographique est celle qui est caractéristique de la plupart des sanctuaires : sur un versant du plateau picard, orienté est-sud-est et dominant la source de la rivière Arré. C'est en ce lieu que la Légende dorée situe le martyre de saint Just dont le corps fut enterré « dans le lieu même qui était entouré de murs antiques" (Bibl. nat., Ms latins, 12598). Or, comme il est habituel sur les sanctuaires celtiques du Nord de la Gaule, un vaste aménagement galloromain reprend le plan d'ensemble des structures gauloises.

Les aménagements architecturaux antérieurs à l'époque romaine consistent en deux fossés se rejoignant à angle droit pour former un $\mathrm{T}$ et, à l'ouest de ces derniers, un bâtiment de plan rectangulaire à deux nefs, de $20 \mathrm{~m}$ de longueur et $14 \mathrm{~m}$ de largeur (Woimant, 1995, fig. 310). Le fossé le plus long était rempli d'os de chevaux et de bovidés sur toute sa longueur. Ceux-ci se trouvant dans la couche supérieure de remplissage avaient malheureusement été en grande partie détruits par les travaux de construction qui avaient débuté avant la fouille. Cependant des dépôts conservés sur une vingtaine de mètres de longueur ont pu être fouillés (fig. 40). Il s'agit d'un petit fossé de $1,50 \mathrm{~m}$ à $2 \mathrm{~m}$ de largeur et d'une profondeur maximale de $80 \mathrm{~cm}$ qui

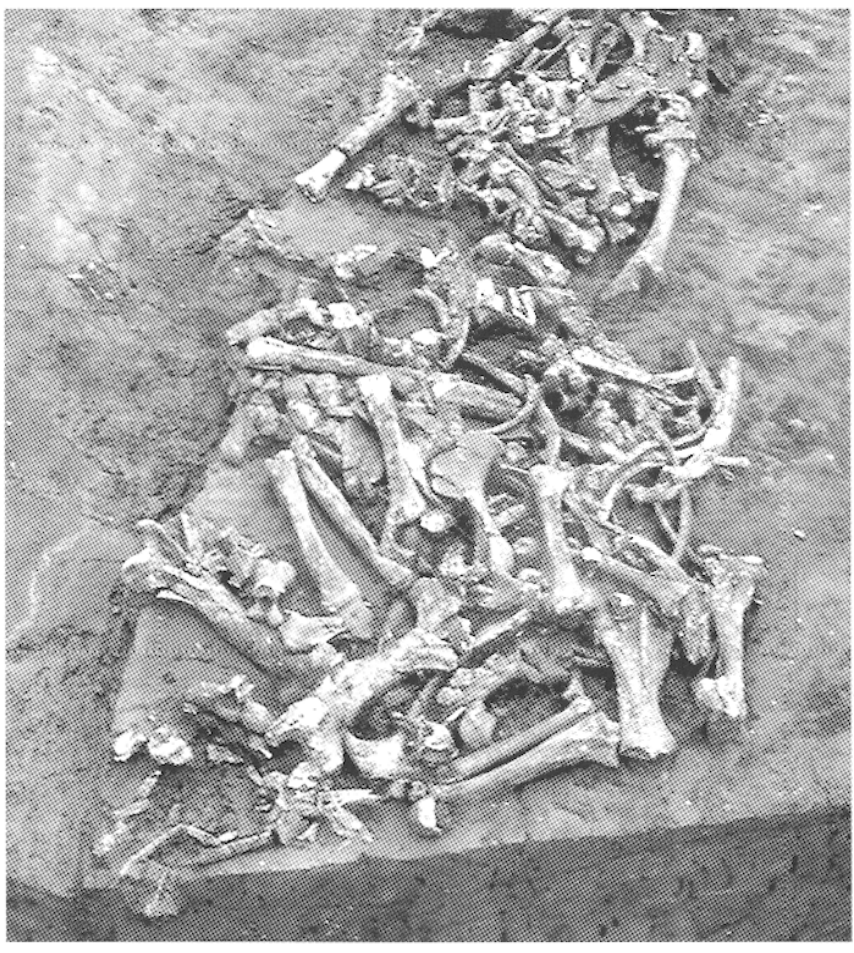

Fig. 40 - Saint-Just-en-Chaussée (Oise), Le Rossignol. Couche supérieure de remplissage du fossé (photo J.-L. Brunaux, CNRS).

est resté assez. longtemps ouvert. Son comblement terminal a été effectué avec des crânes de bovidés et des squelettes entiers de chevaux. Ces derniers surtout retiennent l'attention car ils n'étaient pas totalement déconnectés : les bassins étaient en relation anatomique et surtout les crânes, dont l'un possédait encore le mors dans la bouche. Ces dépôts ressemblent assez à ceux des chevaux déposés dans le fossé de Gournay-sur-Aronde. Leur état de conservation suggère qu'il s'agit de squelettes demeurés entiers avant leur dépôt. L'état des relations anatomiques montrent par ailleurs que les cadavres, certainement gardés à l'abri, s'étaient momifiés peut-être partiellement. L'absence d'organisation de ces restes dans le fossé et leur association avec de nombreux morceaux de torchis, quelques armes et des éléments de char (Woimant, 1995, fig. 311) laissent penser qu'il s'agit du produit de destruction d'un bâtiment où ces restes devaient être entreposés.

Le bâtiment en question est peut-être le grand édifice à deux nefs déjà évoqué. Il était établi sur des sablières conséquentes installées dans des tranchées de fondation d'une quarantaine de centimètres de largeur. C'est dans leur remplissage (et notamment dans la partie la plus proche des fossés) qu'a été trouvé un matériel relativement abondant et de même nature: os de chevaux, os humains, pièces de métal et amphores gréco-italiques. 
Le matériel archéologique permet de dater ces dépôts de la fin de La Tène Dl et plus précisément de la période de la conquête. Ces découvertes sont évidemment trop limitées pour autoriser des interprétations du rituel. Elles confirment seulement ou illustrent mieux des gestes qui avaient été pressentis sur le sanctuaire de Gournay: conservation des dépouilles de chevaux et des crânes de bovidés qui avaient été au préalable sacrifiés, traitement probable de ces derniers, exposition dans des bâtiments conçus pour cela. Bibliographie : Brunaux, 1995 ; Woimant, 1995.

J.-L. BRUNAUX

\section{NOTICE 16}

\section{SAINT-MAUR (OISE)}

\section{Les Catelets}

Le site se trouve sur un vaste plateau, sur une zone qui ne présente pas de caractère topographique remarquable. L'environnement archéologique, bien qu'objet de très nombreuses prospections aériennes, ne se limite qu'à un seul élément mais il est important. C'est une voie romaine qui passe à une centaine de mètres des vestiges gaulois. Celle-ci, reliant Beauvais à l'embouchure de la Somme, ne fait très probablement que reprendre un tracé gaulois. À l'époque gallo-romaine, quand un temple a succédé à l'ancien sanctuaire, la voie qui jadis devait passer au milieu du site décrit une vaste courbe pour l'éviter.

Les vestiges gallo-romains ont fait l'objet d'une fouille expéditive à la fin du $\mathrm{XIX}^{\mathrm{c}} \mathrm{s}$. qui a contribué à détruire encore plus les vestiges gaulois déjà mal conservés. Cependant ces derniers ont pu être étudiés sur une surface assez grande de 1985 à 1987 (Brunaux, Lambot, 1991). L'extension de l'occupation celtique n'est, de ce fait, pas précisément connue. Le principal ensemble est matérialisé par un double enclos, de plan quadrangulaire avec des angles très arrondis, d'une soixantaine de mètres de côté (fig. 41). Comme pour le sanctuaire de Gournay-surAronde, dont celui de Saint-Maur paraît être la réplique, le système de clôture est complexe. Il apparaît sous la forme de deux fossés, dont la fonction était différente, et d'une palissade simple. Le fossé extérieur a servi d'implantation à un mur palissadé puissant (4 à $5 \mathrm{~m}$ de hauteur, construit comme les murs palissadés de Ribemont-sur-Ancre sur des poteaux verticaux ancrés dans des sablières basses posées au fond du fossé). Le second fossé, intérieur, de plan carré et de 34 m de côté, se présentait, au contraire, sous la forme d'un fossé ouvert, comme le fossé principal de Gournay ou celui de l'enclos carré de Ribemont. Enfin à

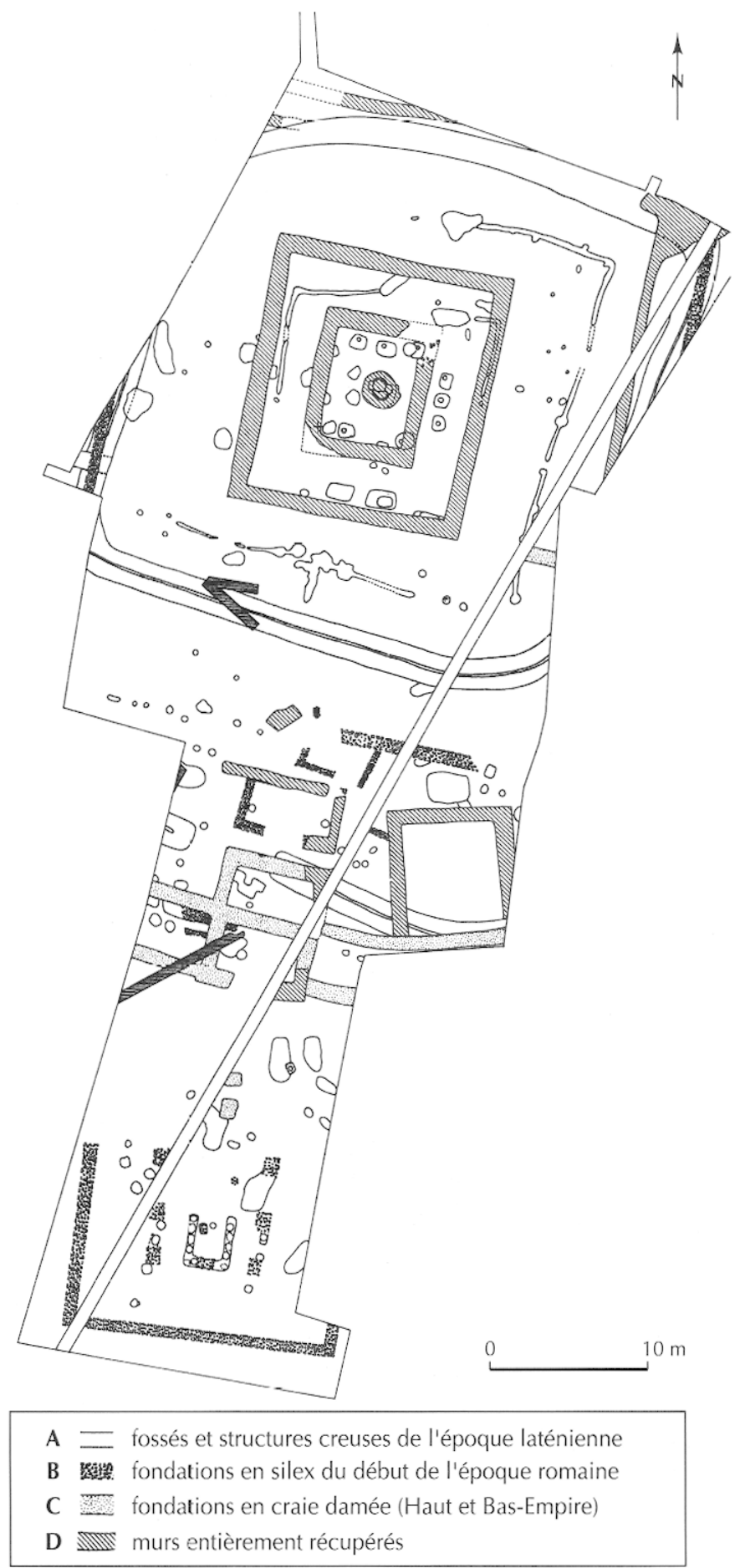

Fig. 41 - Saint-Maur (Oise), Les Catelets. Plan du sanctuaire (d'après Brunaux, Lambot, 1991).

l'intérieur de celui-ci, un nouvel enclos, parfaitement carré, de $24 \mathrm{~m}$ de côté, consistait en une palissade de poteaux, séparés par des sablières basses, directement implantés dans le sol. Le système d'entrée présentait les mêmes caracté- 


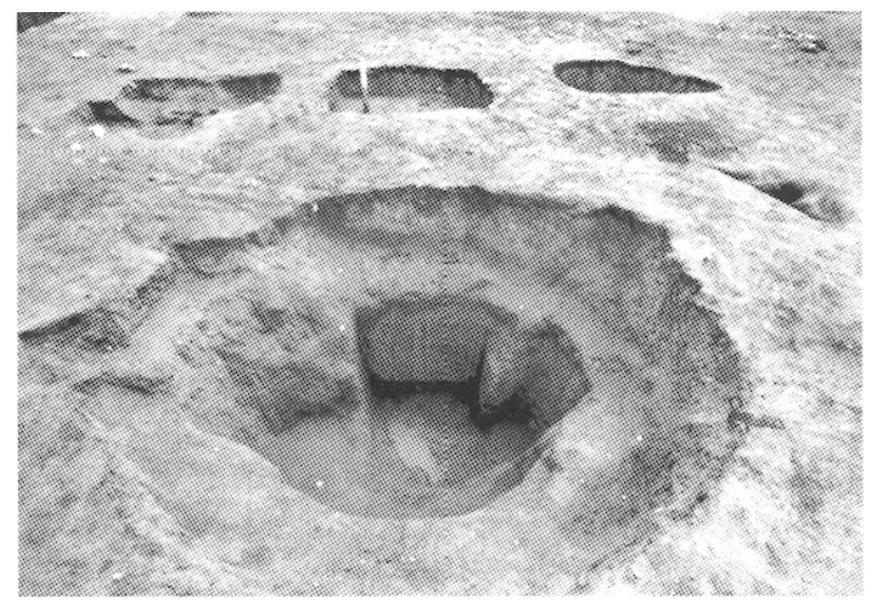

Fig. 42 - Saint-Maur (Oise), Les Catelets. Fosses centrales du sanctuaire (photo J.-L. Brunaux, CNRS).

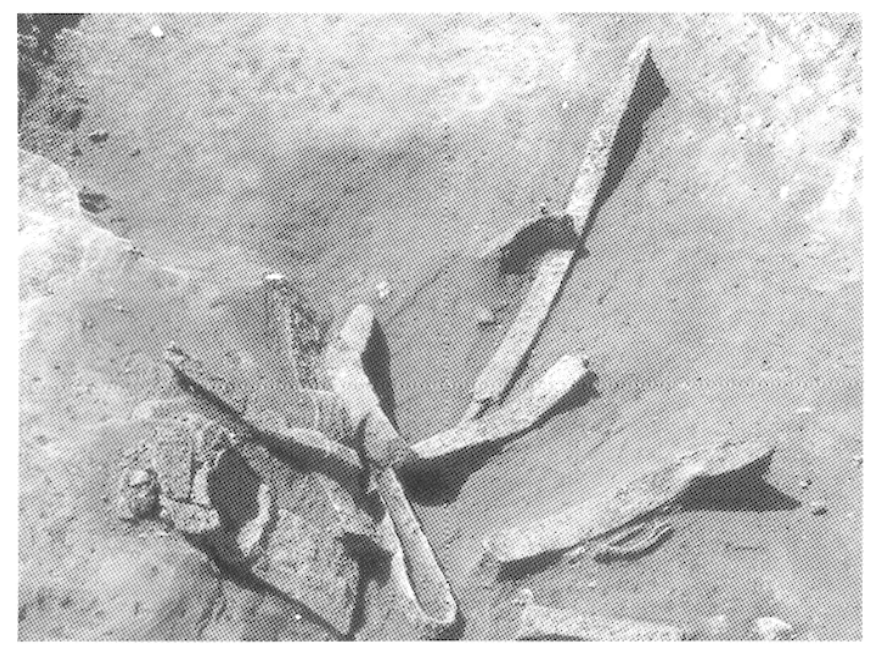

Fig. 43 - Saint-Maur (Oise), Les Catelets. Armes découvertes dans le fossé (photo J.-L. Brunaux, CNRS).

ristiques que celui du sanctuaire de Gournay. L'entrée se trouvait dans la direction est-sud-est. Au niveau de l'enclos palissadé, il s'agissait d'un porche puissant, un bâtiment reposant au moins sur six poteaux (le plan d'origine est malheureusement effacé en partie par les reconstructions augustéenne et gallo-romaine). Au niveau du fossé ouvert, le passage en direction du centre de l'enclos n'était marqué par aucune interruption du fossé et suppose l'utilisation d'une passerelle. Enfin la dernière palissade devait s'ouvrir par une porte munie de vantaux, comme le suggèrent les deux puissants trous de poteaux qui encadrent le passage.

La conception de ce plan parfaitement concentrique culmine avec l'installation cultuelle proprement dite. Celleci montre encore un emboîtement spectaculaire de struc- tures autour de la fosse centrale. Cependant ces éléments appartiennent probablement à deux ensembles de chronologie distincte que l'absence de matériel archéologique, due notamment à la fouille du $\mathrm{XIX}^{\mathrm{e}} \mathrm{s}$., ne permet pas de reconnaître avec une certitude absolue ; mais la comparaison avec le sanctuaire de Gournay nous aide. On reconnait, en effet, au centre un ensemble de structures qui est l'équivalent exact de celui de Gournay, une fosse centrale, cylindrique, de $2 \mathrm{~m}$ de diamètre et $2 \mathrm{~m}$ de profondeur, entourée de neuf fosses, groupées trois par trois, de même forme et de même taille que celles de Gournay, rectangulaires à angles arrondis, de $1 \mathrm{~m}$ à $1,20 \mathrm{~m}$ de côté (fig. 42). Ces fosses furent totalement vidées au XIX ${ }^{\mathrm{e}}$ s. Le second ensemble paraît se greffer sur celui-ci. C'est probablement la réutilisation des neuf fosses comme trous de poteaux pour un bâtiment qui serait une sorte de cella et, autour de ce carré, une palissade de plan également carré, formant galerie, de $13 \mathrm{~m}$ de côté. Si le premier ensemble appartient de toute évidence à la période la plus ancienne du site, le second date probablement de La Tène D1 ou D2. Il est en tout cas antérieur au début de notre ère, car à cette époque apparaissent partout des constructions sur fondations de silex.

Le sanctuaire de Saint-Maur, on le voit, vaut surtout par le plan de ses aménagements architecturaux, à la fois étonnamment complexe et d'une rare perfection géométrique. Il est, par ailleurs, le pendant exact, avec des dimensions légèrement moindres, de celui de Gournay. En revanche, il livre des informations assez pauvres sur le culte et sur la chronologie. Cela tient essentiellement à la mauvaise conservation générale des restes pourtant très abondants. Les sols anciens n'ont pas été conservés. L'acidité de la roche a dissous presque tous les ossements et a fortement dégradé les objets métalliques. Les armes sont assez abondantes (fig. 43). Elles ont été découvertes dans les deux fossés, ainsi que quelques-unes dans les vides laissés par le pourrissement de la palissade intérieure. On peut donc présumer que beaucoup de ces armes se trouvaient accrochées à cette palissade, ainsi qu'à celle de l'enclos extérieur. C'est cette exposition non protégée qui expliquerait leur état très avancé de corrosion. Parmi elles on reconnaît quelques exemplaires qui peuvent appartenir à La Tène C1, mais les plus abondants appartiennent à La Tène C2 et D1. L'histoire du lieu de culte diffère sensiblement de celle du sanctuaire de Gournay: ici il n'y a pas d'interruption pendant La Tène $\mathrm{C} 2$ et D1 mais une continuité parfaite qui explique la superposition de tous les aménagements architecturaux, de La Tène moyenne jusqu'à l'époque galloromaine avec une forte représentation de la période augustéenne. Il apparaît ainsi que le site a commencé à connaitrc une activité monétaire importante dès la guerre des Gaules (Delestrée, 1996, p. 65). Malheureusement la mauvaise 
qualité de conservation des vestiges ne permet pas de proposer des hypothèses de reconstitutions des pratiques rituelles.

Bibliographie : Brunaux, Lambot, 1991 ; Woimant, 1995 ; Delestrée, 1996.

J.-L. BRUNAUX

\section{NOTICE 17}

\section{VENDEUIL-CAPLY (OISE)}

\section{Les Châtelets}

Le sanctuaire de Vendenil-Caply occupe la position la plus habituelle aux sanctuaires picards, une position dominante, en l'occurrence le sommet d'une petite colline qui domine deux vallées. Dans celles-ci s'est installée une agglomération gallo-romaine qui a fait suite à un habitat gaulois dont on ignore l'extension. La colline des Châtelets a elle-même été occupée par un camp romain précoce.

Le lieu de culte, comme ceux de Saint-Maur et de Morvillers qui ont gardé le même toponyme, a été utilisé jusqu'au Moyen Âge, les ruines du temple gallo-romain étant utilisées comme matériau pour la butte d'une petite fortification. Ces vestiges ont très tôt attiré les chercheurs de trésor sur ce site qui a enrichi les collectionneurs privés : dès 1574 le prince de Condé y faisait entreprendre des fouilles. La zone du temple gallo-romain fit elle-même l'objet de fouilles inédites à la fin du XIX et au début du XX ${ }^{\mathrm{e}} \mathrm{s}$. Enfin, en 1976 et 1977, des fouilles programmées ont livré une documentation qui a été exhaustivement publiée (Piton, Dilly, 1985 ; Piton, 1992-1993).

Les photographies aériennes montrent que la zone cultuelle protohistorique est limitée par un vaste enclos en forme de fer à cheval, d'une cinquantaine de mètres de côté, qui n'a malheureusement pas été sondé. Les fouilles n'ont concerné qu'une zone centrale assez exiguë correspondant à l'emprise de la cella du fanum qui, de façon assez habituelle, s'est installé à l'emplacement même des aménagements gaulois. Le plan de ces derniers ressemble étonnamment à ceux de Gournay-sur-Aronde et de Saint-Maur : on y retrouve une fosse centrale circulaire de $2,80 \mathrm{~m}$ de diamètre, d'une profondeur de $1,60 \mathrm{~m}$, entourée de fosses plus petites de $1,50 \mathrm{~m}$ de côté, de plan grossièrement quadrangulaire et groupées trois par trois. Un enclos de plan quadrangulaire de 9 à $10 \mathrm{~m}$ de côté, matérialisé par un petit fossé de $45 \mathrm{~cm}$ de côté, correspond certainement à un bâtiment édifié sur sablières basses. Il occupe la même situation que les fosses. Les relations stratigraphiques entre ces deux ensembles ont malheureusement été rompues par les fouilles anciennes. L'aménagement le plus ancien et le plus original est une couche située entre les fosses et reposant directement sur la roche géologique; il s'agit d'une couche de crémation comprenant des charbons de bois, de la craie et des silex brûlés, mais pratiquement aucun mobilier archéologique.

Le matériel protohistorique rencontré lors des fouilles de 1976-1977 n'était plus en place et se trouvait mêlé à des témoins plus récents, de l'époque augustéenne ou gallo-romaine. Néanmoins, on reconnaît au moins deux fibules de type Dux (fin IV' s. avant J.-C.), d'assez. nombreux exemplaires de fibules en fer et en bronze de schéma de La Tène moyenne, ainsi que de nombreuses autres datables de La Tène D1. Des perles de verre, d'ambre et de lignite confirment ces datations et attestent avec les fibules une occupation qui remonte au moins au III ${ }^{\mathrm{e}} \mathrm{s}$, , mais dont n'ont été conservés que les plus petits objets, visiblement perdus.

Bibliographie : Piton, Dilly, 1985 et 1992-1993.

J.-L. BRUnAUX

\section{NOTICE 18}

\section{LA VILLENEUVE-AU-CHÂTELOT (AUBE)}

\section{Less Grèves}

De 1976 à 1988, les campagnes de fouilles, menées par J. Piette et son équipe au lieu-dit Les Grèves sur la commune de La Villeneuve-au-Châtelot, ont permis de mettre au jour un sanctuaire laténien et gallo-romain (Piette, 1989). Cependant le terrain était bouleversé par de profonds labours, ce qui a empêché des observations stratigraphiques fines. Le site est localisé au pied des petites collines qui constituent les premiers vallonnements du plateau champenois. Installé sur le flanc d'un petit promontoire, aux confins du territoire des Senones et de la Gaule dite Belgique, le sanctuaire présente un faciès monétaire de type sénon (Piette, 1987).

La fouille du site a révélé plusieurs structures appartenant au second âge du Fer, à l'époque gallo-romaine et au Moyen Âge.

- Un fossé partiellement fouillé qui n'a livré aucun indice permettant de le dater précisément (fig. 44, fossé 1) ; il s'agit cependant de l'aménagement le plus ancien étant donné qu'il est recoupé par des éléments de La Tène moyenne et finale.

- Deux fossés quadrangulaires concentriques, tous deux orientés est-ouest et interrompus sur leurs côtés est, de manière similaire au fossé de Gournay-sur-Aronde (Brunaux, 


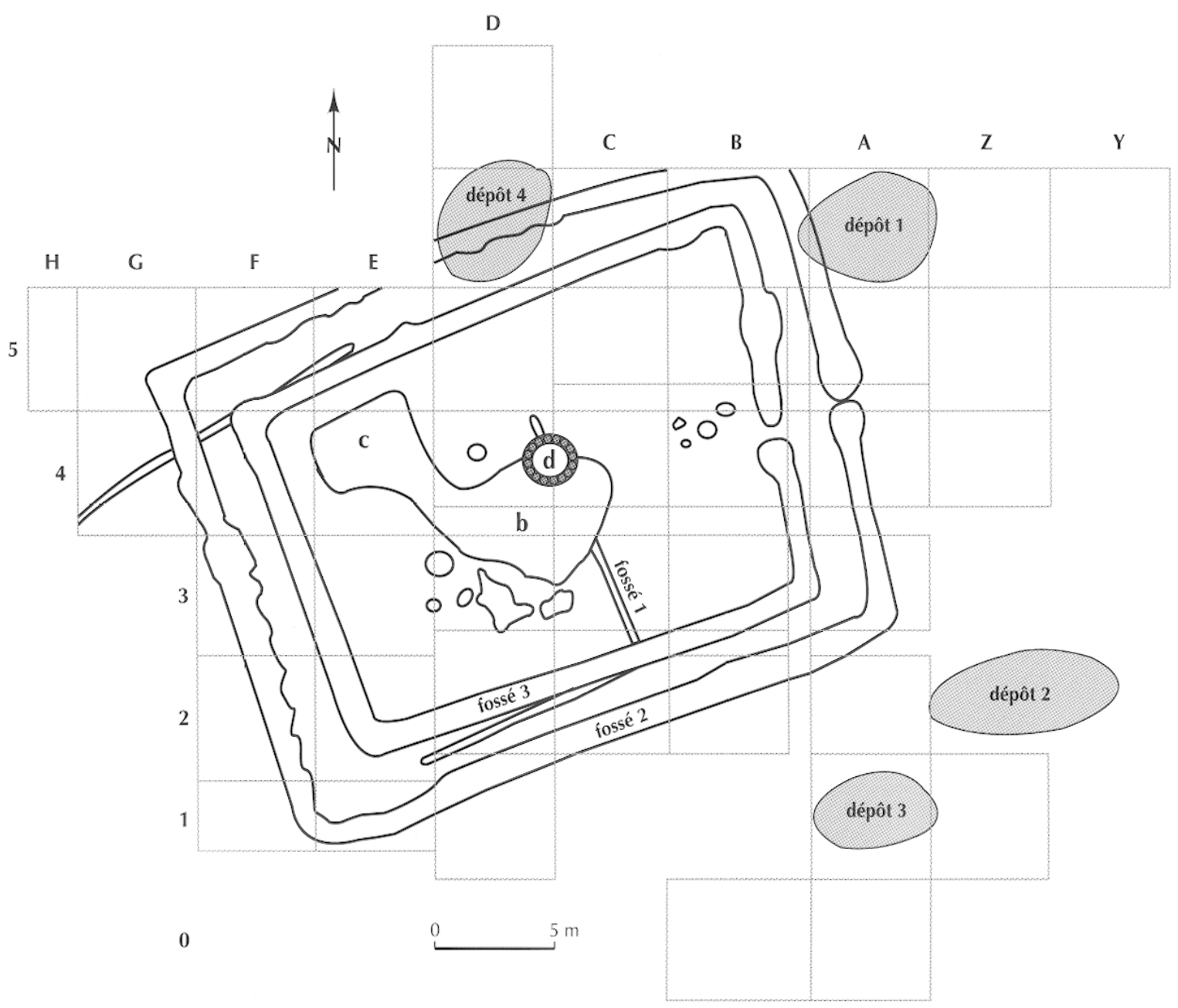

Fig. 44 - La Villeneuve-au-Châtelot (Aube), Les Grèves. Plan du sanctuaire (d'après Gallia, 41, 2, 1983, p. 368).

Méniel, Poplin, 1985). Il est probable que ces deux structures aient été palissadées. L'enclos extérieur (fig. 44, fossé 2) délimite une aire de $25 \mathrm{~m}$ de long sur $19 \mathrm{~m}$ de large. Les monnaies retrouvées dans son comblement permettent de dater son abandon de la fin de l'indépendance gauloise. L'enclos intérieur (fig. 44, fossé 3) mesure $20 \mathrm{~m}$ de long sur $14,5 \mathrm{~m}$ de large. D'après le fouilleur, cette structure semble d'époque augustéenne (Piette, 1989). Son comblement date la fin de son utilisation vers la fin du IV ${ }^{\mathrm{e}} \mathrm{s}$. après J.-C.

- Un autel en creux situé au centre de la zone délimitée par les deux fossés concentriques. Il est constitué d'un petit appendice oblong, débouchant sur une fosse ovoïde (fig. 44b).

- Un bassin a été aménagé dans l'angle nord-ouest de l'aire définie par les deux enclos concentriques à l'époque gallo-romaine (fig. 44c).

- Une fondation d'un bâtiment carré en pierres sèches qui pourrait être un fanum (cella) gallo-romain.
- La dernière structure du site est un puits médiéval creusé en plein milieu de l'aire cultuelle (fig. 44d).

Des travaux universitaires récents ont permis d'apporter de nouvelles précisions à la composition des dépositions laténiennes de ce site (Bataille, 1998, 1999). Le matériel celtique provient essentiellement de quatre grandes zones de déposition (fig. 44) :

- le dépôt 1 , centré sur la zone A6 du carroyage mis en place lors de la fouille;

- le dépôt 2, centré sur les zones Z2 et Y2 ;

- le dépôt 3 , centré sur la zone Al ;

- le dépôt 4 , centré sur la zone D6.

La composition des trois premiers dépôts laténiens est voisine. On y trouve des armes (lances, épées, fourreaux, éléments de suspension, éléments de boucliers), de la parure (uniquement des fibules), de la vaisselle (métallique et céramique), de l'outillage, ainsi que des demi-produits, tels des currency bars, dont certains de petites dimensions 
(longs de 2,5 à $8 \mathrm{~cm}$ et larges de 1 à $1,5 \mathrm{~cm}$ ). En revanche, le faciès de déposition de la quatrième zone est totalement différent. En effet, on y retrouve uniquement des fers de javelines (une quinzaine d'exemplaires). Il est probable que cette concentration d'objets similaires constitue les vestiges d'une exposition d'armes de jets, dont la fouille n'a pu révéler les modalités. On note également sur le site la présence de nombreux ossements appartenant à de la faune, notamment des crânes de bovidés, qui témoignent de pratiques sacrificielles, d'offrandes animales ou de "festins" (étude zooarchéologique non réalisée).

D'après la chronologie des objets, le sanctuaire semble débuter à la fin de La Tène B2, les dépositions croissant pendant La Tène C1. C'est à la fin de La Tène C2, début de I a Tène Dl que les dépôts d'objets, notamment d'armes, sont les plus importants. En revanche, au cours de
La Tène D1 et D2, armements et autres objets sont quasi inexistants. Par contre, des monnaies de ces époques ont été retrouvées en très grand nombre mélangées à de très importantes quantités de rouelles en plomb, potin et bronze, ce qui laisse supposer une mutation des pratiques votives antérieure à la romanisation (Veillon, 1987).

Le sanctuaire perdure à l'époque gallo-romaine, époque au cours de laquelle les manifestations votives se caractérisent surtout par le dépôt de monnaies et de rouelles. Ces objets se concentrent préférentiellement au niveau des interruptions de fossés. Alors que les offrandes de fibules s'interrompent au cours du II ${ }^{\mathrm{e}} \mathrm{s}$. après J.-C., les monnaies les plus récentes datent du $\mathrm{IV}^{\mathrm{c}} \mathrm{s}$. après J.-C.

Bibliographie : Brunaux, Méniel, Poplin, 1985 ; Veillon, 1987 ; Piette, 1987, 1989 ; Bataille, 1998, 1999.

G. BATAILlE 